\title{
Prefrontal Activity During Serial Probe Reproduction Task: Encoding, Mnemonic, and Retrieval Processes
}

Masato Inoue and Akichika Mikami

$J N$ 95:1008-1041, 2006. First published Oct 5, 2005; doi:10.1152/jn.00552.2005

You might find this additional information useful...

This article cites 99 articles, 38 of which you can access free at:

http://jn.physiology.org/cgi/content/full/95/2/1008\#BIBL

Updated information and services including high-resolution figures, can be found at:

http://jn.physiology.org/cgi/content/full/95/2/1008

Additional material and information about Journal of Neurophysiology can be found at: http://www.the-aps.org/publications/jn

This information is current as of February 13, 2006. 


\title{
Prefrontal Activity During Serial Probe Reproduction Task: Encoding, Mnemonic, and Retrieval Processes
}

\author{
Masato Inoue and Akichika Mikami \\ Department of Behavioral and Brain Sciences, Primate Research Institute, Kyoto University, Inuyama, Aichi, Japan
}

Submitted 26 May 2005; accepted in final form 28 September 2005

Inoue, Masato and Akichika Mikami. Prefrontal activity during serial probe reproduction task: Encoding, mnemonic, and retrieval processes. J Neurophysiol 95: 1008-1041, 2006. First published October 5, 2005; doi:10.1152/jn.00552.2005. To study the prefrontal neuronal mechanism for the encoding and mnemonic processing of multiple objects, the order of object presentation, and the retrieval of an object among objects in the working memory, we recorded neuronal activity from the lateral prefrontal cortex while two monkeys performed the serial probe reproduction task. In the task, two objects (C1 and C2) were presented sequentially interleaved with a delay (D1) period, and after the second delay (D2) period, a color cue was presented. Monkeys were trained to select one target object on the basis of the color stimulus. During the $\mathrm{C} 1$ and $\mathrm{C} 2$ periods, we found responses that depended on the order of presentation (order-selective response). During the D1 and/or D2 periods, two-thirds of the neurons with object-selective delay-period activity showed order-selective activity coding either $\mathrm{C} 1$ or $\mathrm{C} 2$. Neurons with larger response magnitudes during the $\mathrm{C} 2$ period showed order-selective delay-period activity during the $\mathrm{D} 2$ period. These order-selective responses during the $\mathrm{C} 2$ period could also contribute to order-selective delay-period activity, and order-selective delay-period activity during the D1 and D2 periods could play an essential role in storing information on both the object and the temporal order of presentation. During the color cue period, two-thirds of the neurons with responses showed target object selectivity (CT and $\mathrm{T}$ responses), although the target object was not presented during this period. The $\mathrm{CT}$ and $\mathrm{T}$ responses could play a critical role in the retrieval of an item among various items in the working memory.

\section{N T R O D U C T I O N}

Previous studies provided evidence that the lateral prefrontal cortex is involved in memory for temporal order. Patients with lesions involving the mid-dorsolateral prefrontal cortex perform more poorly than control subjects or patients with other cortical lesions in a task requiring judgment on which of two items was presented more recently (Kesner et al. 1994; McAndrew and Milner 1991; Milner 1971; Milner et al. 1991; Shimamura et al. 1990). Animal lesion studies also strongly implicated the prefrontal cortex in temporal order memory. Petrides (1991) found that monkeys with lesions involving the mid-dorsolateral prefrontal cortex were impaired in judging the order of object stimuli that had been presented in the middle of a list of objects. Similarly, rats with medial prefrontal lesions performed poorly on tests of temporal order memory for spatial locations (Chiba et al. 1994; Kesner and Holdbrook 1987). These studies of humans and animals with focal brain damage support the idea that the prefrontal cortex plays an important role in memory for temporal order.

Address for reprint requests and other correspondence: A. Mikami, Dept. of Behavioral and Brain Sciences, Primate Research Inst., Kyoto Univ., Kanrin, Inuyama, Aichi 484-8506, Japan (E-mail: mikami@pri.kyoto-u.ac.jp).
On the other hand, many electrophysiological studies have provided evidence that the lateral prefrontal cortex participates in the process of temporary storage of spatial or object information (Chafee and Goldman-Rakic 1998; Constantinidis et al. 2001; di Pellegrino and Wise 1991, 1993; Funahashi et al. 1989, 1993b; Fuster 1973; Fuster et al. 1982; Kubota and Niki 1971; Kubota et al. 1974; Miller et al. 1996; Niki 1974; Niki and Watanabe 1976; Rainer et al. 1998a; Rao et al. 1997; Sawaguchi and Yamane 1999; Takeda and Funahashi 2002; Watanabe 1981; Wilson et al. 1993). Tonic delay-period activity with directional selectivity or object selectivity has been considered to be a neuronal correlate of temporal storage mechanism for spatial or object information in the prefrontal cortex.

A few studies showed prefrontal neuronal activities when monkeys retain information on multiple items simultaneously. Barone and Joseph (1989) recorded prefrontal neuronal activities while a monkey performed a delayed-response task in which a monkey was required to memorize three target positions and the temporal order of presentation and to respond by performing sequential saccades and hand-reaching movements toward the targets in the same temporal order. They found that one class of prefrontal neurons exhibit tonic activity with spatial and temporal selectivity, such that tonic activity was observed only when the first visual cue was presented at one particular position out of three. Funahashi et al. (1997) recorded prefrontal neuronal activities while a monkey performed a delayed sequential reaching task, in which the monkey is required to memorize two of three target positions and the temporal order of presentation and to respond by performing hand-reaching movements toward the targets in the same temporal order. They found two types of delay-period activity: position-dependent and pair-dependent activities. Position-dependent delay-period activity is a selective response to one of three positions. Most of the position-dependent activities arise when a cue is presented at a particular position in a particular temporal order. Pair-dependent delay-period activity is a selective response to a particular combination of two of three positions. Most of the pair-dependent activities arise when two cues are presented in a particular temporal order. Ninokura et al. (2003) found that $43 \%$ of delay-period activity is selective for the sequence in which visual objects are presented during the cue period. They further found that $31 \%$ of this activity was selective for only one of six sequences, and the remaining activity was selective for multiple sequences. These findings suggest that prefrontal neurons can retain information on mul-

The costs of publication of this article were defrayed in part by the payment of page charges. The article must therefore be hereby marked "advertisement" in accordance with 18 U.S.C. Section 1734 solely to indicate this fact. 
tiple items (spatial positions or objects) and the temporal order of cue presentation. However, Ninokura et al. (2003) found the delay-period activity that was selective for multiple sequences, but they did not clarify what information was coded in this delay-period activity. In addition, Funahashi et al. (1997) and Ninokura et al. (2003) used tasks in which monkeys had to memorize spatial locations or objects and to respond by performing sequential movements toward memorized locations or objects, and analyzed neuronal activity during only delay period preceding the sequential movements. Thus these prefrontal neuronal activities could reflect the preparation for the first or second movement or sequential movements. Indeed, there were delay-period activities that coded the direction of movements rather than the location of the cue (Funahashi et al. 1993b; Niki and Watanabe 1976; Takeda and Funahashi 2002). To clarify the neuronal mechanism for the retention of information on multiple items simultaneously, it is necessary to dissociate memorized items and preparation for movements.

In this study, we introduced a serial probe reproduction (SPR) task, in which a monkey had to memorize two objects and their order of presentation, and one target object was selected from two memorized objects on the basis of a color stimulus. In this task, because the target object was determined on the basis of the color cue during the color cue period, monkeys could not determine the target object until the color cue period. Thus the memory during the first and second delay periods must be nothing else but the two objects and their order of presentation.

Previous studies indicated that neurons with cue-period and delay-period activities exhibited a similar spatial or object preference between the cue and delay periods, suggesting that the visual input to the prefrontal cortex plays an important role in contrasting delay-period activity (Funahashi and Inoue 2000; Funahashi et al. 1990; O'Scalaidhe et al. 1999). Recently, Ninokura et al. (2004) have found visual responses in the lateral prefrontal cortex that depend on both the object and the order of object presentation. However, because Ninokura et al. (2004) did not analyze the relationship between visual response and delay-period activity, the functional role of these responses in the process of encoding object information and temporal order information has not been clarified. To examine this issue, we analyzed prefrontal neuronal activities during the first and second cue periods of the SPR task and compared the visual response and delay-period activity.

In addition, the lateral prefrontal cortex (LPFC) plays a crucial role in response selection, which is the ultimate goal of purposeful behavior. Many studies showed that the responses of the prefrontal cortex to visual stimuli are related to the selection of an object from an array of objects (Hasegawa et al. 2000; Iba and Sawaguchi 2002) and the selection of forthcoming movements based on external stimuli (Hasegawa et al. 1998; Hoshi and Tanji 2004; Hoshi et al. 2000; Kim and Shadlen 1999; Sakagami and Niki 1994a,b; Sakagami and Tsutsui 1999; Sakagami et al. 2001; Watanabe 1986). These results suggest that the LPFC contributes to the retrieval of one object from the working memory. Although a few human neuroimaging studies showed that the LPFC is also involved in the retrieval of one item from the working memory (Rowe and Passingham 2001; Rowe et al. 2000), the neuronal mechanism for the retrieval of one item from the working memory in the LPFC has not been clarified. To investigate the neuronal mechanism in the LPFC for this process, we analyzed neuronal activity during the color cue period of the SPR task. In this period, a monkey retrieves one object from two memorized objects. These data were reported elsewhere in abstract form (Inoue and Mikami 2001, 2002a,b, 2003).

\section{METHODS}

\section{Animals and apparatus}

We used one male and one female rhesus monkey (Macaca mulatta; monkey G, $9 \mathrm{~kg}$; monkey $\mathrm{H}, 5 \mathrm{~kg}$ ). Experiments were conducted according to the Guide for the Care and Use of Laboratory Animals by the National Institute of Health and the Guide for the Care and Use of Laboratory Primates by the Primate Research Institute, Kyoto University.

The monkey was seated on a primate chair in a dark room, and a head-restraining device was fixed its head. It was trained to look at a 17-in CRT monitor (FlexScan T565, Nanao), which was placed $40 \mathrm{~cm}$ from its face. A computer (PC-9821Xa200, NEC) presented a fixation spot and a stimulus on the CRT monitor. The monkey's horizontal and vertical eye positions were sampled at $250 \mathrm{~Hz}$ with a monitoring system using an infrared camera (R-21C-AC, RMS Hirosaki). Sampled eye positions were fed into a computer (PC-9801BX, NEC) through an $\mathrm{A} / \mathrm{D}$ converter to determine whether the monkey maintained its fixation and performed a correct saccade.

\section{Behavioral task}

The monkeys were trained to perform an SPR task (Fig. 1A). In this task, after a 1-s intertrial interval, a fixation spot (a white circle; $0.1^{\circ}$ diam) was presented at the center of the monitor. After the monkey maintained its fixation for $1.5 \mathrm{~s}$, the first object cue $(\mathrm{C} 1)$, which was one of three objects (a double cone, a cross, and a circle, $3^{\circ} \times 3^{\circ}$ in size), was presented at the center of the monitor for $0.5 \mathrm{~s}$. After $1 \mathrm{~s}$ of the first delay (D1) period, the second object cue (C2), which was one of the two remaining objects, was presented at the center of the monitor for $0.5 \mathrm{~s}$. After $1 \mathrm{~s}$ of the second delay (D2) period, a color cue $\left(\mathrm{a}\right.$ red or a green rectangle, $3^{\circ} \times 3^{\circ}$ ) was presented at the center of the monitor for $0.5 \mathrm{~s}$. The presentation of a color cue was followed by the third delay (D3) period of 1-1.5 s. Then the three objects were presented in the upper, lower left, and lower right positions at $9^{\circ}$ of eccentricity from the center of the monitor. The fixation spot was extinguished simultaneously. When the color cue was red, the monkey had to perform a saccade to the object presented as the first cue $(\mathrm{C} 1)$, and when the color cue was green, the monkey had to perform a saccade to the object presented as the second cue (C2). We prepared three patterns of arrangement of target objects (Fig. 1D), and one of the patterns was randomly selected during the response period. Therefore the monkeys could not determine the spatial location to which a saccade should be performed until the appearance of objects during the response period.

The monkeys also performed a delayed-matching-to-sample (DMS) task (Fig. $1 B$ ). In this task, after a 1-s intertrial interval, a fixation spot (a white circle; $0.1^{\circ}$ diam) was presented at the center of the monitor. After the monkey maintained its fixation for $1.5 \mathrm{~s}$, the object cue, which was one of three objects (a double cone, a cross, and a circle, $3^{\circ} \times 3^{\circ}$ in size), was presented at the center of the monitor for $0.5 \mathrm{~s}$. After 2-3 s of the delay period, the three objects were presented in the upper, lower left, and lower right positions from the center of the monitor at $9^{\circ}$ of eccentricity. The fixation spot was extinguished simultaneously. The monkey had to perform a saccade to the object presented as the object cue. We prepared three patterns of arrangement of target objects (Fig. 1D), and one of the patterns was randomly selected during the response period. Therefore the monkeys could not determine the spatial location to which a saccade should be performed until the appearance of objects during the response period. 
A Serial probe reproduction (SPR) task

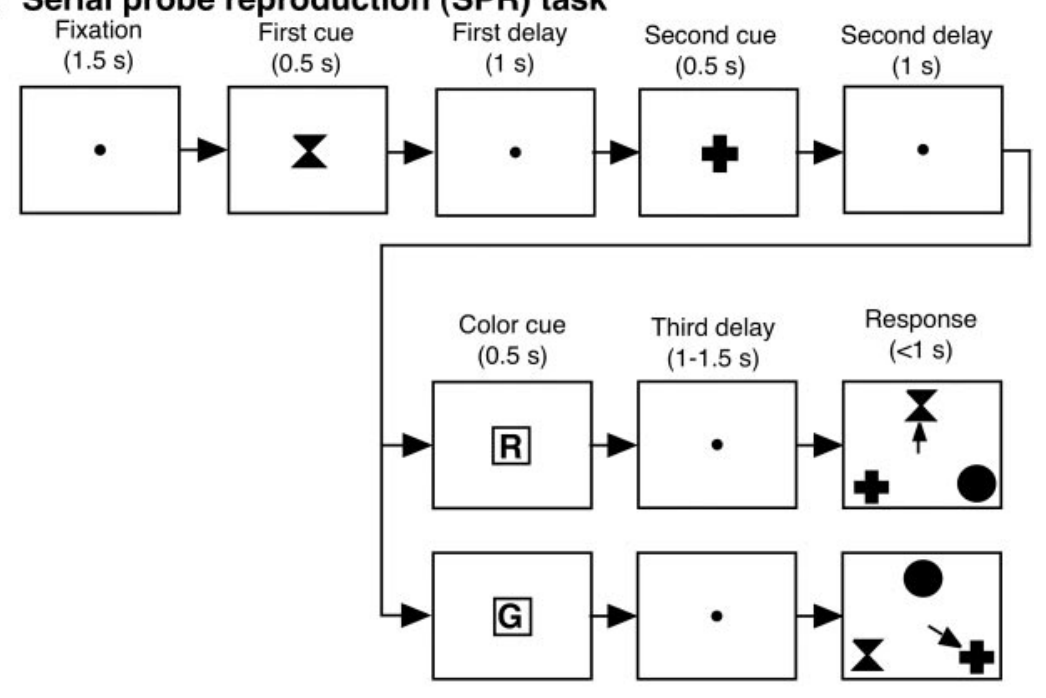

B Delayed-matching-to-sample (DMS) task

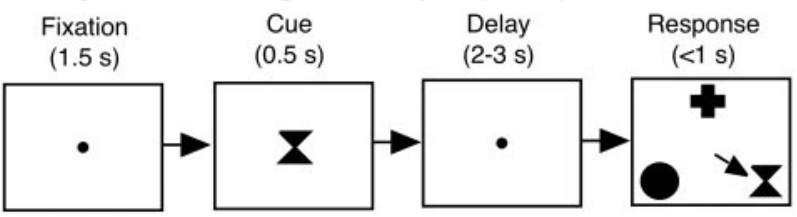

FIG. 1. Sequence of trial events of serial probe reproduction (SPR) task $(A)$, delayed-matching-to-sample (DMS) task $(B)$, and fixation task $(C)$. R and $\mathrm{G}$ indicate the red and green stimuli, respectively. $D$ : arrangement of target objects during response period.

\section{Fixation task}

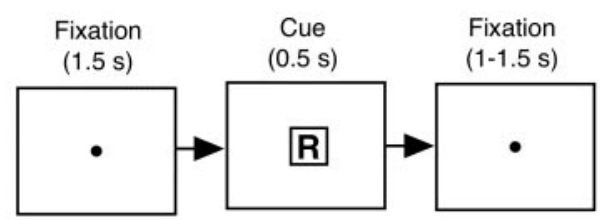

D

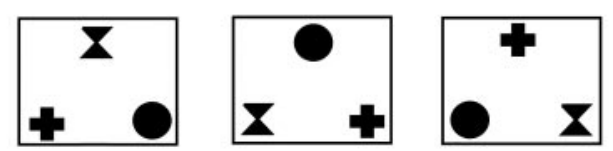

The monkeys also performed a fixation task (Fig. 1C), which allows the examination of neuronal activity when selection was not required. While the monkey maintained its fixation, we presented a color stimulus, which was the same as that used in the SPR task.

\section{Surgical procedure}

To fix the head during training, a head-restraining device was attached to the skull. Surgery was performed under aseptic conditions. The monkeys were first administered ketamine $(10 \mathrm{mg} / \mathrm{kg}$ body weight) intramuscularly, and then an intravenous injection of pentobarbital sodium $(20 \mathrm{mg} / \mathrm{kg}$ body weight). After partially exposing the skull, polycarbonate screws ( $3 \mathrm{~mm}$ in diameter and $5 \mathrm{~mm}$ in length) were used to attach firmly the head-restraining device to the skull. These screws and the head-restraining device were fixed with dental acrylic resin. The monkeys were administered systemic antibiotics for 1 wk after surgery and were allowed free access to water and chow for at least $1 \mathrm{wk}$ after surgery.

After the training was completed, surgery for attaching a recording chamber was performed under aseptic conditions. We performed MRI before surgery, and on the basis of this MRI, we determined the stereotaxic position of the principal sulcus. The position of the recording chamber (anterior-posterior $=32 \mathrm{~mm}$ and lateral $=18 \mathrm{~mm}$ ) was determined by this sterotaxic coordination.

\section{Training procedure}

The monkeys were first trained to perform the DMS task. When the monkeys showed an $80 \%$ correct performance or higher for $2 \mathrm{wk}$, the monkeys were trained to perform the SPR task. The SPR task training was divided into three stages. In stage 1 , the monkeys were trained to perform the red cue trials, in which the monkeys had to select the $\mathrm{C} 1$ object. During the early period of training, the duration of $\mathrm{C} 2$ presentation was $100 \mathrm{~ms}$. When the monkeys showed a $70 \%$ correct performance or higher for $2 \mathrm{wk}$, the duration of $\mathrm{C} 2$ presentation was progressively extended to $500 \mathrm{~ms}$. In stage 2 , monkeys were trained to perform the green cue trials, in which the monkeys had to select the $\mathrm{C} 2$ object. During the early period of training, the duration of $\mathrm{C} 1$ presentation was $100 \mathrm{~ms}$. When the monkeys showed a $70 \%$ correct performance or higher for $2 \mathrm{wk}$, the duration of $\mathrm{C} 1$ presentation was progressively extended to $500 \mathrm{~ms}$. In stage 3 , we intermingled the red cue trials and green cue trials. The training was considered completed 
when the monkeys showed a $70 \%$ correct performance or higher for 2 wk. The training process was completed in $\sim 18$ (monkey G) and 24 (monkey H) mo.

\section{Recording procedure and data analysis}

Neuronal activity was recorded using glass-coated Elgiloy microelectrodes (1-2 M $\Omega$ ). Single-neuronal activity was isolated and converted to pulses by a window discriminator (DIS-1, BAK), and stored with task events as a data file on a hard disk. Recording sites were determined by MRI. The dorsolateral prefrontal cortex (DLPFC) was defined as the region dorsal to the principal sulcus, and the ventrolateral prefrontal cortex (VLPFC) was defined as the region ventral to the principal sulcus (Fig. 2). To determine whether the recording site was in the frontal eye field, we applied intracortical microstimulation (ICMS) through the tips of inserted electrodes (22 pulses of $0.25-\mathrm{ms}$ duration at $333 \mathrm{~Hz}$; current intensity, $100 \mu \mathrm{A}$ ). In this study, there were no recording sites where ICMS evoked saccades.

In this study, we analyzed neuronal activity during the $\mathrm{C} 1$ and $\mathrm{C} 2$ periods, D1 and D2 periods, color cue period, and D3 period. When we analyzed neuronal activity during the $\mathrm{C} 1$ and $\mathrm{C} 2$ periods, six perievent time histograms triggered by the onset of the $\mathrm{C} 1$ and $\mathrm{C} 2$
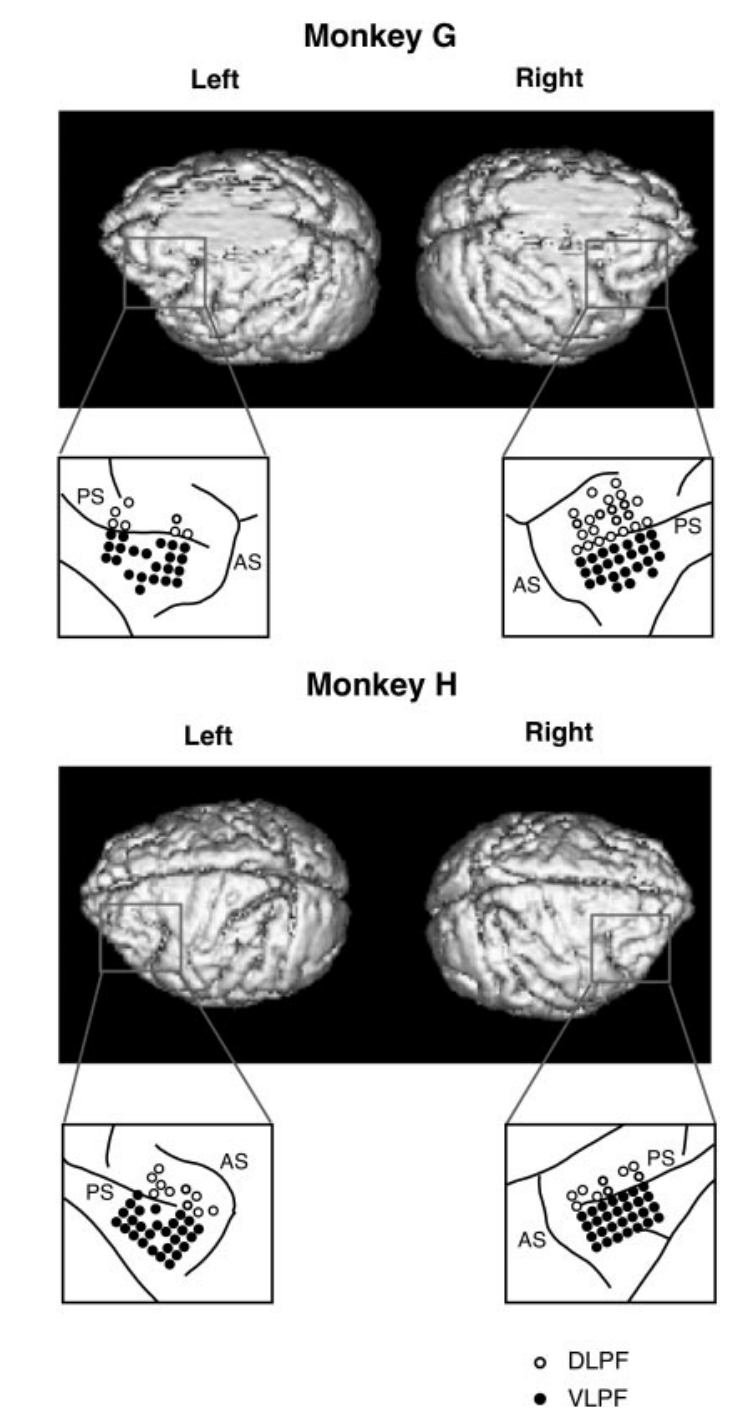

FIG. 2. Surface location of recording sites of neurons. Surface images were obtained by MRI performed before training. $O$, recording sites in the dorsolateral prefrontal cortex (DLPFC); $\bullet$, recording sites in the ventrolateral prefrontal cortex (VLPFC). AS, arcuate sulcus; PS, principal sulcus. were constructed for each stimulus: a double cone, a cross, and a circle (bin width, $10 \mathrm{~ms}$ ). From these histograms, when a neuron exhibited an excitatory response during the $\mathrm{C} 1$ and/or $\mathrm{C} 2$ period, the histogram with the highest peak value for the $\mathrm{C} 1$ and $\mathrm{C} 2$ periods was chosen for determining the response window. In this histogram, the starting point of response (the time at which the 1 st 3 consecutive bins differed from the discharge rates for $1 \mathrm{~s}$ before the cue presentation by $>2 \mathrm{SD}$ or $<2 \mathrm{SD}$ ) and the endpoint of response (the time of the last bin) were determined. The time from the onset of the cue to the starting point of the response was taken as onset latency. When the discharge rate during the response window of the cue period differed significantly (Mann-Whitney $U$ test) from that of the fixation period (for $1 \mathrm{~s}$ before the $1 \mathrm{st}$ cue period), we concluded that the neuron exhibited a response. When the starting and the endpoints of response could not be determined, we calculated mean discharge rate from 100 ms after cue onset to the end of the cue period. We performed two-way ANOVA of responses during the $\mathrm{C} 1$ and $\mathrm{C} 2$ periods, in terms of the order ( $\mathrm{C} 1$ or $\mathrm{C} 2$ period) and object (a double cone, a cross, or a circle) factors. When the difference in response in terms of the object factor was significant and the difference in response in terms of the order factor was not significant, we classified the response as object-selective and order-nonselective. When the difference in response in terms of the object factor was not significant and the difference in response in terms of the order factor was significant, we classified the response as object-nonselective and order-selective. When the difference in responses in terms of both the object factor and order factor were significant or the difference of interaction was significant, we classified the response as object-selective and orderselective. When the differences in responses in terms of both the object factor and order factor were not significant, we classified the response as object-nonselective and order-nonselective.

When we analyzed neuronal activity during the D1 and D2 periods, we constructed six histograms and rasters for each combination of $\mathrm{C} 1$ and $\mathrm{C} 2$ objects aligned at the start of the D1 and D2 periods. We calculated mean discharge rate during the last 1-s interval of the fixation period (control period) and the D1 and D2 periods. First, we analyzed neuronal activity during the D1 period when the mean discharge rate during the D1 period was significantly different from that during the control period (Mann-Whitney $U$ test; $P<0.05$ ); we considered that the neuron had a significant delay-period activity. We considered that delay-period activity was object-selective when the difference was significant as determined by ANOVA $(P<0.05)$.

A significant response during the D2 period was determined similarly (Mann-Whitney $U$ test; $P<0.05$ ). To determine whether delay-period activity during the $\mathrm{D} 2$ period depends on the $\mathrm{C} 1$ object, $\mathrm{C} 2$ object, or one sequence, we compared delay-period activities during the D2 period under six trial conditions by ANOVA. When the difference in delay-period activity under the six trial conditions was significant $(P<0.05)$, we compared the highest delay-period activity with other delay-period activities by a post hoc test (Fisher's PLSD) and determined whether delay-period activity was selective in only one sequence. Results showed that there were no neurons activated during the D2 period in only one of six sequences, and the delayperiod activity depended on either the $\mathrm{C} 1$ object or the $\mathrm{C} 2$ object. We calculated selectivity index for the $\mathrm{C} 1$ object $\left(\mathrm{SI}_{\mathrm{C} 1}\right)$ and that for the $\mathrm{C} 2$ object $\left(\mathrm{SI}_{\mathrm{C} 2}\right)$. SI is defined as

$$
\begin{aligned}
& \mathrm{SI}_{\mathrm{C} 1}=1-\mid R_{\mathrm{C} 1 \text { pref, C2pret }}-R_{\mathrm{Cl} \text { pref, C2nonpref }} /\left(R_{\mathrm{Clpref}, \mathrm{C} 2 \text { pref }}+R_{\mathrm{Cl} \text { pref, C2nonpref }}\right) \\
& \mathrm{SI}_{\mathrm{C} 2}=1-\mid R_{\mathrm{C} 1 \text { pref, C2pret }}-R_{\text {Clnonpref, C2pref }} /\left(R_{\mathrm{Cl} \text { pref, C2pref }}+R_{\text {Clnonpref, C2pref }}\right)
\end{aligned}
$$

where $R_{\mathrm{C} 1 \text { pref, C2pref }}=$ firing rate of the highest delay-period activity during the D2 period, $R_{\mathrm{C} 1 \text { pref, } \mathrm{C} 2 \text { nonpref }}=$ firing rate in response to the same $\mathrm{C} 1$ object and a different $\mathrm{C} 2$ object during the $\mathrm{D} 2$ period, and $R_{\mathrm{C} 1 \text { nonpref, C2pref }}=$ firing rate in response to a different C1 object and the same $\mathrm{C} 2$ object during the $\mathrm{D} 2$ period. If the delay-period activity depended on the $\mathrm{C} 1$ object, $\mathrm{SI}_{\mathrm{C} 1}$ is 1 , and if the delay-period activity depended on the $\mathrm{C} 2$ object, $\mathrm{SI}_{\mathrm{C} 2}$ is 1 . When $\mathrm{SI}_{\mathrm{C} 1}$ was greater than 
$\mathrm{SI}_{\mathrm{C} 2}$, we defined that this delay-period activity depended on the $\mathrm{C} 1$ object, and when $\mathrm{SI}_{\mathrm{C} 2}$ was greater than $\mathrm{SI}_{\mathrm{C} 1}$, we defined that this delay-period activity depended on the $\mathrm{C} 2$ object.

We classified object-selective delay-period activities into three types: order-nonselective activity, C1-coding activity, and C2-coding activity. In a neuron with order nonselective activity, delay-period activity during the $\mathrm{D} 1$ period depended on the $\mathrm{C} 1$ object, delay-period activity during the D2 period depended on the $\mathrm{C} 2$ object, and the preferred objects during the D1 and D2 periods were identical. In a neuron with C1-coding activity, delay-period activity during the D1 and/or D2 period depended on the $\mathrm{C} 1$ object. In a neuron with C2-coding activity, delay-period activity during the D1 period was not detected or object-nonselective, but delay-period activity during the D2 period depended on the $\mathrm{C} 2$ object.

When we analyzed neuronal activity during the color cue period, six averaged perievent time histograms ( 2 colors and 3 objects to which a saccade should be performed) triggered by the onset of the color cue were constructed (bin width, $10 \mathrm{~ms}$ ). From these histograms, when a neuron exhibited an excitatory response, the histogram with the highest peak value was chosen for determining the response window, and when a neuron exhibited an inhibitory response, the histogram with the lowest peak value was chosen. In this histogram, the starting point of response (the time at which the 1 st 3 consecutive bins differed from discharge rates for $1 \mathrm{~s}$ before the color cue presentation by $>2 \mathrm{SD}$ or $<2 \mathrm{SD}$ ) and the endpoint of response (the time of the last bin) were determined. The time from the onset of the color cue to the starting point of the response window was taken as onset latency. When the discharge rate of a neuron during the response window of the color cue period differed significantly (Mann-Whitney $U$ test) from that during the fixation period (for $1 \mathrm{~s}$ before the $1 \mathrm{st}$ cue period), we concluded that the neuron exhibited a response. We performed two-way ANOVA of the response magnitude during the color cue period in terms of the color (red or green) and target (object to which a saccade should be performed; a double cone, a cross, or a circle) factors. When the difference in response magnitude in terms of the color factor was significant and the difference in terms of the target factor was not significant, we considered the neuron as having a $\mathrm{C}$ response. When the difference in response magnitude in terms of the color factor was not significant and the difference in response magnitude in terms of the target factor was significant, we considered the neuron as having a $\mathrm{T}$ response. When the difference in response magnitude in terms of both the color factor and target factor were significant or the difference of interaction was significant, we considered the neuron as having a $\mathrm{CT}$ response.

When we analyzed neuronal activity during the D3 period, six averaged perievent time histograms ( 2 colors and 3 objects to which a saccade should be performed) triggered by the offset of the color cue were constructed (bin width, $50 \mathrm{~ms}$ ). When the discharge rate of a neuron during the first $1 \mathrm{~s}$ of the D3 period differed significantly (Mann-Whitney $U$ test) from that during the fixation period (for $1 \mathrm{~s}$ before the 1st cue period), we concluded that the neuron exhibited delay-period activity during the D3 period. We performed two-way ANOVA of delay-period activity during the D3 period in terms of the color (red or green) and the target (object to which a saccade should be performed; a double cone, a cross, or a circle) factors. When the difference in response magnitude in terms of the color factor was significant and the difference in response magnitude in terms of the target factor was not significant, we considered the neuron as having a $\mathrm{C}$ delay-period activity. When the difference in response magnitude in terms of the color factor was not significant and the difference in response magnitude in terms of the target factor was significant, we considered the neuron as having a $\mathrm{T}$ delay-period activity. When the difference in response magnitude in terms of both the color factor and target factor were significant or the difference of interaction was significant, we considered the neuron as having a CT delay-period activity.

\section{RES U L T S}

\section{Behavioral performance}

Two monkeys performed the SPR task well but not perfectly. The chance level of this task is $33 \%$, and the monkeys performed much higher than the chance level. We examined performance accuracy during trials for all recording sessions. The mean correct percent during recording trials was $75 \pm 5 \%$ (SD) for monkey $\mathrm{G}$ and $70 \pm 3 \%$ for monkey $\mathrm{H}$. There was no tendency for direction preference, but there was tendency for object preference. Both monkeys performed better when the target object was a circle $(84 \pm 10 \%$ for monkey G, $88 \pm 9 \%$ for monkey $\mathrm{H}$ ) than when the target object was a double cone $(70 \pm 6 \%$ for monkey $\mathrm{G}, 62 \pm 6 \%$ for monkey $\mathrm{H}$ ) or a cross ( $72 \pm 8 \%$ for monkey G, $66 \pm 7 \%$ for monkey G). Monkey G performed better in the trials in which the $\mathrm{C} 2$ object was the target $(86 \pm 7 \%)$ than in the trials in which the $\mathrm{C} 1$ object was the target $(66 \pm 6 \%)$. In contrast, for monkey $\mathrm{H}$, there was no difference in performance between the trials in which the $\mathrm{C} 1$ object was the target $(69 \pm 5 \%)$ and the trials in which the $\mathrm{C} 2$ object was the target $(71 \pm 5 \%)$. The mean latencies for saccades from the onset of target object presentation were $284 \pm 105 \mathrm{~ms}$ for monkey $\mathrm{G}$ and $260 \pm 89 \mathrm{~ms}$ for monkey $\mathrm{H}$.

\section{Neuronal database}

While two monkeys performed the SPR task, we recorded the activity of 611 single neurons from the DLPFC $(n=173)$ and the VLPFC $(n=438)$. Of these neurons, 483 responded during at least one epoch of the SPR task. Of these, 119 neurons showed a response during the $\mathrm{C} 1$ and/or $\mathrm{C} 2$ period, 183 neurons exhibited delay-period activity during the D1 and/or D2 period, 139 neurons showed a response during the color cue period, 260 neurons showed delay-period activity during the D3 period, and 361 neurons exhibited a response during the response period. In this paper, we focused on neuronal activity in the C1, D1, C2, D2, color cue, and D3 periods, and we will deal with the response period in a separate report.

\section{Object-selective response during $\mathrm{Cl}$ and $\mathrm{C} 2$ periods}

During the $\mathrm{C} 1$ and/or $\mathrm{C} 2$ periods, 119 neurons exhibited responses. Of these, 81 neurons showed the object-selective response during the $\mathrm{C} 1$ or $\mathrm{C} 2$ period. Of these, 22 neurons showed response magnitudes that were not significantly different between the $\mathrm{C} 1$ and $\mathrm{C} 2$ periods (order-nonselective). On the other hand, the magnitudes of responses of 59 neurons during the $\mathrm{C} 1$ and $\mathrm{C} 2$ periods were significantly different (order-selective). Of these neurons, 33 showed larger response magnitudes during the $\mathrm{C} 1$ period than during the $\mathrm{C} 2$ period (C1-dominant), and 26 showed larger response magnitudes during the $\mathrm{C} 2$ period than during the $\mathrm{C} 1$ period (C2-dominant).

Figure $3 A$ shows the histograms of the $\mathrm{C} 1$-dominant response of a neuron. During the $\mathrm{C} 1$ period, the neuron exhibited a large response magnitude (36.92 spikes/s) to the circle, a small response magnitude (20.22 spikes/s) to the cross, and no response to the double cone. Although the activity slightly increased in all trial conditions toward the end of the D1 period, discharge rates during the D1 period were not significantly different from those during the control period. During 


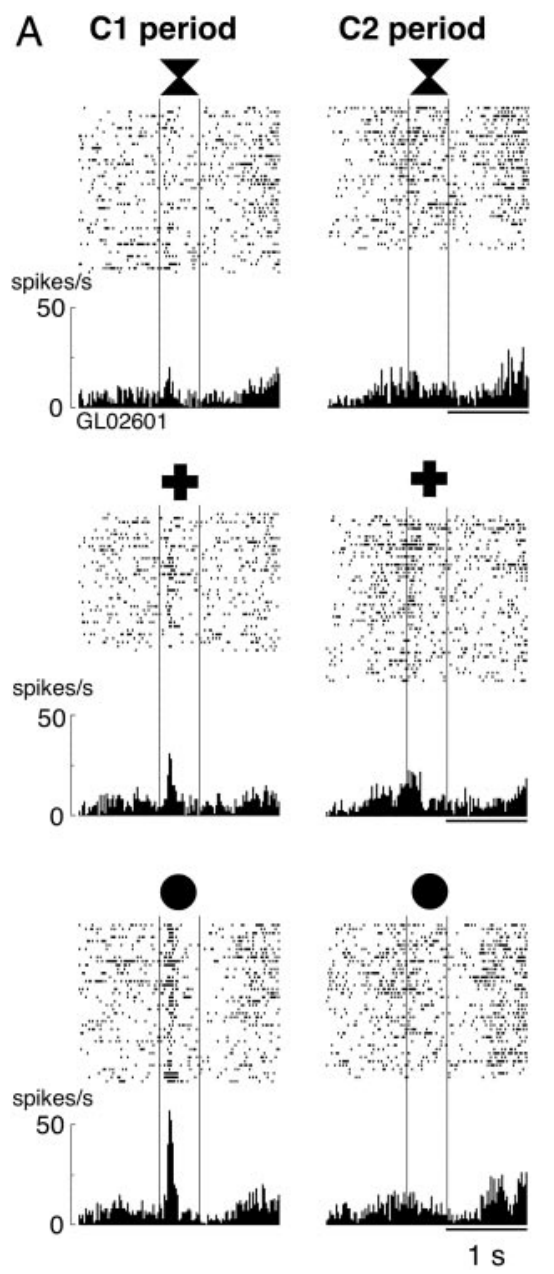



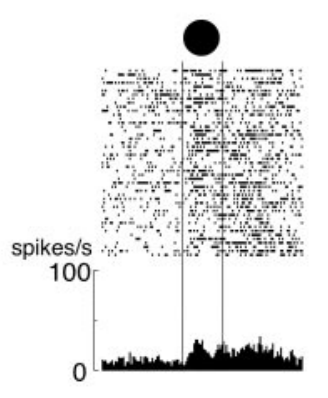

FIG. 3. Histograms of object-selective and order-selective responses. A: histograms of C1-dominant response of a neuron. The neuron exhibited response when the circle was presented during the $\mathrm{C} 1$ period but did not show response during $\mathrm{C} 2$ period. $B$ : histograms of $\mathrm{C} 2$ dominant response of a neuron. The neuron exhibited a small response magnitude when the circle was presented during $\mathrm{C} 1$ period but showed a large response magnitude when the circle was presented during $\mathrm{C} 2$ period. Bin width is $20 \mathrm{~ms}$. the $\mathrm{C} 2$ period, this neuron did not respond to any of the three visual stimuli. The difference in response magnitude was significant in terms of both the object $[F(2,228)=8.62, P<$ $0.0005]$ and order factors $[F(1,228)=29.72, P<0.0001)$. Therefore this neuron was considered as having the C1-dominant response, and we defined the circle as the preferred object of this neuron.

Figure $3 B$ shows an example of the $\mathrm{C} 2$-dominant response. During the $\mathrm{C} 1$ period, the neuron showed a small response magnitude when the circle was presented (27.03 spikes/s). During the $\mathrm{C} 2$ period, the neuron exhibited a large response magnitude when the circle was presented (60.44 spikes/s). During the D1 and D2 periods, this neuron also exhibited delay-period activity after the presentation of the circle. The difference in response magnitude between the $\mathrm{C} 1$ and $\mathrm{C} 2$ periods was significant in terms of both the object $[F(2,280)=$ 87.72, $P<0.0001]$ and order factors $[F(1,280)=38.44, P<$ 0.0001]. Therefore this neuron was considered as having the C2-dominant response, and we defined the circle as the preferred object of this neuron.

To compare the temporal profiles of the order-nonselective, C1-dominant, and $\mathrm{C} 2$-dominant responses, we constructed population histograms of these responses (Fig. 4A). Neurons with the order-nonselective response showed large responses to the preferred object presented during both $\mathrm{C} 1$ and $\mathrm{C} 2$ periods (Fig. 4A, black lines). Neurons with the

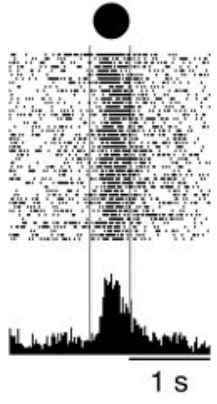

C1-dominant and C2-dominant responses showed large responses to the preferred object presented during the $\mathrm{C} 1$ and C2 period, respectively. Although these differential responses depended on the object and/or the order of presentation, the temporal profiles of the order-nonselective, C1dominant, and $\mathrm{C} 2$-dominant responses were similar. Figure $4 B$ shows the cumulative summation curves of the latencies of the order-nonselective, C1-dominant, and C2-dominant responses. During the $\mathrm{C} 1$ period, the mean latencies of responses were $137 \pm 44$ (order-nonselective), $124 \pm 34$ (C1-dominant), and $127 \pm 51 \mathrm{~ms}$ (C2-dominant). During the $\mathrm{C} 2$ period, the mean latencies of responses were $160 \pm 45$ (order-nonselective), $137 \pm 70$ (C1-dominant), and $141 \pm$ $56 \mathrm{~ms}$ (C2-dominant). Although the difference in latency among these responses was not statistically significant $[F(2,123)=1.48, P>0.05]$, the latencies of the $\mathrm{C} 1$ dominant and $\mathrm{C} 2$-dominant responses were slightly shorter than that of the order-nonselective response. The durations of these responses were also not different. During the C1 period, the mean durations of responses were $172 \pm 25$ (order-nonselective) and $156 \pm 15 \mathrm{~ms}$ (C1-dominant). During the $\mathrm{C} 2$ period, the mean durations of responses were $154 \pm 21$ (order-nonselective) and $157 \pm 14 \mathrm{~ms}$ (C2dominant). The difference in durations among these responses was not statistically significant $[F(2,123)=0.06$, $P>0.05]$. 
A Order-nonselective response
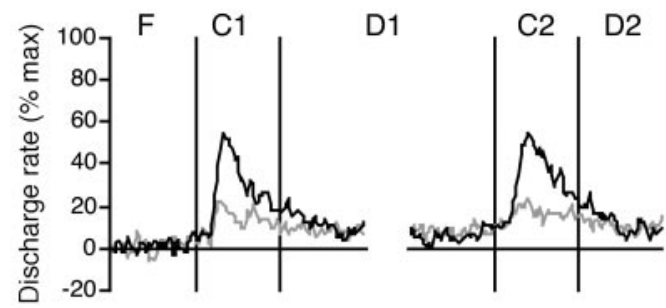

C1-dominant response

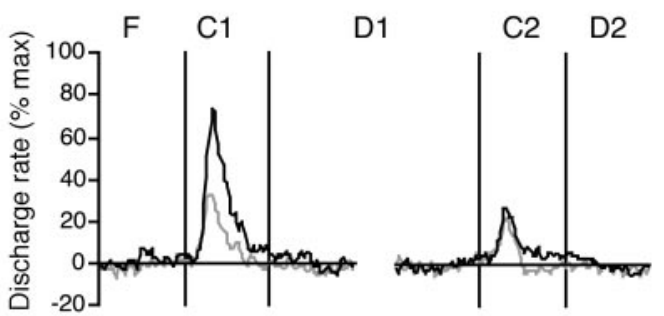

C2-dominant response
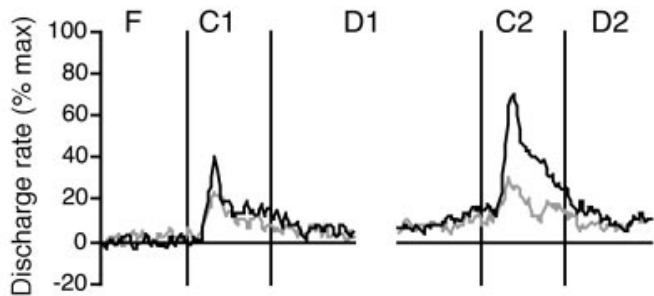

B

C1 period
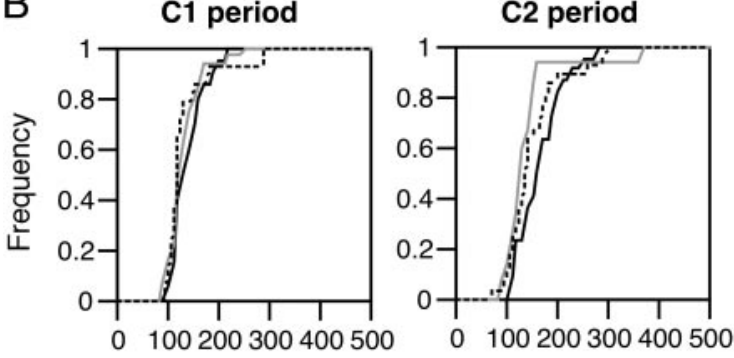

Latency $(\mathrm{ms})$

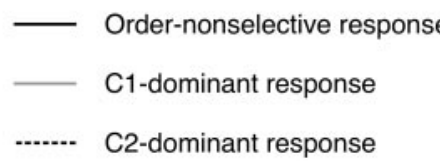

FIG. 4. A: population activities in preferred object trials (black) and nonpreferred object trials (gray) of neurons with order-nonselective, C1-dominant, and $\mathrm{C} 2$-dominant responses. $\mathrm{F}$, fixation period; $\mathrm{C} 1,1$ st cue period; $\mathrm{D} 1,1$ st delay period; $\mathrm{C} 2$, 2nd cue period; D2, 2nd delay period. $B$ : cumulative summation curve of latencies of order-nonselective, C1-dominant, and $\mathrm{C} 2$ dominant responses during $\mathrm{C} 1$ and $\mathrm{C} 2$ periods.

For the order-nonselective response, the significant difference in response magnitude appeared $120 \mathrm{~ms}$ after the $\mathrm{C} 1$ onset and $140 \mathrm{~ms}$ after the $\mathrm{C} 2$ onset. For the $\mathrm{C} 1$-dominant response, the significant difference in response magnitude appeared 110 $\mathrm{ms}$ after the $\mathrm{C} 1$ onset, but could not be detected during the $\mathrm{C} 2$ period. For the $\mathrm{C} 2$-dominant response, the significant difference in response magnitude appeared $120 \mathrm{~ms}$ after the $\mathrm{C} 2$ onset, but could not be detected during the $\mathrm{C} 1$ period.

\section{C1 objects modulated responses during C2 period}

We examined whether responses during the $\mathrm{C} 2$ period were affected by the $\mathrm{C} 1$ object. Among neurons with the $\mathrm{C} 1-$ dominant response $(n=33)$, most of these neurons $(n=32)$ did not show a significant difference in response magnitude during the $\mathrm{C} 2$ period depending on the $\mathrm{C} 1$ object presented (Mann-Whitney $U$ test, $P<0.05$ ). Among neurons with the C2-dominant response $(n=26), 35 \%(n=9)$ showed a significant difference in response magnitude during the $\mathrm{C} 2$ period depending on the $\mathrm{C} 1$ object presented (Mann-Whitney $U$ test, $P<0.05$ ).

Figure 5 shows an example of the $\mathrm{C} 2$-dominant response of a neuron that varied depending on the $\mathrm{C} 1$ object presented. As shown in Fig. 5A, the neuron exhibited the response when the cross was presented, and the response magnitude during the $\mathrm{C} 2$ period (34.43 spikes/s) was significantly larger than that during the $\mathrm{C} 1$ period $(16.49$ spikes/s). The magnitude of response to the cross during the $\mathrm{C} 2$ period varied significantly with the $\mathrm{C} 1$ (Fig. 5B). When the double cone was presented during the $\mathrm{C} 1$ period, the magnitude of response to the cross during the $\mathrm{C} 2$ period was 22.31 spikes/s. When the circle was presented during the $\mathrm{C} 1$ period, the magnitude of response to the cross during the $\mathrm{C} 2$ period was 46.15 spikes/s. These response magnitudes were significantly different $(z=4.13 ; P<$ $0.0001)$.

\section{Object-selective response during DMS task}

Order-selective response magnitudes were significantly different between the $\mathrm{C} 1$ period and $\mathrm{C} 2$ period. This difference

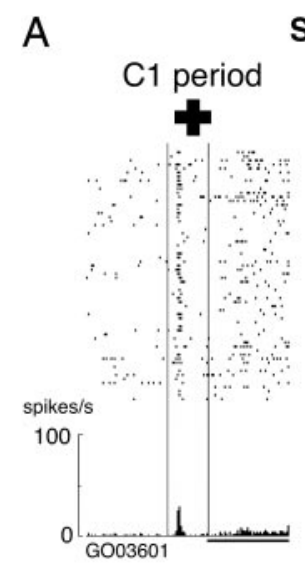

SPR task
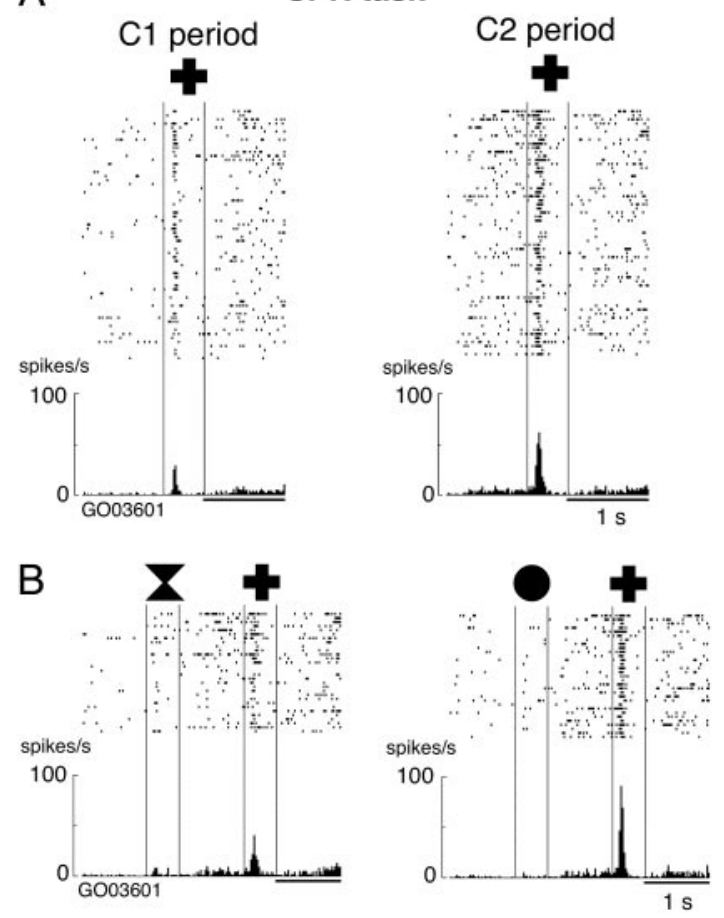

FIG. 5. Histograms of C2-dominant responses of a neuron that varied with $\mathrm{C} 1$ object. The neuron showed response when the cross was presented, and magnitude of response during $\mathrm{C} 2$ period was larger than that during $\mathrm{C} 1$ period (A). Response magnitude during $\mathrm{C} 2$ period when the double cone was presented during $\mathrm{C} 1$ period was significantly different from that when the circle was presented during $\mathrm{C} 1$ period $(B)$. 
could be caused by the enhancement or suppression of responses during the $\mathrm{C} 1$ or $\mathrm{C} 2$ period. To test this hypothesis, we compared responses during the SPR task with those during the DMS task. Figure $6 A$ shows the C1-dominant response of a neuron during the SPR task and that during the DMS task. The neuron responded when the double cone was presented during the $\mathrm{C} 1$ period (34.92 spikes/s), but did not respond when the same double cone was presented during the $\mathrm{C} 2$ period. During the DMS task, the magnitude of response to the double cone (35.61 spikes/s) was similar to that during the $\mathrm{C} 1$ period of the SPR task. The response magnitude during the cue period of the DMS task was not significantly different (Mann-Whitney $U$
A

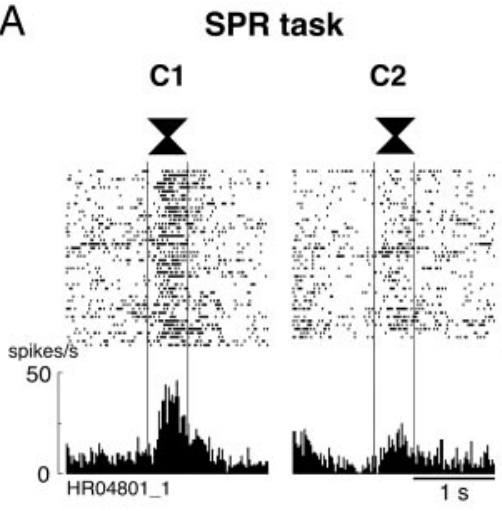

C

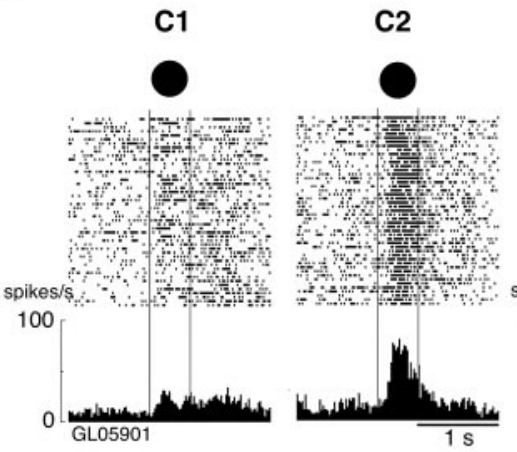

D

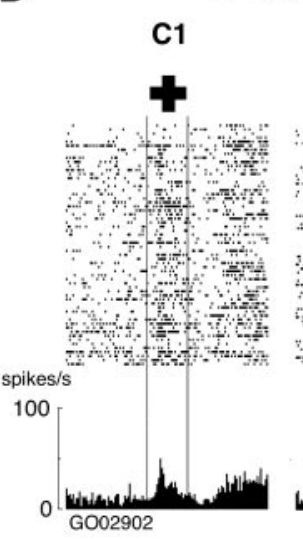

SPR task

C2

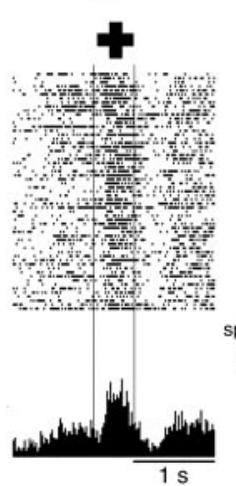

DMS task

DMS task

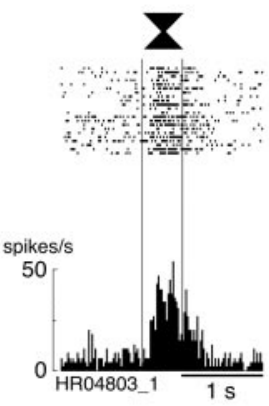

B

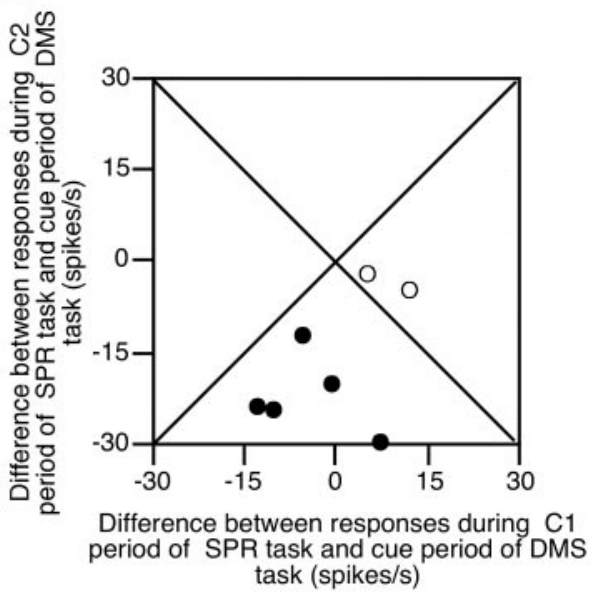

E

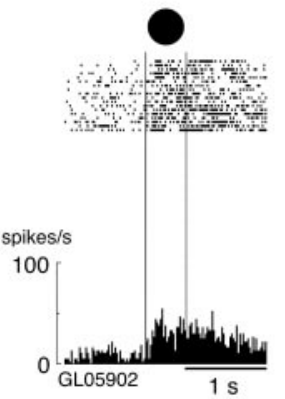

DMS task

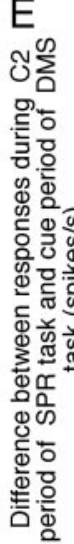

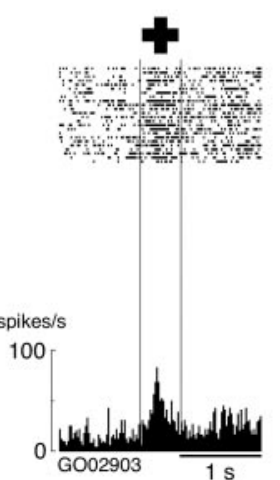

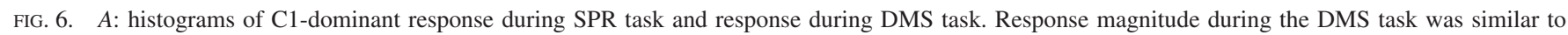

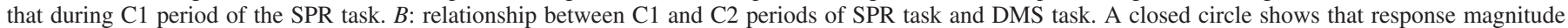

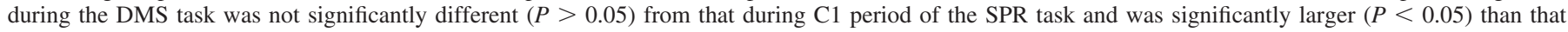

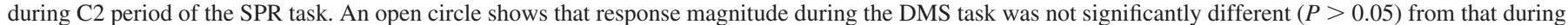

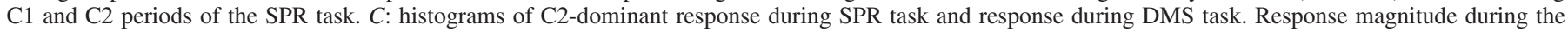

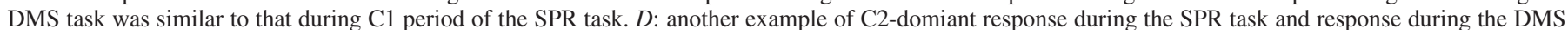

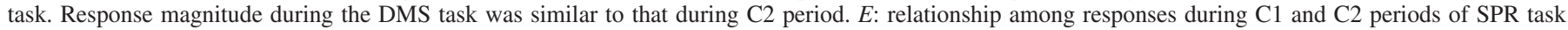

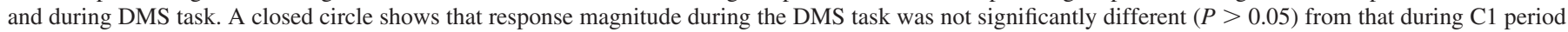

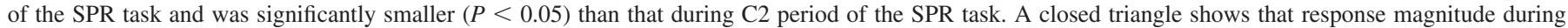

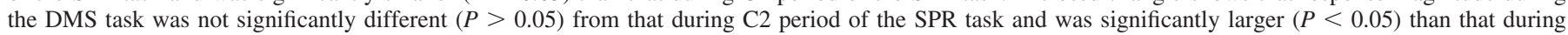

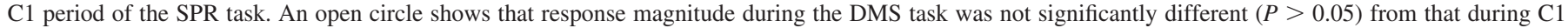
and $\mathrm{C} 2$ periods of the SPR task. 
test, $z=0.03, P>0.05)$ from that during the $\mathrm{C} 1$ period of the SPR task, and was significantly larger $(z=4.18 ; P<0.0001)$ than that during the $\mathrm{C} 2$ period of the SPR task. Among seven tested neurons with the $\mathrm{C} 1$-dominant response, five showed a similar response magnitude during the DMS task to that during the $\mathrm{C} 1$ period of the SPR task (Fig. $6 B$ ).

Figure $6 C$ shows an example of the C2-dominant response of a neuron during the SPR task and that during the DMS task. The neuron exhibited a small response magnitude (27.03 spikes/s) during the $\mathrm{C} 1$ period and a large response magnitude (60.44 spikes/s) during the $\mathrm{C} 2$ period when the visual cue was a circle. During the DMS task, this neuron exhibited a small response magnitude (35.12 spikes/s) similar to that during the $\mathrm{C} 1$ period in the SPR task. The response magnitude of this neuron during the cue period of the DMS task was not significantly different $(z=1.83, P>0.05)$ from that during the $\mathrm{C} 1$ period of the SPR task and was significantly smaller $(z=$ 4.68, $P<0.0001)$ than that during the $\mathrm{C} 2$ period of the SPR task. Figure $6 D$ shows another example of the C2-dominant response during the SPR task and that during the DMS task. This neuron exhibited a small response magnitude (31.44 spikes/s) during the $\mathrm{C} 1$ period and a large response magnitude (60.84 spikes/s) during the C2 period. During the DMS task, this neuron exhibited a response magnitude (50.52 spikes/s) similar to that during the $\mathrm{C} 2$ period in the SPR task. The response magnitude of this neuron during the cue period of the DMS task was significantly larger $(z=2.83, P<0.005)$ than that during the $\mathrm{C} 1$ period of the SPR task and not significantly different $(z=1.33, P>0.05)$ from that during the $\mathrm{C} 2$ period of the SPR task. Among 12 tested neurons with the C2dominant response, 7 showed a significant increase in response magnitude during the $\mathrm{C} 2$ period and 4 showed a significant decrease during the $\mathrm{C} 1$ period (Fig. $6 E$ ).

\section{Object-selective response during $C 1$ and $C 2$ periods in error trials}

To evaluate the behavioral significance of neuronal activity, we examined neuronal activity when the monkeys incorrectly performed. Although we observed two types of error in the SPR task, breaking the fixation during the cue or delay period and making a saccade to an incorrect target object during the response period, we analyzed error trials in which the monkeys had to make a saccade to a preferred object but made a saccade to an incorrect object.

To evaluate the behavioral significance of the object-selective and order-selective responses during the $\mathrm{C} 1$ and $\mathrm{C} 2$ periods in encoding information regarding the object and order of presentation, we compared the response to the preferred object in the correct trials with that in the error trials. The ordernonselective response magnitudes in the correct trials were not significantly different from those in the error trials during both the $\mathrm{C} 1$ (Wilcoxon signed-rank test, $z=0.43, P>0.05$, mean $=31.87$ spikes $/ \mathrm{s}$ in correct trials, mean $=30.76$ spikes $/ \mathrm{s}$ in error trials $)$ and the $\mathrm{C} 2(z=1.61, P>0.05$, mean $=35.26$ spikes/s in correct trials, mean $=33.73$ spikes/s in error trials) periods (Fig. 7A). The C1-dominant response magnitudes in the correct trials were also not significantly different from those in the error trials during both the $\mathrm{C} 1(z=0.64, P>0.05$, mean $=47.35$ spikes $/ \mathrm{s}$ in correct trials, mean $=46.68$ spikes $/ \mathrm{s}$ in error trials $)$ and the $\mathrm{C} 2(z=0.27, P>0.05$, mean $=30.88$
A C1 period
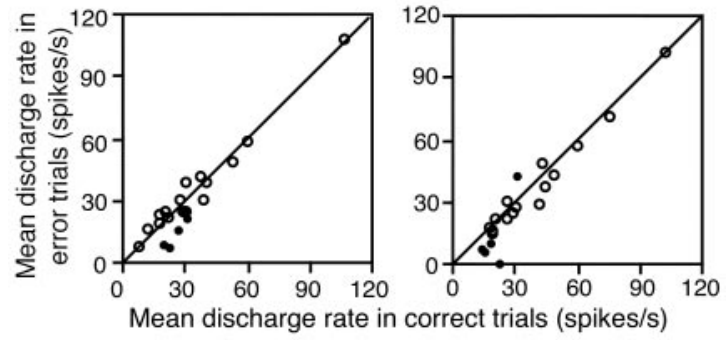

B

C1 period



C2 period

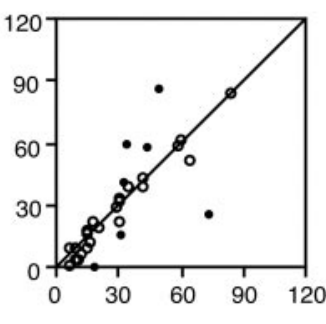

Mean discharge rate in correct trials (spikes/s)
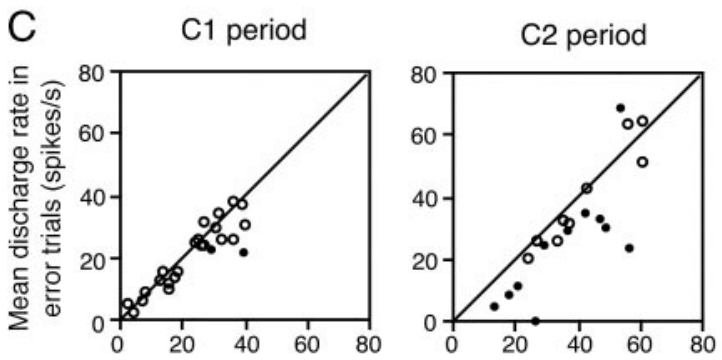

Mean discharge rate in correct trials (spikes/s)

FIG. 7. Comparison of responses during correct trials and error trials. A: order-nonselective response during $\mathrm{C} 1$ and $\mathrm{C} 2$ periods in correct and error trials. Mean discharge rates during the $\mathrm{C} 1$ and $\mathrm{C} 2$ periods in correct and error trials were not significantly different. $B$ : $\mathrm{C} 1$-dominant response in correct and error trials. Mean discharge rates in correct and error trials were not significantly different during $\mathrm{C} 1$ and $\mathrm{C} 2$ periods. $C$ : $\mathrm{C} 2$-dominant response in correct and error trials. Mean discharge rates in correct and error trials were significantly different during $\mathrm{C} 2$ period but not significantly different during $\mathrm{C} 1$ period. Closed circles show discharge rate of neurons whose responses were significantly different between correct and error trials (Mann-Whitney $U$ test, $P<0.05)$. Open circles show discharge rate of neurons whose responses were not significantly different between correct and error trials $(P>0.05)$.

spikes/s in correct trials, mean $=29.63$ spikes/s in error trials) periods (Fig. 7B). C2-dominant response magnitude (Fig. 7C) was not significantly different between the correct and error trials during the $\mathrm{C} 1$ period $(z=1.01, P>0.05$, mean $=22.51$ $\mathrm{s} / \mathrm{s}$ in correct trials, mean $=21.00 \mathrm{spikes} / \mathrm{s}$ in error trials), but was significantly smaller in the error trials than in the correct trials during the $\mathrm{C} 2$ period $(z=2.50, P<0.05$, mean $=38.20$ spikes $/ \mathrm{s}$ in correct trials, mean $=31.48 \mathrm{~s} / \mathrm{s}$ in error trials).

\section{Object-nonselective response during $C 1$ and $C 2$ periods}

Thirty-eight neurons showed the object-nonselective response. Of these, 17 neurons showed the order-nonselective response, and 21 neurons showed the $\mathrm{C} 1$-dominant response. No neurons showed the $\mathrm{C} 2$-dominant response.

To compare the temporal profiles between the object-selective and object-nonselective responses, we constructed the 
histograms of these population activities (Fig. 8A). We could not find differences in latency and duration between the objectselective and object-nonselective responses in the order-nonselective response. However, in the $\mathrm{C} 1$-dominant response, the latency of the object-selective response was slightly shorter than that of the object-nonselective response. Figure $8 B$ shows the difference in response latency. Neurons with the objectselective and order-selective responses were activated early, and the latencies of the object-nonselective and order-nonselective responses were slightly longer.

\section{Object-selective delay-period activity during D1 and D2} periods

One hundred eighty-three neurons were activated during the D1 and/or D2 period. Of these, 52 neurons exhibited object-nonselective delay-period activity during the D1 and/or D2 period. In the remaining 131 neurons, delayperiod activity during the D1 and/or D2 period showed object selectivity. We classified these delay-period activities into three types: order-nonselective activity, C1-coding activity, and C2-coding activity.
A
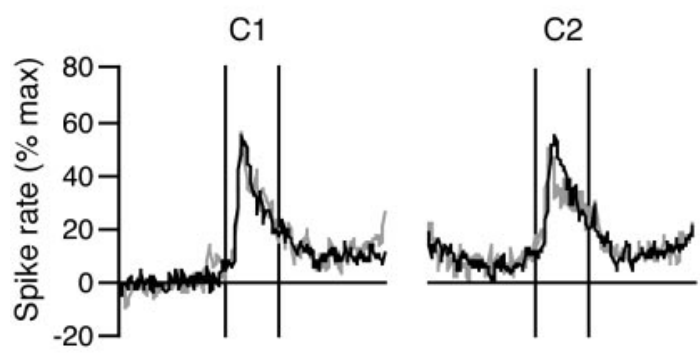

C1-dominant
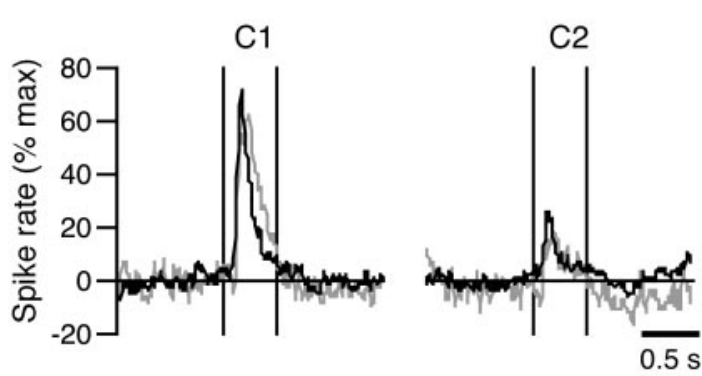

Figure $9 A$ shows the histograms of the order-nonselective delay-period activity of a neuron. The neuron exhibited delayperiod activity during the $\mathrm{D} 1$ period when the $\mathrm{C} 1$ object was a circle (Fig. 9, $A$, trial conditions 5 and 6, and $B$ ). This delay-period activity during the $\mathrm{D} 1$ period was object-selective $[F(2,142)=73.29, P<0.0001]$, and the activity returned to the baseline level after the appearance of the $\mathrm{C} 2$ object. During the D2 period, this neuron exhibited delay-period activity after the circle was presented as $\mathrm{C} 2$ (Fig. 9, $A$, trial conditions 2 and 4 , and $C$ ). When the double cone or the cross was presented as $\mathrm{C} 2$, this neuron showed an increase in activity at the end of the D2 period (Fig. 9A, trial conditions 1, 3, 5, and 6), and discharge rates during the D2 period of these trials were not significantly different from those during the control period (Fig. 9C). The delay-period activity during the D2 period had selectivity $[F(5,139)=57.41, P<0.0001)$. This neuron showed the highest delay-period activity during the D2 period in trial condition 4 , and this delay-period activity was significantly different $(P<0.05)$ from those in trial conditions 1,3 , 5 , and 6 , and not significantly different $(P>0.05)$ from that in trial condition 2 . This indicates that this delay-period activity
FIG. 8. A: population activities of neurons with object-selective (black) and object-nonselective (gray) responses during $\mathrm{C} 1$ and $\mathrm{C} 2$ periods, and cumulative summation curve of latencies of object-selective and object-nonselective visual response. $B$ : cumulative summation curve of latencies of 4 types of response.
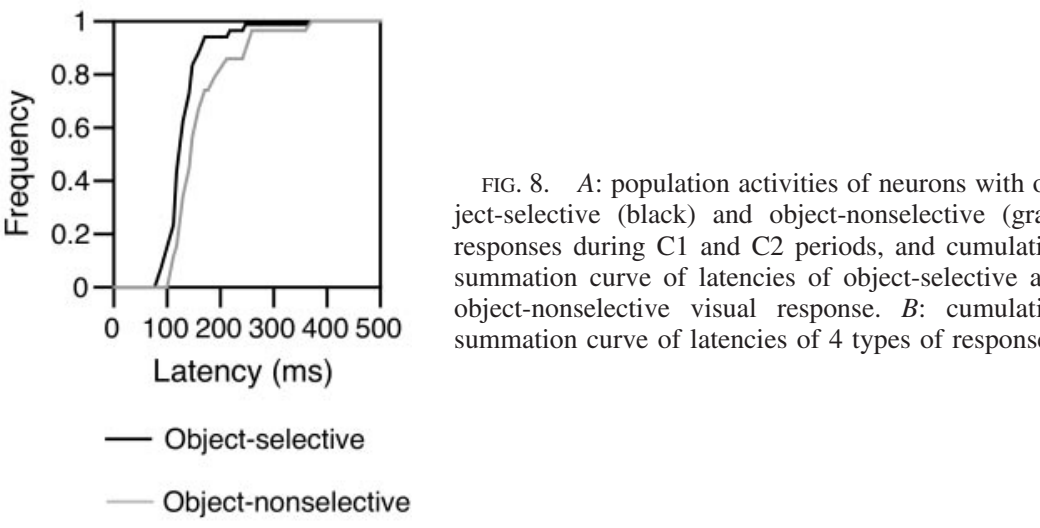

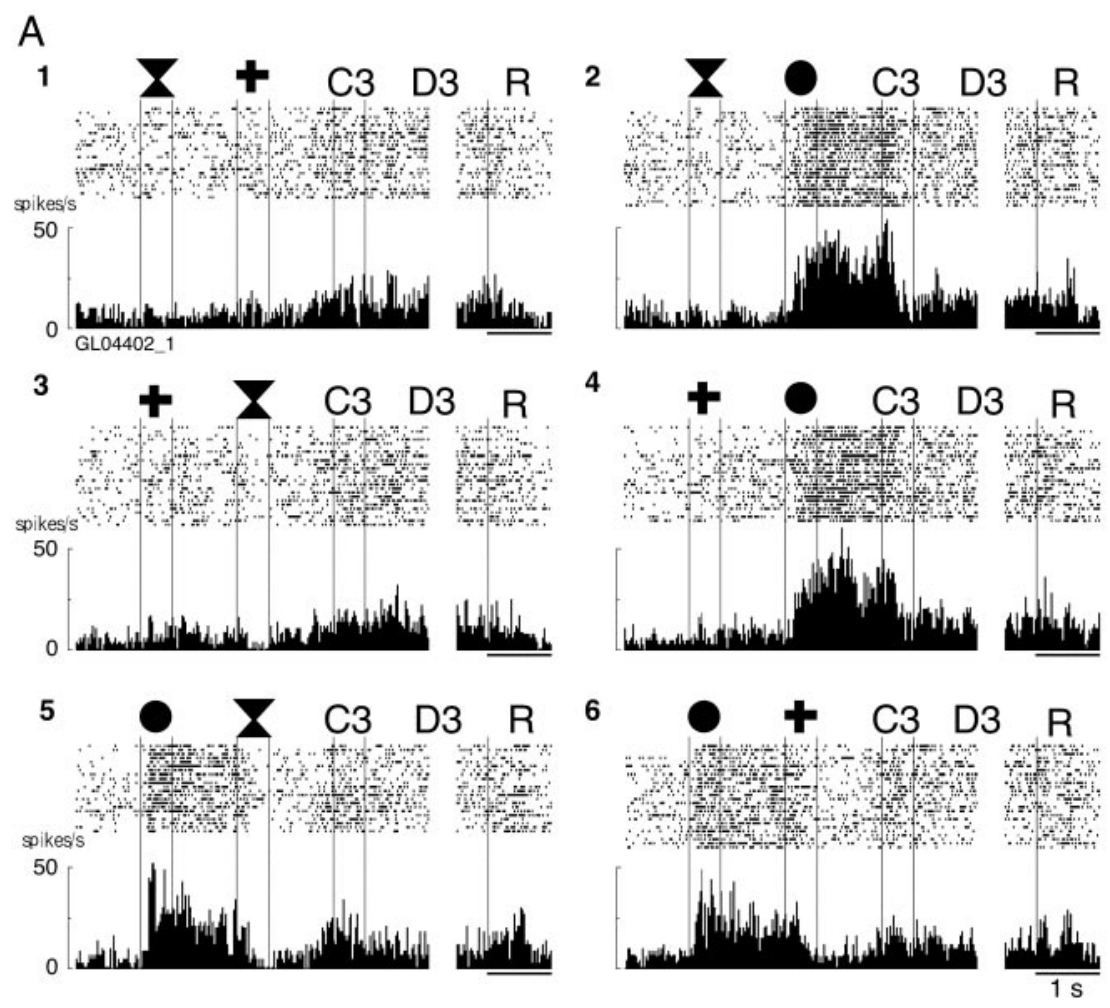

FIG. 9. A: histograms of order-nonselective delay-period activity of a neuron. The neuron was activated during the D1 period under trial conditions 5 and 6 and during the D2 period under trial conditions 2 and 4; this neuron was activated after presentation of a circle cue regardless of order of presentation. Bin width is $25 \mathrm{~ms}$. C3, color cue period; D3, 3rd delay period; R, response period. $B$ : average discharge rates during D1 period. Error bar indicates SD. Dashed line indicates mean discharge rate during control period. Asterisk indicates significant increase in activity during delay period. C: average discharge rate during D2 period for 6 trial conditions. Dashed line indicates mean discharge rate during control period. Asterisks indicate significant increase in activity during delay period.
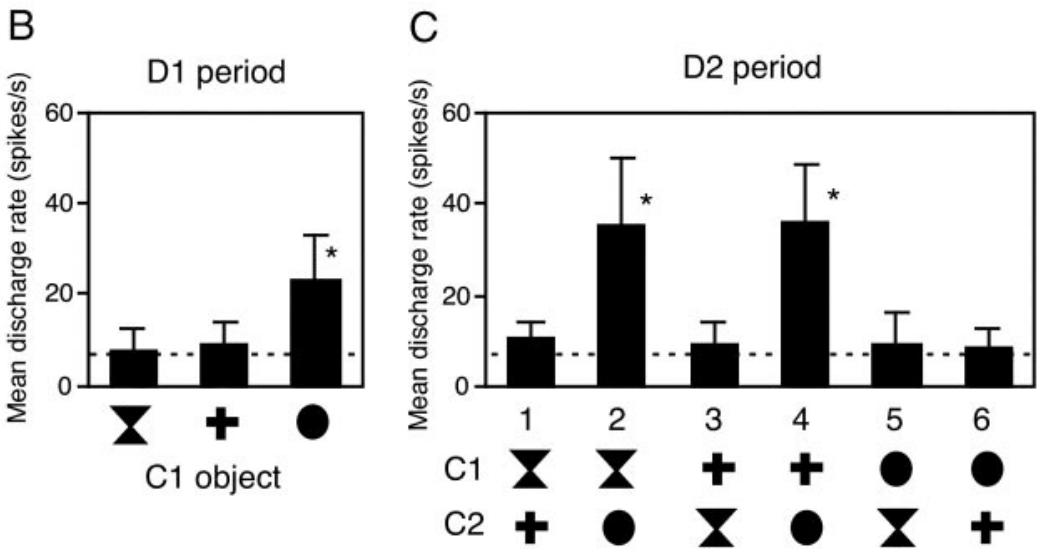

during the D2 period was not selective in only one sequence. $\mathrm{SI}_{\mathrm{C} 1}(0.41)$ was lower than $\mathrm{SI}_{\mathrm{C} 2}$ (0.98). Therefore delay-period activity during the $\mathrm{D} 2$ period depended on the $\mathrm{C} 2$ object. Thus we classified neuronal activities depending on the degree of selectivity for both stimuli, when the delay-period activity during the D2 period was selective in terms of the C1 and C2 objects (see METHODS). In this neuron, delay-period activity was detected after the circle cue was presented as $\mathrm{C} 1$ or $\mathrm{C} 2$, and the delay-period activity during the D1 or D2 period returned to the baseline level when the $\mathrm{C} 2$ object or color cue was presented, respectively. Thus this delay-period activity was order-nonselective, and we defined the circle as the preferred object of this neuron. Thirty-eight neurons showed ordernonselective excitatory delay-period activity, and two neurons showed a significant decrease in activity during the delay periods.

Figure $10 \mathrm{~A}$ shows the histograms of the $\mathrm{C} 1$-coding delayperiod activity of a neuron. The neuron exhibited delay- period activity during the D1 period when the $\mathrm{C} 1$ object was double cone or the cross (Fig. 10, A, trial conditions 1-4, and $B)$. This was object-selective $[F(2,122)=15.4, P<$ 0.0001]. During the last of the D2 period, this neuron showed activation in all trial conditions (Fig. 10A), but delay-period activity was not selective $[F(5,119)=0.67$, $P>0.05]$. Thus this neuron coded $\mathrm{C} 1$-object information during the D1 period and was identified as having C1coding (D1) delay-period activity, and we defined the double cone as the preferred object of this neuron. Sixteen neurons were identified as having this type of activity.

Figure $11 A$ shows other examples of the C1-coding delayperiod activity of a neuron. The neuron did not show delayperiod activity during the D1 period under all trial conditions (Fig. 11B). During the D2 period, however, this neuron exhibited a large delay-period activity when the $\mathrm{C} 1$ object was the circle (Fig. 11, A, trial conditions 5 and 6 , and $C$ ). The delay-period activity during the D2 period had selectivity 


\section{A}
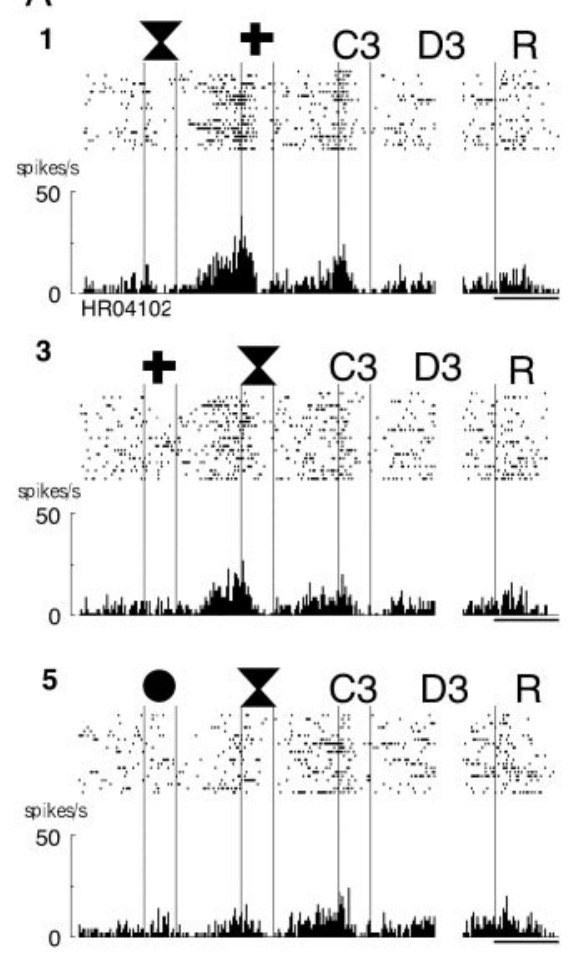


4

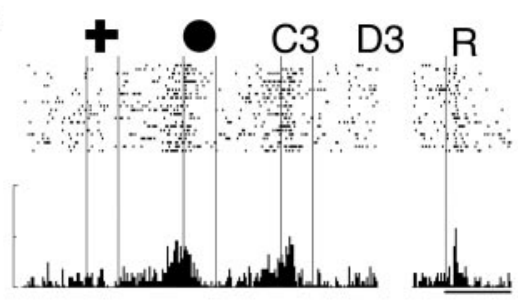

6

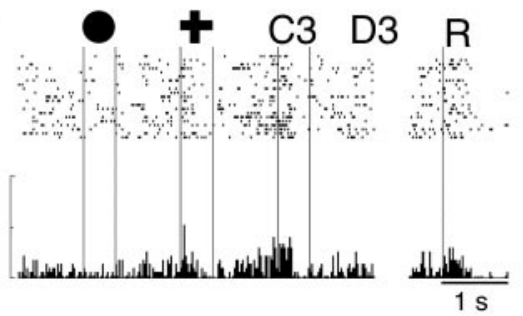

FIG. 10. A: histograms of C1-coding (D1) delayperiod activity of a neuron. Format is the same as that in Fig. $9 A$. The neuron was activated during the $\mathrm{D} 1$ period under the trial conditions 1-4; this neuron was activated during $\mathrm{D} 1$ period when $\mathrm{C} 1$ object was the double cone or cross. $B$ : average discharge rates during $\mathrm{D} 1$ period. $C$ : average discharge rate during D2 period for 6 trial conditions. Format is same as that in Fig. 9, $B$ and $C$.

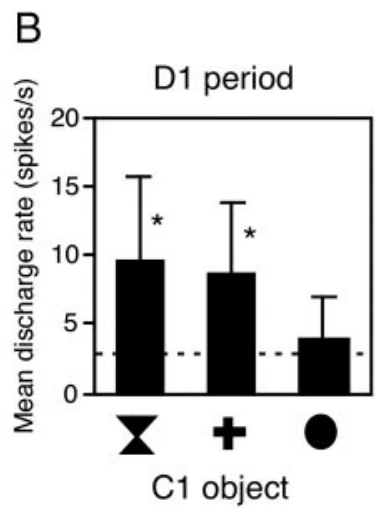

C

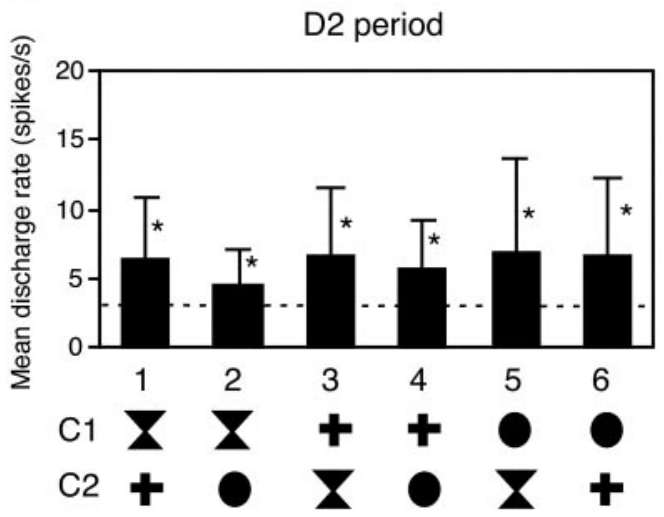

$[F(5,139)=14.49, P<0.0001]$. This neuron showed the highest delay-period activity during the D2 period in trial condition 6 , and this delay-period activity was significantly different $(P<0.05)$ from those in trial conditions $1-4$ and not significantly different $(P>0.05)$ from that in trial condition 5 . $\mathrm{SI}_{\mathrm{C} 2}(0.59)$ was lower than $\mathrm{SI}_{\mathrm{C} 1}(0.86)$. Therefore this delayperiod activity was classified as C1-coding (D2), and we defined the circle as the preferred object of this neuron. Thirty-four neurons were identified as having C1-coding (D2) delay-period activity, and two neurons exhibited C1-coding (D1 and D2) delay-period activity.

Figure $12 A$ shows the histograms of the $\mathrm{C} 2$-coding delayperiod activity of a neuron. The neuron did not exhibit delay-period activity during the D1 period under all trial conditions (Fig. 12B). During the D2 period, this neuron was significantly activated when the $\mathrm{C} 2$ object was the cross (Fig. 12, A, trial conditions 1 and 6 , and $C$ ). The delayperiod activity during the D2 period had selectivity
$[F(5,140)=15.73, P<0.0001]$. This neuron showed the highest delay-period activity during the D2 period in trial condition 1 , and this delay-period activity was significantly different $(P<0.05)$ from those in trial conditions $2-5$ and not significantly different $(P>0.05)$ from that in trial condition 6. $\mathrm{SI}_{\mathrm{C} 1}(0.52)$ was lower than $\mathrm{SI}_{\mathrm{C} 2}(0.90)$. Therefore this delay-period activity was classified as $\mathrm{C} 2$-coding, and we defined the cross as the preferred object of this neuron. Thirty neurons exhibited C2-coding delay-period activity during the $\mathrm{D} 2$ period.

We were unable to detect neurons with delay-period activity coding both the $\mathrm{C} 1$ and $\mathrm{C} 2$ objects during the $\mathrm{D} 2$ period. We compared the highest delay-period activity with the other delay-period activities by a post hoc test (Fisher's PLSD), and determined whether delay-period activity was selective in only one sequence. Results showed that there were no neurons activated during the D2 period in only one sequence of six sequences. 


\section{A}
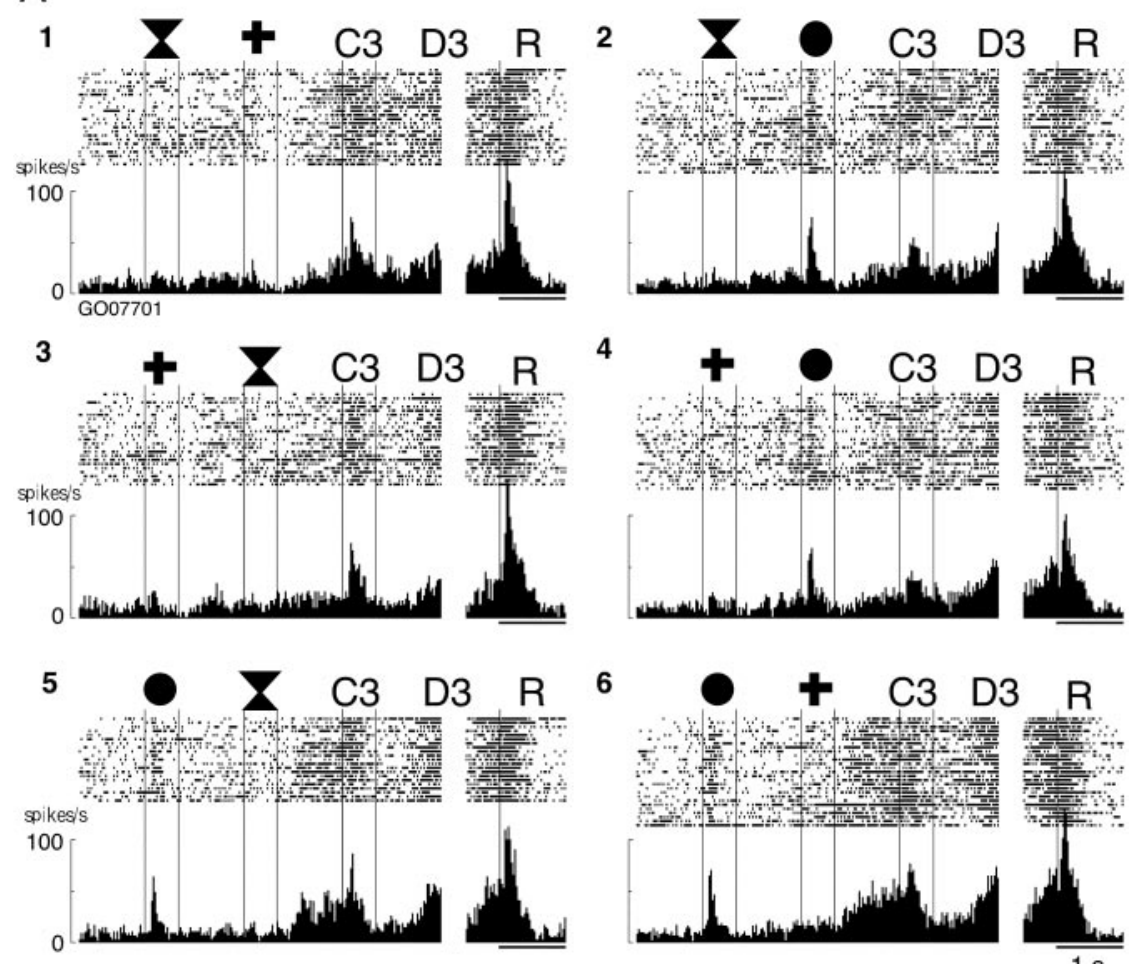

4

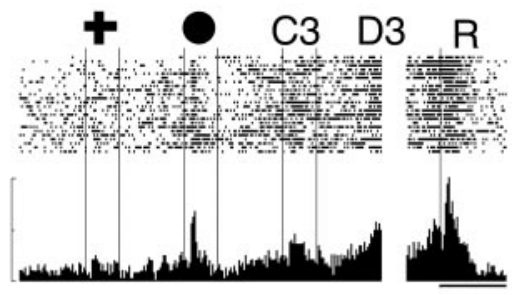

6

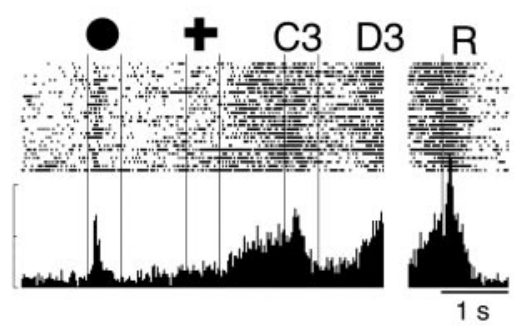

FIG. 11. A: histograms of C1-coding (D2) delay-period activity of a neuron. Format is the same as that in Fig. 9A. The neuron was activated during D2 period under trial conditions 5 and 6 ; this neuron was activated during D2 period when $\mathrm{C} 1$ object was the circle. $B$ : average discharge rates during D1 period. $C$ : average discharge rate during D2 period for 6 trial conditions. Format is same as that in Fig. 9, $B$ and $C$.
B



C

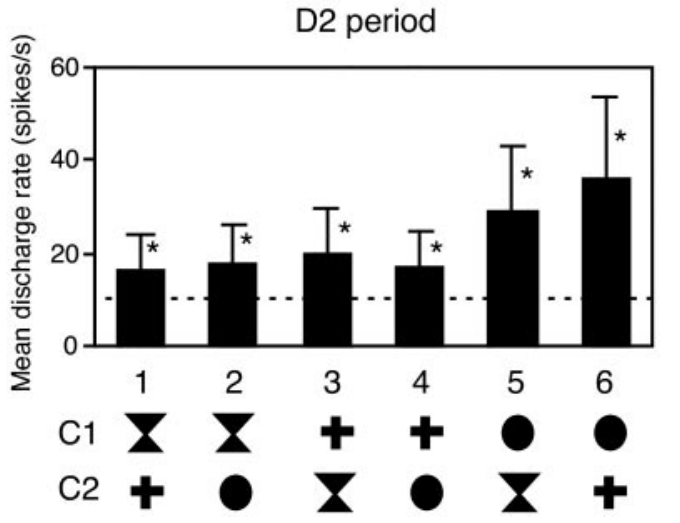

Temporal profile of delay-period activities

To compare temporal profiles among order-nonselective, $\mathrm{C} 1$-coding, and $\mathrm{C} 2$-coding delay-period activities, we constructed the population histograms of these activities (Fig. 13, $A-D)$. In these figures, red lines indicate population activities in trials in which the preferred object was presented during the $\mathrm{C} 1$ period, and green lines indicate population activities in trials in which the preferred object was presented during the $\mathrm{C} 2$ period. Blue lines indicate differences between the red and green lines. The starting point of difference in delay-period activity (the time at which the 1st 3 consecutive bins differed from the difference of activity for $1 \mathrm{~s}$ of the control period by $>2 \mathrm{SD}$ or $<2 \mathrm{SD}$ ) and the endpoint (the time of the last bin) of the difference in delay-period activity were determined. For order-nonselective delay-period activity, when the preferred object was presented as $\mathrm{C} 1$, population activity was elicited at $125 \mathrm{~ms}$ after $\mathrm{C} 1$ presentation and continued during the delay period until $100 \mathrm{~ms}$ after $\mathrm{C} 2$ presentation (Fig. 13, $A$ and $E$, red line). When the preferred object was presented as $\mathrm{C} 2$, population activity was elicited at $175 \mathrm{~ms}$ after $\mathrm{C} 2$ presentation and continued during the delay period until $100 \mathrm{~ms}$ after color cue presentation (Fig. 13, A, green line, and $E$, red line). For the C1-coding (D1) delay-period activity, a difference in population activity was first observed $275 \mathrm{~ms}$ after $\mathrm{C} 1$ presentation and continued until $200 \mathrm{~ms}$ after $\mathrm{C} 2$ presentation (Fig. 13, B, blue line, and $E$, green line). Although population activity showed delay-period activity during the D2 period, a difference could not be found during the D2 period. A significant difference in C1-coding (D2) delay-period activity could not also be found during the D1 period, and it was first observed $325 \mathrm{~ms}$ after $\mathrm{C} 2$ presentation, and during the D2 period, population activity increased toward the end of the delay period until $600 \mathrm{~ms}$ after color cue presentation (Fig. 13, C and $E$, blue lines). A significant difference in $\mathrm{C} 2$-coding delay- 
A
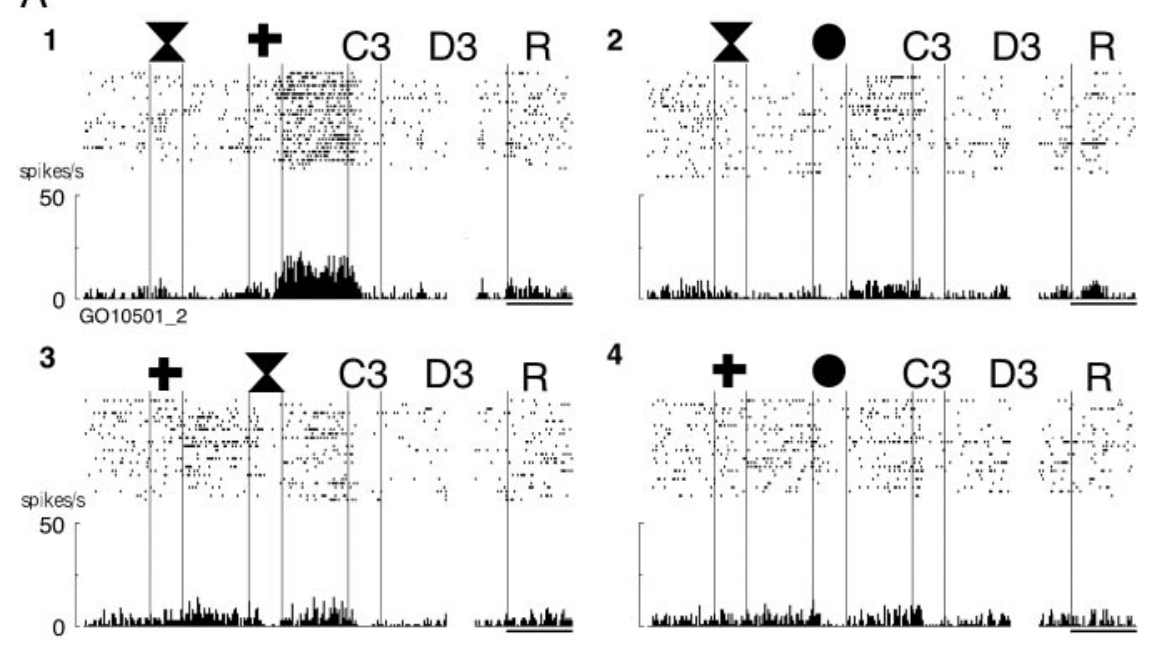

4
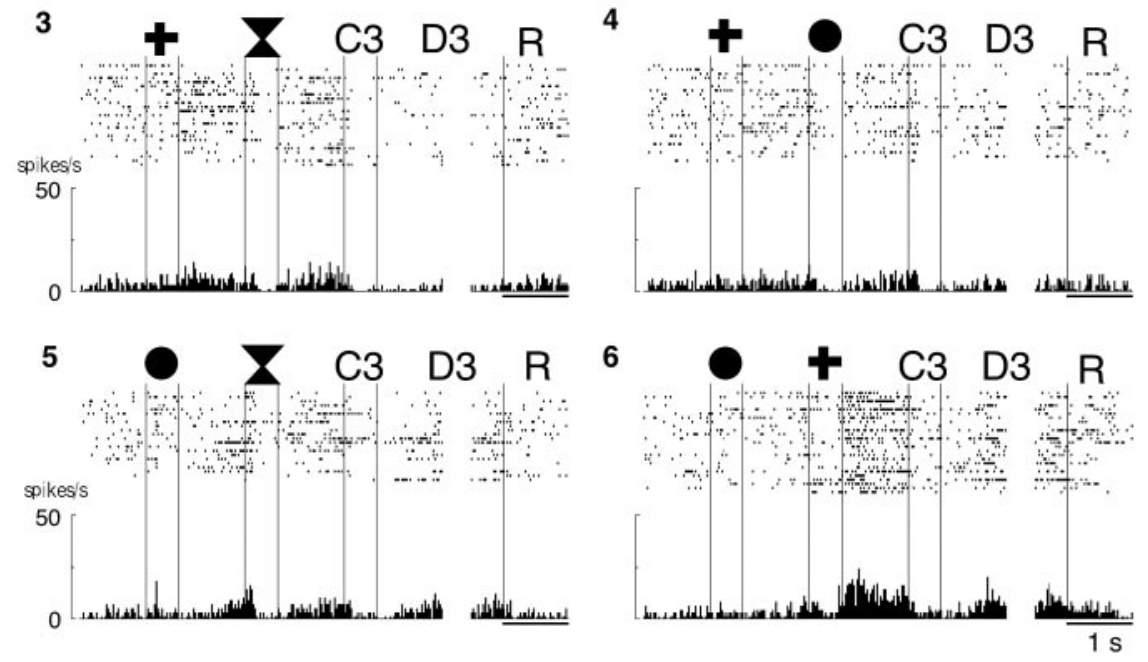

FIG. 12. A: histograms of C2-coding delay-period activity of a neuron. Format is the same as that in Fig. $9 A$. The neuron was activated during D2 period under trial conditions 1 and 6; this neuron was activated during $\mathrm{D} 2$ period when $\mathrm{C} 2$ object was the cross. $B$ : average discharge rates during D1 period. $C$ : average discharge rate during D2 period for 6 trial conditions. Format is same as that in Fig. 9, $B$ and $C$.
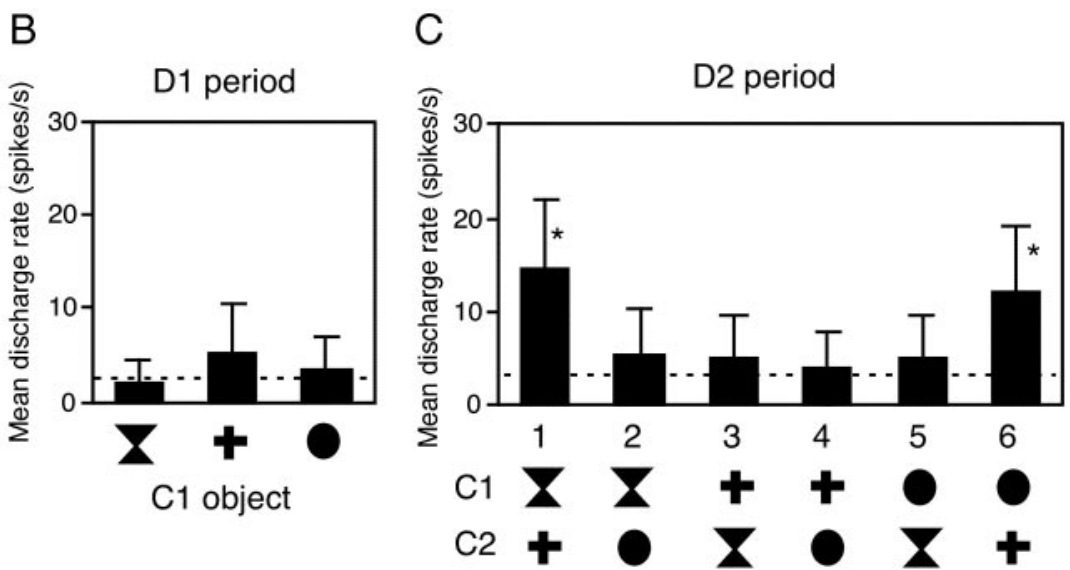

period activity could not be found during the D1 period, and it was first observed $275 \mathrm{~ms}$ after C2 presentation, and population activity increased toward the end of the delay period until $175 \mathrm{~ms}$ after color cue presentation (Fig. 13, D, blue line, and $E$, light blue line).

\section{Delay-period activities during DMS task}

To evaluate the importance of order-nonselective and orderselective (C1-coding and C2-coding) delay-period activities in retaining information regarding the object cue and order of presentation, we examined neuronal activity during the DMS task, in which the monkey had to memorize only one object information during the delay period. Of 131 neurons with object-selective delay-period activity during the SPR task, 42 neurons were also tested for their activity during the DMS task.

Figure 14 shows two examples of neuronal activity during the DMS task. Figure $14 A$ shows the activity during the DMS task of a neuron, whose activity during the SPR task is shown in Fig. 9. This neuron showed order-nonselective delay-period activity during the SPR task, and the preferred object was the circle. During the DMS task, this neuron exhibited excitatory delay-period activity (early $1 \mathrm{~s}, z=-4.51, P<0.0001$; last $1 \mathrm{~s}, z=-3.85, P<0.0001)$ when the object cue was the circle. This delay-period activity was object-selective during both the first $1 \mathrm{~s}[F(2,54)=20.83, P<0.0001]$ and the last $1 \mathrm{~s}$ $[F(2,54)=4.39, P<0.05]$ of the delay period.

Figure $14 B$ shows the activity during the DMS task of a neuron, whose activity during the SPR task is shown in Fig. 11. This neuron showed C1-coding delay-period activity during the SPR task. During the DMS task, the discharge rates increased during the last $1 \mathrm{~s}$ of the delay period under all three trial conditions. However, the delay-period activity of this neuron during the DMS task was not object-selective $[F(2,55)=0.13, P>0.05]$. This result indicates that the 
A

Order-nonselective activity

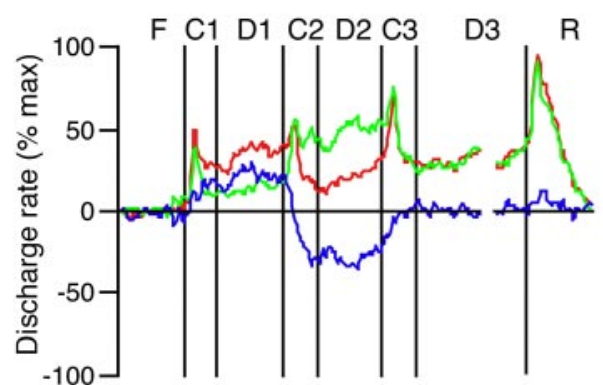

C

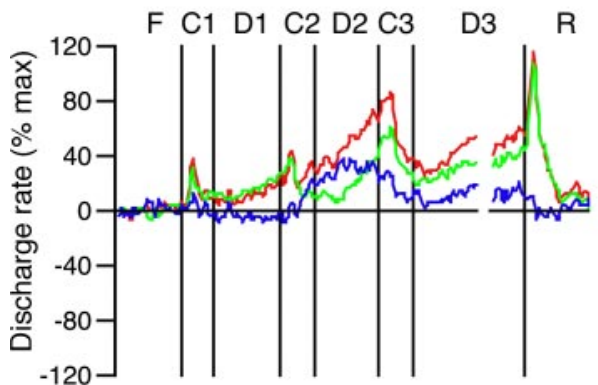

B

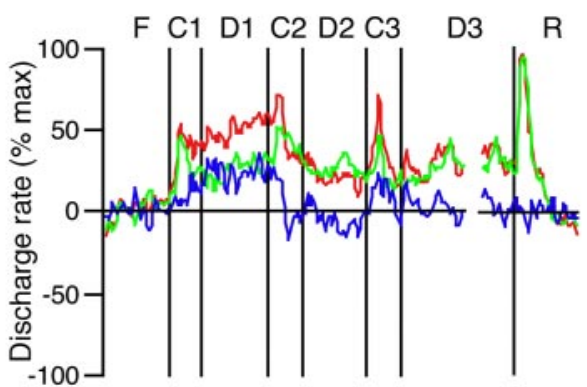

D

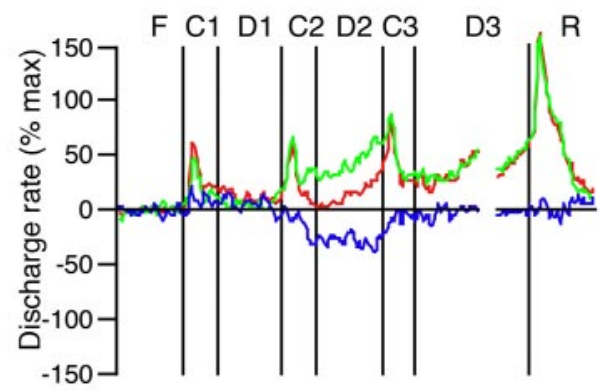

FIG. 13. Population histograms of order-nonselective delay-period activity $(A)$, C1-coding (D1) delay-period activity (B), C1-coding (D2) delay-period activity $(C)$, and $\mathrm{C} 2$-coding delayperiod activity $(D)$. Red lines indicate population histograms of trials in which preferred object was presented during $\mathrm{C} 1$ period, green lines indicate population histograms of trials in which preferred object was presented during $\mathrm{C} 2$ period, and blue lines indicate difference between red and green lines. $E$ : time-course of difference in activity between trials in which preferred object was presented as $\mathrm{C} 1$ and $\mathrm{C} 2$. $F$ : fixation period. $\mathrm{C} 1,1$ st cue period; $\mathrm{D} 1,1$ st delay period; $\mathrm{C} 2$, 2 nd cue period; D2, 2nd delay period; C3, color cue period; D3, 3rd delay period; $R$, response period.

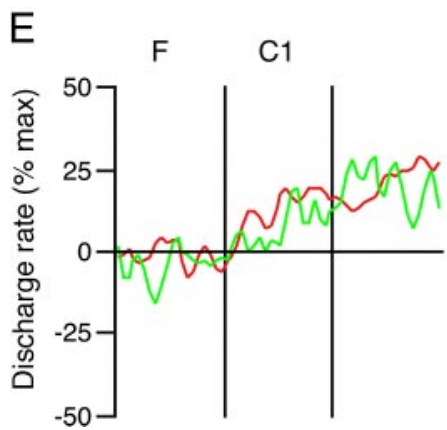

D1
C2

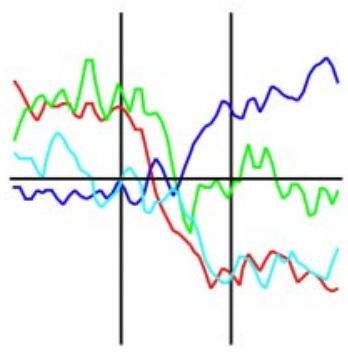

Order-nonselective

C1-coding (D1)

C1-coding (D2)

C2-coding order-selective delay-period activities during the SPR task were not related to the preparation for the behavioral response.

Nineteen neurons with order-nonselective delay-period activity were also tested during the DMS task. Of these, 18 (95\%) neurons exhibited object-selective delay-period activity during the DMS task, and 1 (5\%) neuron showed object-nonselective delay-period activity (Fig. 14C). Fifteen neurons with C1coding delay-period activity and five neurons with C2-coding delay-period activity were tested during the DMS task. Of these, $2(10 \%)$ neurons exhibited object-selective delay-period activity during the DMS task, $13(65 \%)$ neurons showed object-nonselective delay-period activity, and 5 (25\%) neurons did not exhibit delay-period activity (Fig. 14D).

\section{Delay-period activity in error trials}

To evaluate the importance of order-nonselective and orderselective (C1-coding and C2-coding) delay-period activities in retaining information regarding the object cue and order of presentation during the D1 and D2 periods, we compared discharge rates during the delay period between the correct trials and error trials in all neurons with object-selective delayperiod activity (Fig. 15, $A-D$ ). In the neurons with order- nonselective delay-period activity, the delay-period activity was not significantly different between the correct and error trials during both the D1 (Fig. 15A; Wilcoxon signed-rank test, $z=-0.24, P>0.05$, mean $=20.25$ spikes $/ \mathrm{s}$ in correct trials, mean $=20.60$ spikes/s in error trials) and D2 (Fig. 15B; $z=$ $-0.98, P>0.05$, mean $=23.43$ spikes $/ \mathrm{s}$ in correct trials, mean $=24.23$ spikes/s in error trials) periods. In contrast, neurons with C1-coding (Fig. 15C) and C2-coding (Fig. 15D) delay-period activities showed significantly weaker delay-period activities during the error trials than during the correct trials (C1-coding activity, $z=-1.96, P<0.05$, mean $=23.19$ spikes/s in correct trials, mean $=21.45$ spikes/s in error trials; C2-coding activity, $z=-2.23, P<0.05$, mean $=24.18$ spikes $/ \mathrm{s}$ in correct trials, mean $=18.04$ spikes $/ \mathrm{s}$ in error trials).

We compared discharge rates during the delay period between the correct trials and error trials in all neurons with object-selective delay-period activity during the DMS task and order-nonselective delay-period activity during the SPR task. In these neurons, the delay-period activity during the correct trials was significantly different from that during the error trials (Fig. 15E; Wilcoxon signed-rank test, $z=-2.12, P<0.05$, mean $=17.89$ spikes $/ \mathrm{s}$ in correct trials, mean $=16.12$ spikes $/ \mathrm{s}$ in error trials). 
A
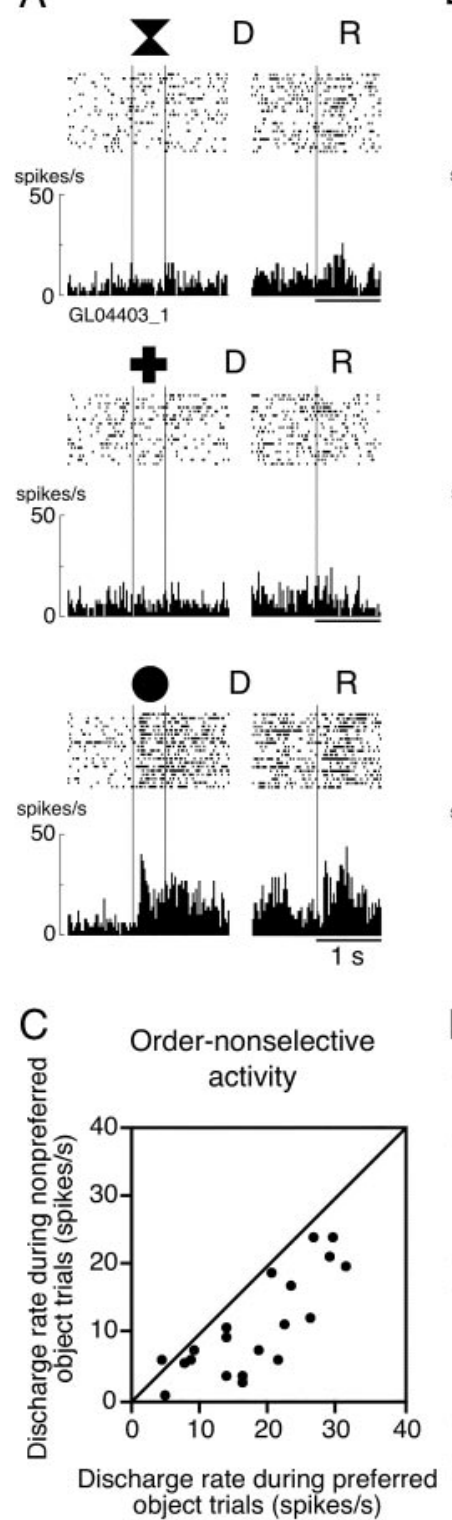

B
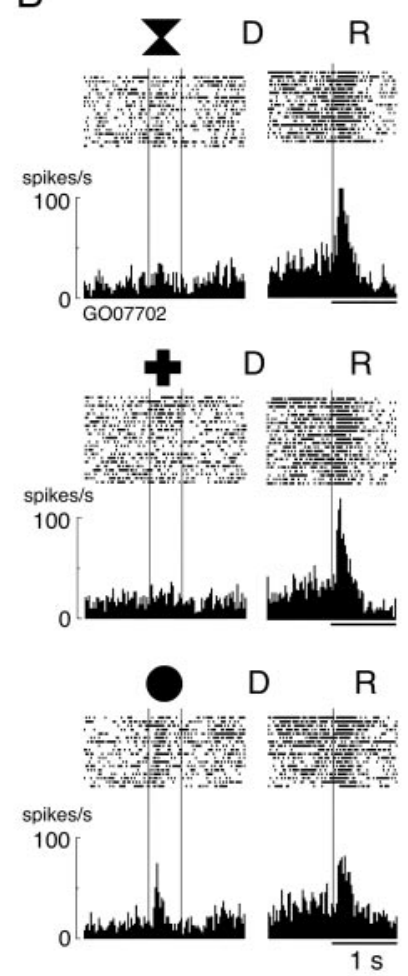

D

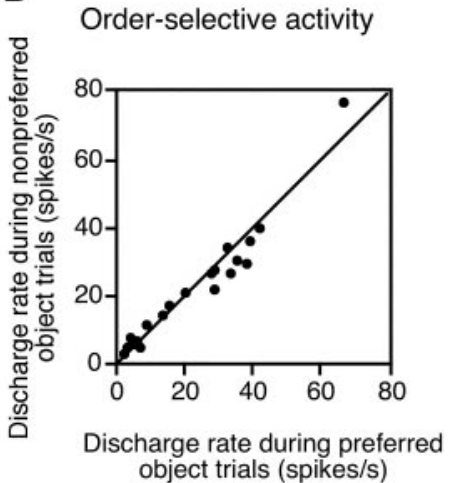

FIG. 14. Neuronal activity during DMS task. A: activity during DMS task of a neuron, whose activity the SPR task is shown in Fig. 9. This neuron showed order-nonselective delay-period activity during the SPR task. Because duration of delay was randomly selected to be between 2 and $3 \mathrm{~s}$, rasters and histograms are aligned at onset of cue presentation and at start of response period. This neuron exhibited delay-period activity when the object cue was the circle during the DMS task. $B$ : activity during DMS task of a neuron, whose activity during the SPR task is shown in Fig. 11. This neuron showed C1-coding (D2) delay-period activity during the SPR task. This neuron exhibited delay-period activity during the DMS task, but delay-period activity was not object-selective. $C$ : comparison of delay-period activities between preferred object and nonpreferred object trials during DMS task for neurons with order-nonselective delay-period activity during SPR task. Preferred object trial and nonpreferred object trial were determined by result of the SPR task. $D$ : comparison of delay-period activities between preferred object and nonpreferred object trials during DMS task for neurons with order-selective delay-period activity during the SPR task. Preferred object trial and nonpreferred object trial were determined by result of the SPR task. For example, the neuron shown in $B$ did not show object-selective delay-period activity during the DMS task. However, this neuron showed object-selective and C1-coding delay-period activity during the SPR task (see Fig. 11), and this neuron's preferred object was the circle and nonpreferred object was the double cone.
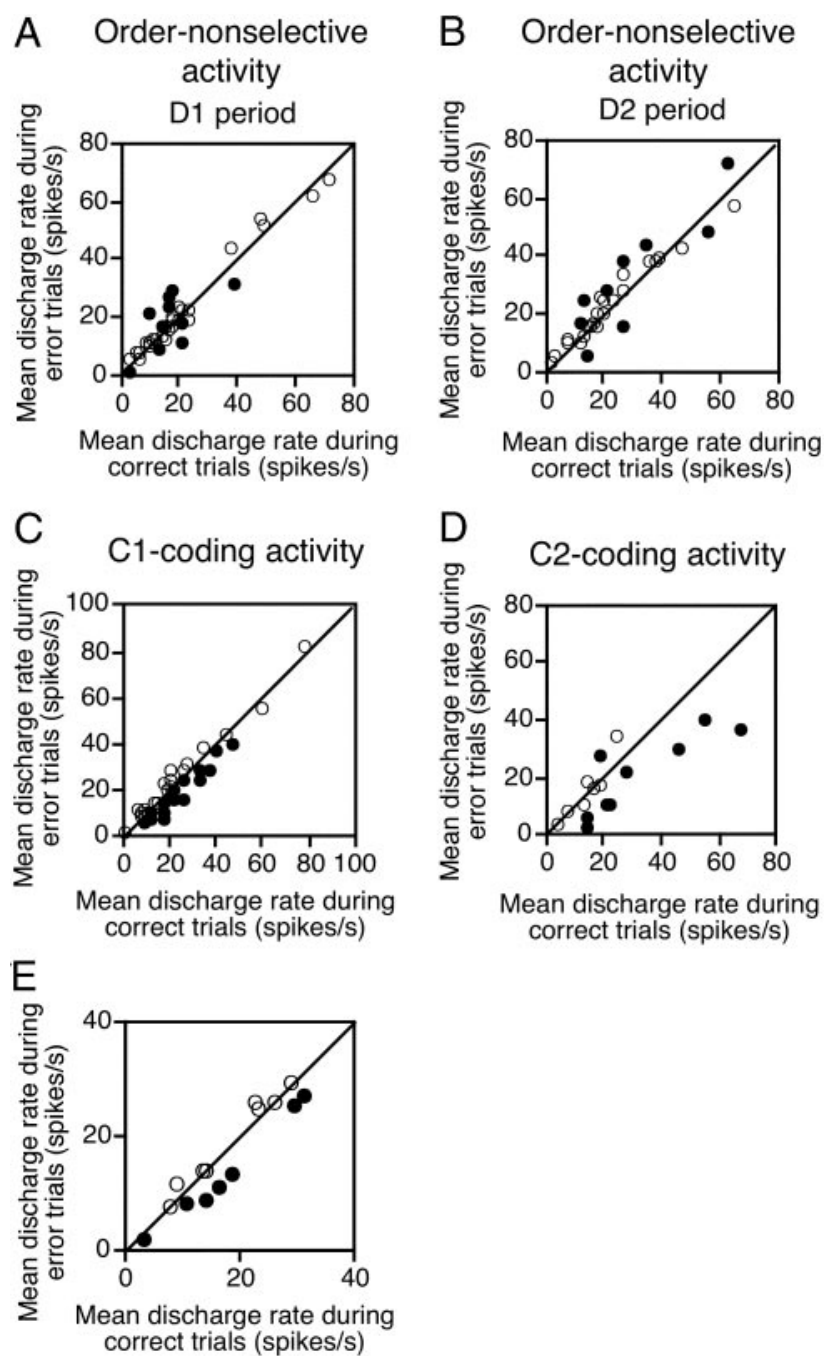

FIG. 15. Comparison between delay-period activities during correct and error trials. A: order-nonselective delay-period activity during D1 period in correct and error trials. Mean discharge rates during D1 period on correct and error trials were not significantly different. $B$ : order-nonselective delay-period activities during D2 period in correct and error trials. Mean discharge rates during D2 period in correct and error trials were not significantly different. $C$ : C1-coding delay-period activities during correct and error trials. Mean discharge rates during correct and error trials were significantly different. $D$ : C2-coding delay-period activities during correct and error trials. Mean discharge rates during correct and error trials were significantly different. $E$ : delay-period activities during correct and error trials in the DMS task. Mean discharge rates during correct and error trials were significantly different. Closed circles indicate discharge rate of neurons whose activities were significantly different between correct and error trials (Mann-Whitney $U$ test, $P<$ $0.05)$. Open circles indicate discharge rate of neurons whose activities were not significantly different between correct and error trials $(P>0.05)$.

\section{Relationship between neuronal activities during C1/C2 periods and D1/D2 periods}

To study the relationship between neuronal activities during the cue and delay periods, we compared the preferred object of individual neurons that had both visual and delay-period activities. During the SPR task, about one-half of the neurons with the object-selective response to the object cue also exhibited object-selective delay-period activity (Table 1). Among neurons with the order-nonselective object-selective response, eight $(36 \%)$ also exhibited object-selective delay-period activity. Most of these neurons exhibited order-nonselective delay- 
TABLE 1. Number of neurons with both object-selective visual response and object-selective delay-period activity

\begin{tabular}{|c|c|c|c|c|c|c|c|}
\hline & \multicolumn{7}{|c|}{ D1 and D2 Period } \\
\hline & $\begin{array}{c}\text { Order- } \\
\text { nonselective }\end{array}$ & $\begin{array}{l}\text { C1-coding } \\
\text { (D1) }\end{array}$ & $\begin{array}{l}\text { C1-coding } \\
\text { D2 }\end{array}$ & C2-coding & $\begin{array}{c}\text { Object- } \\
\text { nonselective }\end{array}$ & No activity & Total \\
\hline \multicolumn{8}{|l|}{ Object-selective } \\
\hline Order-nonselective & $5(4)$ & $2(2)$ & $1(1)$ & $0(0)$ & 5 & 9 & 22 \\
\hline C1-dominant & $2(1)$ & $1(0)$ & $2(1)$ & $3(3)$ & 3 & 22 & 33 \\
\hline C2-dominant & $6(2)$ & $1(1)$ & $3(1)$ & $3(1)$ & 5 & 8 & 26 \\
\hline \multicolumn{8}{|l|}{ Object-nonselective } \\
\hline Order-nonselective & 2 & 2 & 1 & 2 & 2 & 8 & 17 \\
\hline C1-dominant & 1 & 0 & 2 & 1 & 3 & 14 & 21 \\
\hline No response & 24 & 10 & 25 & 21 & 43 & 369 & 492 \\
\hline Total & 40 & 16 & 34 & 30 & 61 & 430 & 611 \\
\hline
\end{tabular}

Numbers in parentheses are the numbers of neurons with the same object preference during the cue period and delay period.

period activity. Figure $16 A$ shows an example of the activity of a neuron with both the order-nonselective response during the $\mathrm{C} 1$ and $\mathrm{C} 2$ periods and order-nonselective delay-period activity during the D1 and D2 periods. In this histogram, black lines indicate activity in trials in which $\mathrm{C} 1$ was the preferred object, and gray lines indicate activity in trials in which $\mathrm{C} 2$ was the preferred object. This neuron showed a response when the preferred object (circle) was presented and showed delayperiod activity following the presentation of the preferred object. Among neurons with the C1-dominant object-selective response, eight (24\%) also exhibited object-selective delayperiod activity. Figure $16 \mathrm{C}$ shows an example of the activity of a neuron with both the $\mathrm{C} 1$-dominant response and $\mathrm{C} 2$-coding delay-period activity. Among neurons with the $\mathrm{C} 2$-dominant object-selective response, $13(50 \%)$ also exhibited objectselective delay-period activity. These neurons exhibited ordernonselective, C1-coding (D2), C2-coding delay-period activity. However, for the majority of these neurons, object preferences were different between the object cue period and delay period. Figure $16 E$ shows an example of the activity of a
Order-nonselective response Example

A

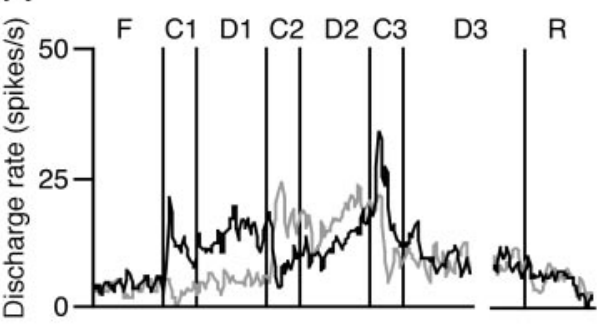

C1-dominant response


E

Example

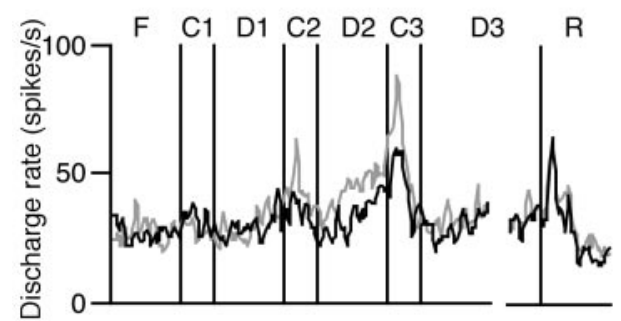

\section{Order-nonselective response}

B

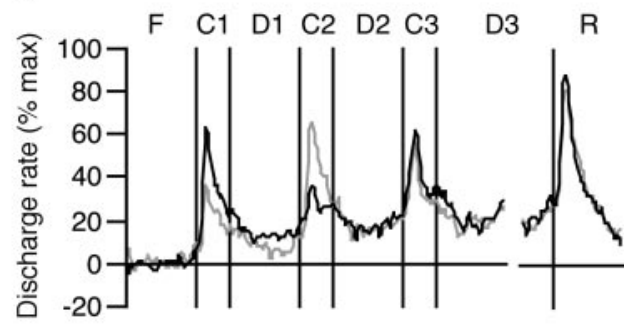

C1-dominant response

Population $(n=33)$

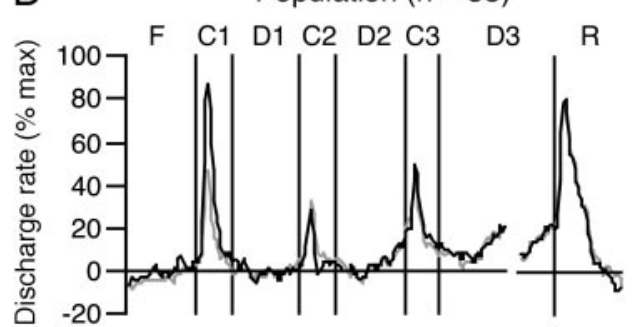

C2-dominant response

F

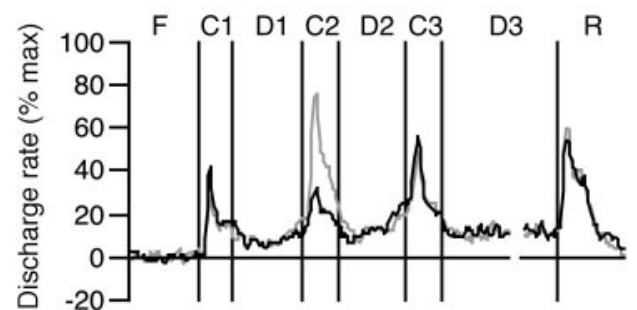

FIG. 16. Histograms of activity of neurons with order-nonselective response $(A)$, C1-dominant response $(C)$, and $\mathrm{C} 2$-dominant response $(E)$, and population activity histograms of neurons with order-nonselective response $(B), \mathrm{C} 1$-dominant response $(D)$, and $\mathrm{C} 2$-dominant response $(F)$. Black lines indicate activity histograms for trials in which the preferred object of the $\mathrm{C} 1$ period was presented, and gray lines indicate activity histograms for trials in which the preferred object of the $\mathrm{C} 2$ period was presented. F, fixation period; $\mathrm{C} 1,1$ st cue period; $\mathrm{D} 1,1 \mathrm{st}$ delay period; C2, 2nd cue period; D2, 2nd delay period; $\mathrm{C} 3$, color cue period. 
neuron with the C2-dominant response and C1-coding (D2) delay-period activity. In this neuron, the preferred object during the cue period was the double cone and the preferred object during the delay period was the circle.

To examine the relationship between responses during the cue period and delay-period activity, we constructed the histograms of the population activities of neurons with the ordernonselective, C1-dominant, and $\mathrm{C} 2$-dominant responses (Fig. $16, B, D$, and $F)$. In these histograms, black lines indicate population activity in trials in which $\mathrm{C} 1$ was the preferred object, and gray lines indicate population activity in trials in which $\mathrm{C} 2$ was the preferred object. Figure $16 B$ shows the population activities of neurons with the order-nonselective response during the cue period. Population activity coded information on the $\mathrm{C} 1$ object during the $\mathrm{C} 1$ and the $\mathrm{D} 1$ periods and on the $\mathrm{C} 2$ object during the $\mathrm{C} 2$ period. During the D2 period, population activity increased, but a difference in population activity between the C1-preferred and C2-preferred trials could not be found. Figure $16 D$ shows the population activities of neurons with the C1-dominant response during the cue period. During the D1 period and the early phase of the D2 period, population activity did not increase in terms of discharge rate. During the last phase of the D2 period, population activity slightly increased, but a difference in population activity between the C1-preferred and C2-preferred trials could not be found. Figure $16 \mathrm{~F}$ shows the population activities of neurons with the $\mathrm{C} 2$-dominant response during the cue period. During the first phase of the D1 period, population activity did not change, but during the last phase of the D1 period, population activity was higher in the C2-preferred trials than in the C1-preferred trials. During the D2 period, population activity was higher in the $\mathrm{C} 2$-preferred trials than in the $\mathrm{C} 1$ preferred trials.

To examine how many neurons showed anticipatory activity preceding the $\mathrm{C} 2$ presentation, we compared activity for 500 $\mathrm{ms}$ preceding the $\mathrm{C} 2$ presentation with activity for $500 \mathrm{~ms}$ preceding the $\mathrm{C} 1$ presentation by repeated measures ANOVA. In the neurons with the order-nonselective response, 10 (45\%) neurons did not show a significant increase or decrease in activity during the pre-C2 period, $10(45 \%)$ neurons showed a significant $(P<0.05)$ increase in activity during the pre-C2 period, and $2(10 \%)$ neurons showed a significant $(P<0.05)$ decrease in activity during the pre-C2 period. In the neurons with the $\mathrm{C} 1$-dominant response, $17(52 \%)$ neurons did not show a significant increase or decrease in activity during the pre-C2 period, 9 (27\%) neurons showed a significant $(P<$ $0.05)$ increase in activity during the pre-C2 period, and $7(21 \%)$ neurons showed a significant $(P<0.05)$ decrease in activity during the pre-C2 period. In the neurons with the $\mathrm{C} 2$-dominant response, $10(38 \%)$ neurons did not show a significant increase or decrease in activity during the pre-C2 period, 16 (62\%) neurons showed a significant $(P<0.05)$ increase in activity during the pre-C2 period, and no neuron showed a significant $(P<0.05)$ decrease in activity during the pre-C2 period.

\section{Object-nonselective delay-period activity}

Sixty-one neurons exhibited object-nonselective delay-period activity during the D1 and/or D2 periods. Of these, 38 neurons $(63 \%)$ exhibited this activity during both the D1 and D2 periods. Three neurons (5\%) showed object-nonselective delay-period activity during the D1 period but did not show delay-period activity during the D2 period. Twenty neurons (33\%) showed object-nonselective delay-period activity during the $\mathrm{D} 2$ period but did not show delay-period activity during the D1 period.

\section{Target- and/or color-selective response during color cue period}

During the color cue period, 139 neurons exhibited a significantly larger response magnitude than the baseline response during the fixation period. Figure 17A shows the histograms of the responses of a neuron that depended on both the color cue and the target object. The neuron was activated during the color cue period when the color cue was green and the target object was the circle. However, when the target object was the double cone or cross and the color cue was green, this neuron showed a small response magnitude; therefore the neuron was not simply responding on the basis of color information. When the color cue was red, this neuron did not respond during the color cue period. The response magnitudes of this neuron were significantly different in terms of both the color factor $[F(1,118)=61.67, P<0.0001]$ and the target factor $[F(2,118)=16.47, P<0.0001]$. Thus this response during the color cue period depended on both the color cue and target object, and we defined green as the preferred color of this neuron and the circle as the preferred target object of this neuron. These histograms showed that movements in all directions occurred. In addition, the monkey could not determine the direction of a movement until the response period. These findings indicate that this selective neuronal activity was not caused by the movements. This type of activity was classified as the CT response. Seventy neurons were identified as having the $\mathrm{CT}$ response in this study.

Figure $17 B$ shows the histograms of the responses of a neuron that depended on the color cue. The neuron exhibited a response when the color cue was red regardless of the target object. The response magnitudes were significantly different in terms of the color factor $[F(1,127)=88.95, P<0.0001]$ but not significant in terms of the target factor $[F(2,127)=1.45$, $P>0.05]$. Thus this response during the color cue period depended on the color cue. This type of response was classified as the $\mathrm{C}$ response, and we defined red as the preferred color of this neuron. Thirty-six neurons were identified as having the $\mathrm{C}$ response in this study.

Figure $17 C$ shows the histograms of the response of a neuron that depended on the target object. The neuron was activated when the target object was the circle and was not activated when the target object was the double cone or cross. The magnitudes of responses that depended on the color itself were not significantly different. The response magnitude was significantly different in terms of the target factor $[F(2,76)=14.37$, $P<0.0001]$ but not significant in terms of the color factor $[F(1,76)=0.05, P>0.05]$. Thus the response of this neuron during the color cue period depended on the target object not on the color. This type of response was classified as the $\mathrm{T}$ response, and we defined the circle stimulus as the preferred target object of this neuron. Fifteen neurons were identified as having the $\mathrm{T}$ response in this study. 
A

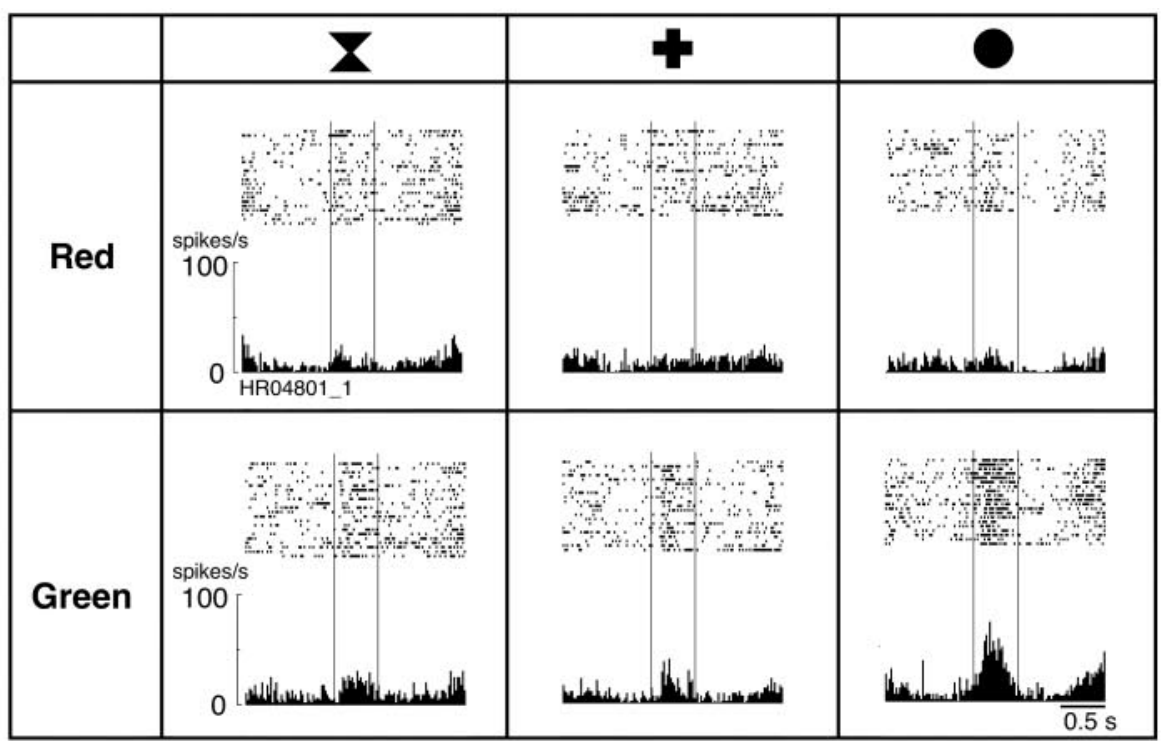

B

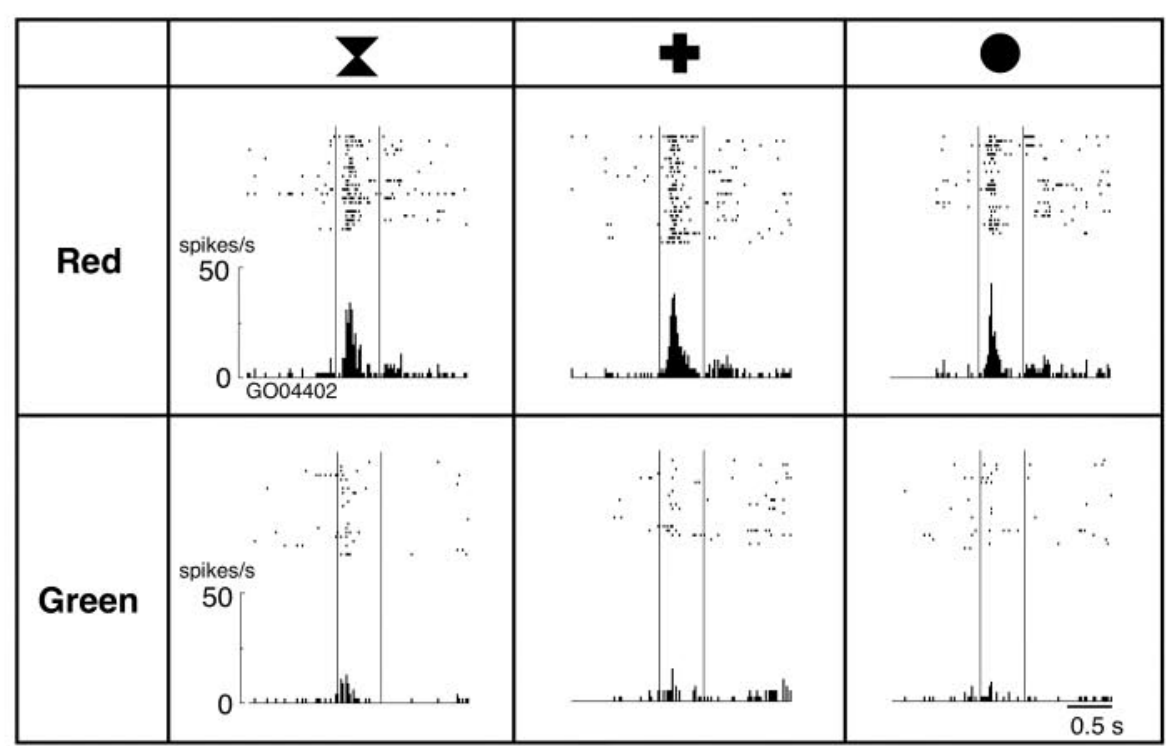

C

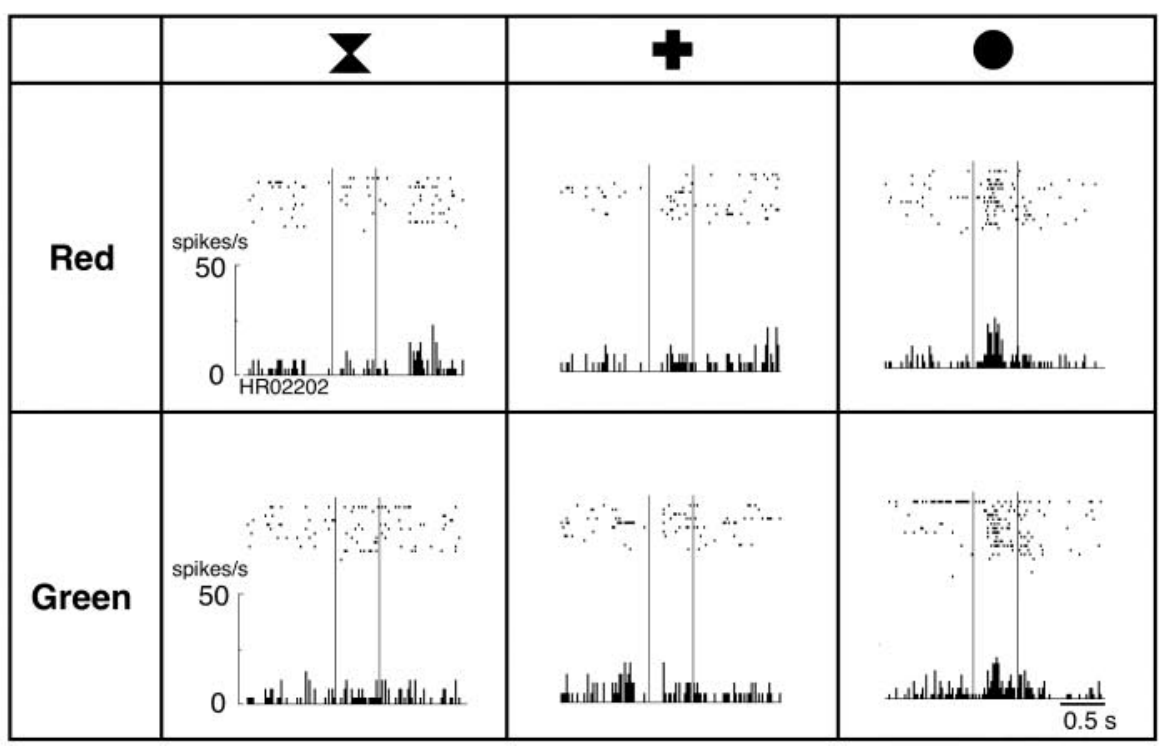

$J$ Neurophysiol • VOL $95 \cdot$ FEBRUARY $2006 \bullet$ www.jn.org
FIG. 17. A: histograms of CT response of a neuron. Each histogram was aligned to onset of color cue presentation. Top and bottom histograms correspond to neuronal activities when color cues were red and green, respectively. Left, middle, and right histograms correspond to neuronal activities when the monkey had to perform a saccade to the double cone, cross, and circle, respectively. Two vertical lines in each histogram indicate onset and offset of color cue presentation. This neuron was activated when color cue was green and target object was the circle. Bin width is 20 ms. $B$ : histograms of $C$ response of a neuron. This neuron was activated when color cue was red. Activities did not depend on target object. $C$ : histograms of $\mathrm{T}$ response of a neuron. This neuron was activated when target object was the circle. These activities did not depend on color. 


\section{Response during color cue period in error trials}

To evaluate the importance of the $\mathrm{CT}$, $\mathrm{T}$, and $\mathrm{C}$ responses during the color cue period in memory retrieval, we examined neuronal activity when the monkeys performed incorrectly. The magnitudes of the CT responses (Fig. 18A) during the error trials were significantly smaller than those during the correct preferred-color and preferred-target trials (Wilcoxon signed-rank test, $z=-4.72, P<0.0001$, mean $=42.86$ spikes/s in correct trials, mean $=34.60$ spikes $/ \mathrm{s}$ in error trials). Similarly, the magnitudes of the T responses (Fig. 18B) during the error trials were significantly smaller than those during the correct preferred-target trials $(z=-2.78, P<0.01$, mean $=$ $39.97 \mathrm{spikes} / \mathrm{s}$ in correct trials, mean $=32.52 \mathrm{spikes} / \mathrm{s}$ in error trials). In contrast, the magnitudes of the $\mathrm{C}$ responses (Fig. $18 C$ ) were not significantly different between the correct and error preferred-color trials $(z=-0.74, P>0.05$, mean $=$ 39.33 spikes/s in correct trials, mean $=38.43$ spikes $/ \mathrm{s}$ in error trials).

\section{Latency of target- and/or color-selective response}

Latencies were slightly different among the CT, C, and T responses. Figure 19 shows the cumulative summation of the latencies of the CT, C, and T responses that were $<200 \mathrm{~ms}$. The latencies of the $\mathrm{T}$ responses (mean $=137 \mathrm{~ms}$ ) were slightly longer than those of the CT (mean $=127 \mathrm{~ms}$ ) and C responses $($ mean $=121 \mathrm{~ms}$ ), but these differences were not statistically significant $[F(2,78)=0.98, P>0.05]$.

\section{Comparison of response with color cue response in the fixation task}

When selection is not required, do neurons with the CT response or $\mathrm{T}$ response also respond to color stimuli? To answer this question, we examined neuronal activity during a fixation task. While the monkey maintained its fixation, we presented the same color stimulus as that used in the SPR task. Figure 20A shows the histograms of the CT response during the SPR task and the fixation task. The response magnitude during the fixation task $(61.00 \pm 29.65$ spikes/s $)$ was similar to that during the preferred-color and preferred-target trials of the SPR task (46.82 \pm 17.01 spikes/s). Differences between these response magnitudes were not significant (Mann-Whitney $U$ test, $z=1.46, P>0.05)$. Thus the object-selectivity in this CT response was elicited by the suppression of response in the preferred-color and the nonpreferred-target trials. In all the tested neurons, the magnitudes of their CT responses $(n=17)$

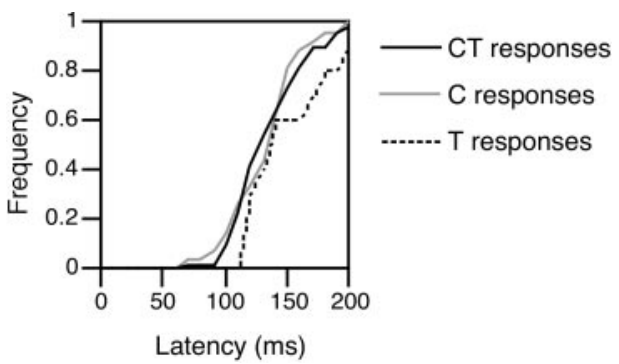

FIG. 19. Distribution of latencies of CT, C, and T responses. Cumulative summation curve of latencies of CT response $(n=58)$, C response $(n=32)$, and $\mathrm{T}$ response $(n=12)$ that were $<200 \mathrm{~ms}$.

during the preferred-color and preferred-target trials of the SPR task were not significantly $(P>0.05)$ different from those during the fixation task (Fig. 20B). The population activity of the CT responses also exhibited similar patterns during the preferred-color and preferred-target trials in the SPR task to those during the preferred-color trial in the fixation task (Fig. 20C).

Figure $20 D$ shows the histograms of the $\mathrm{T}$ response during the SPR task and fixation task. The neuron showed no clear responses during the fixation task. All tested neurons with T response $(n=6)$ showed no responses during the fixation task (Fig. 20E). The population activity of the $\mathrm{T}$ responses also showed no responses during the fixation task (Fig. 20F).

\section{Relationship between neuronal activities during color cue period and C1/C2 periods and D1/D2 periods}

Of 139 neurons with a response during the color cue period, 45 neurons (CT responses, $n=24$; $\mathrm{C}$ responses, $n=16 ; \mathrm{T}$ responses, $n=5$ ) showed an object-selective response during the $\mathrm{C} 1$ and/or $\mathrm{C} 2$ period (Table 2). We compared the object preference between the color cue period and the object cue period of the CT and T neurons. About one-third of the neurons (CT neurons, $n=8$; T neurons, $n=1$ ) showed the same object-preference during the color cue period and object cue period (Table 2). Figure $21 A$ shows an example of responses of a neuron with the same preference during the color cue period and object cue period. This neuron responded to the circle stimulus during the $\mathrm{C} 1$ and $\mathrm{C} 2$ periods and also responded when the color cue was red and the target object was the circle during the color cue period. In contrast, the remaining twothirds of neurons (CT neurons, $n=16$; T neurons, $n=4$ ) did not show the same object preference. Figure $21 B$ shows an example of responses of a neuron with the different preference

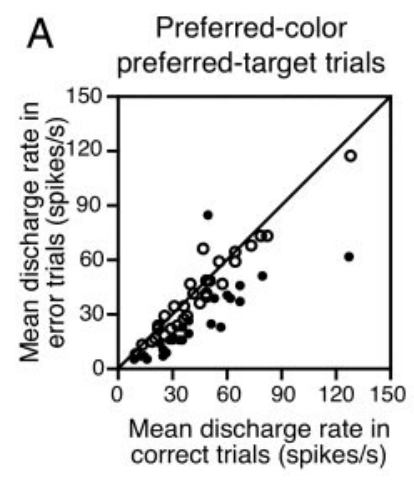

C

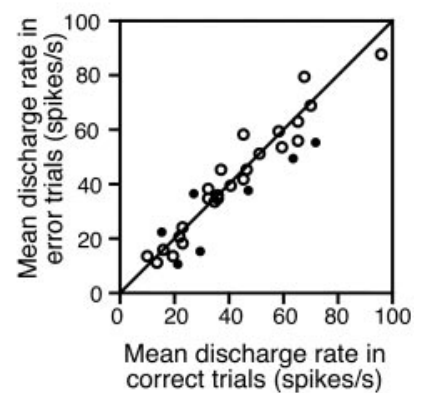

FIG. 18. A: comparison between CT responses during correct and error trials in preferred-color preferred-target trials. $B$ : comparison between $\mathrm{T}$ responses during correct and error trials in preferred-target trials. $C$ : comparison between $\mathrm{C}$ responses during correct and error trials in preferred-color trials. $\bigcirc$, discharge rate of neurons whose responses during correct and error trials were not significantly different (Mann-Whitney $U$ test, $P>0.05$ ); $\bullet$, discharge rate of neurons whose responses during correct and error trials were significantly different (Mann-Whitney $U$ test, $P<0.05$ ). 
A

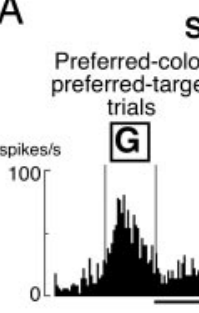

SPR task

Preferred-color nonpreferred-target

trials

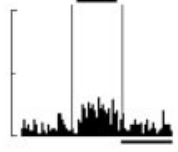

C

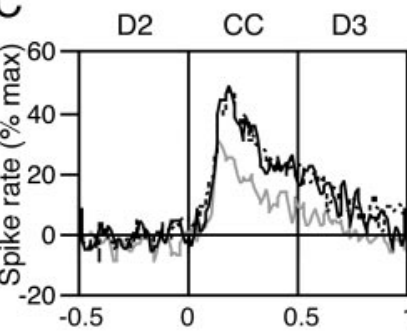

33

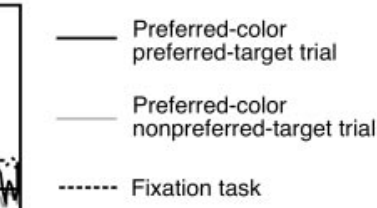

$1(\mathrm{~s})$

D

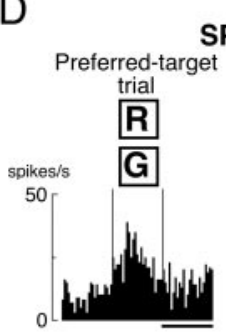

SPR task

Nonpreferred-target

trial

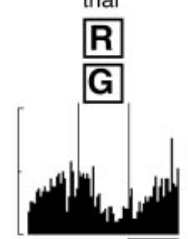

$\mathrm{F}$

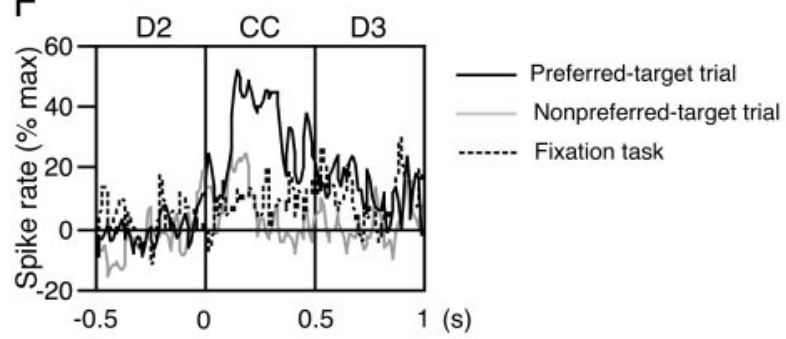

B

SPR task (spikes/s)

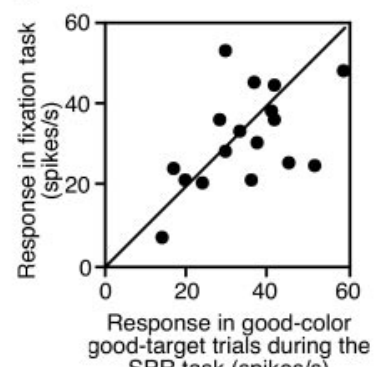

FIG. 20. Comparison of CT and T responses during the SPR task with response during fixation task. A: neuronal activities during SPR task and fixation task of a neuron with $C$ T response. $B$ : comparison between discharge rates during preferred-color preferred-target trials during the SPR task and fixation task. $C$ : population activities for CT response $(n=17)$ during SPR task and fixation task. $D$ : neuronal activity during SPR task and fixation task of a neuron with $\mathrm{T}$ response. $E$ : comparison between discharge rates during preferred-target trials of SPR task and fixation task. $F$ : population activities of T response $(n=6)$ during SPR task and fixation task. during the color cue period and object cue period. The preferred object of this neuron was the circle during the $\mathrm{C} 1$ and $\mathrm{C} 2$ periods and the double cone during the color cue period. Indeed, the object selectivity was not clear in the population activity. We constructed the histograms of the population activities of the neurons with $\mathrm{CT}$ response that preferred red (Fig. 21C, left) and those that preferred green (Fig. 21C, right). We also constructed the histograms of the population activities of the neurons with $\mathrm{T}$ response when the color cues were red (Fig. 21D, left) and green (Fig. 21D, right). The left histograms show that the preferred target object was presented during the $\mathrm{C} 1$ period and the right histograms show that the preferred target object was presented during the $\mathrm{C} 2$ period. The fact that the population activities during the $\mathrm{C} 1$ period and $\mathrm{C} 2$ period were not different between the presentations of preferred target objects (black line) and nonpreferred target objects (gray line) implies that the object selectivity of the CT or T neurons could not be derived from the activities during the cue period.

Of 139 neurons with a response during the color cue period, 44 neurons (CT response, $n=24$; $\mathrm{C}$ response, $n=16$; $\mathrm{T}$
TABLE 2. Number of neurons with responses during color cue period and other periods

\begin{tabular}{lcccr}
\hline \hline & \multicolumn{4}{c}{ Color Cue Period } \\
\cline { 2 - 5 } & CT response & C response & T response & Total \\
\hline C1 and C2 period & & & & \\
Order-nonselective & $8(3)$ & 4 & $1(1)$ & 22 \\
C1-dominant & $8(2)$ & 5 & $3(0)$ & 33 \\
C2-dominant & $8(3)$ & 7 & $1(0)$ & 26 \\
D1 and D2 period & & & & \\
Order-nonselective & $11(3)$ & 4 & $1(0)$ & 40 \\
C1-coding (D1) & $2(0)$ & 1 & $1(0)$ & 16 \\
C1-coding (D2) & $6(3)$ & 7 & $0(0)$ & 34 \\
C2-coding & $5(3)$ & 4 & $2(1)$ & 30 \\
D3 period & & & & \\
CT activity & $23(19)$ & $5(3)$ & $2(1)$ & 102 \\
C activity & $8(3)$ & $4(4)$ & 0 & 61 \\
T activity & $5(3)$ & 0 & $4(2)$ & 38 \\
Total & 70 & 36 & 15 & \\
\hline
\end{tabular}

Numbers in parentheses are the numbers of neurons with the same object or color preference during the color cue period and other periods. 

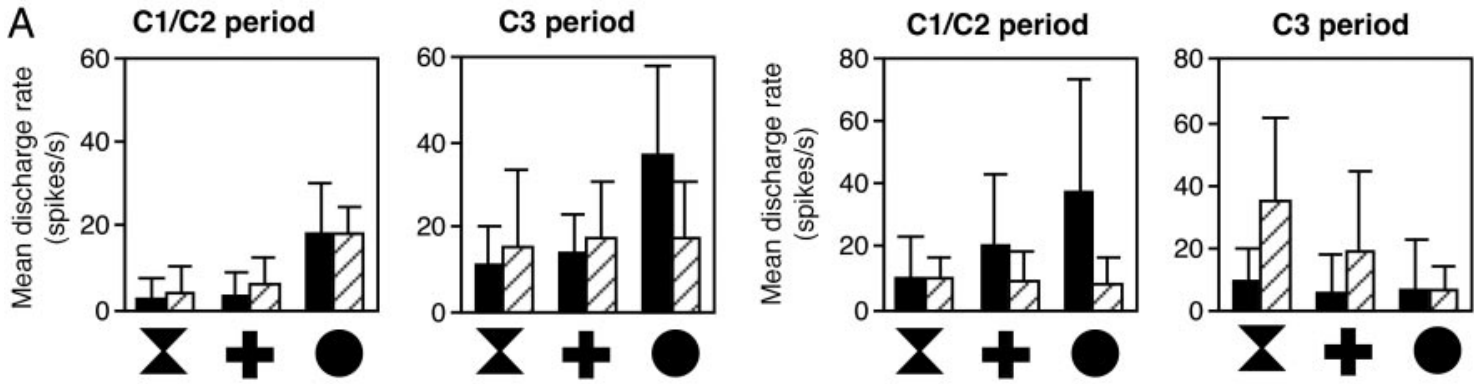

B

CT responses
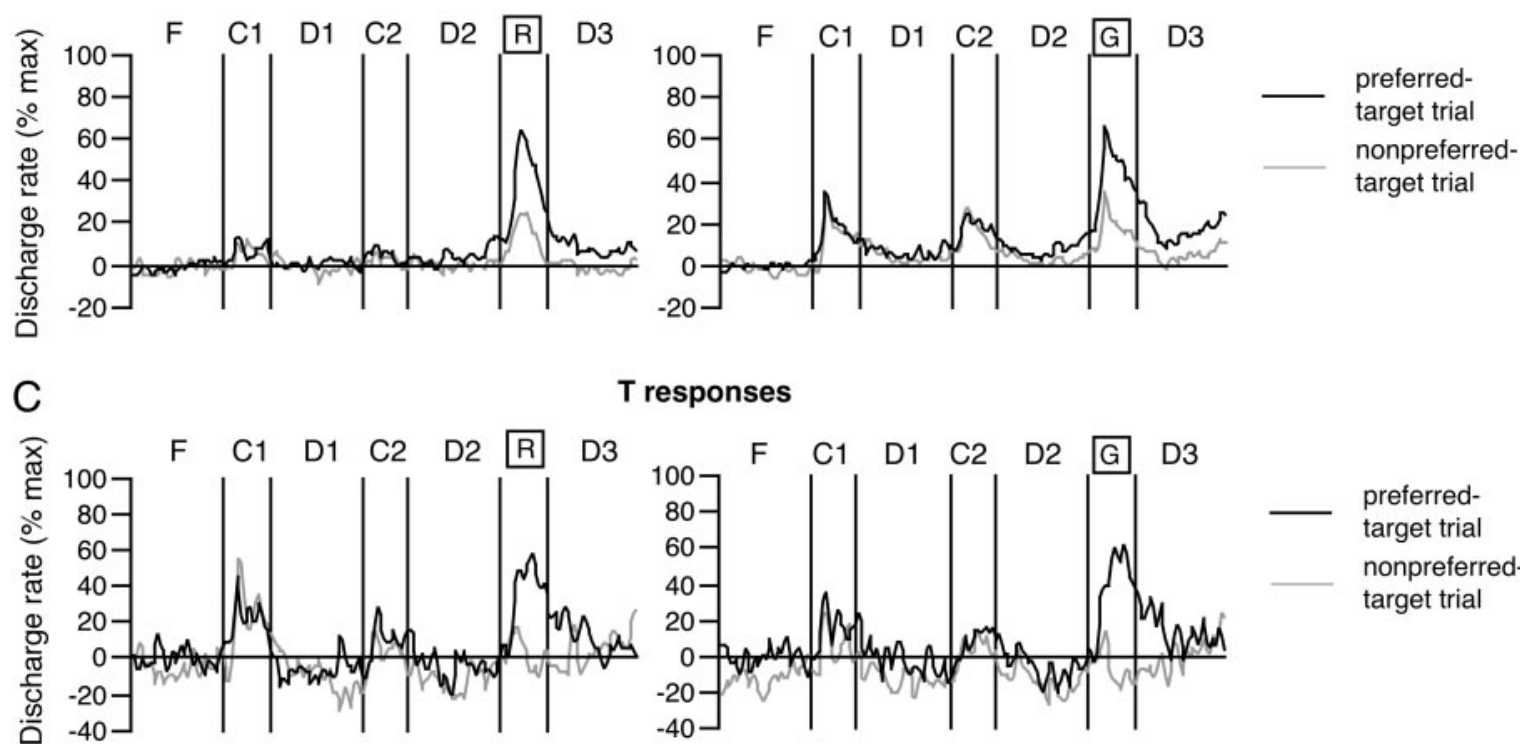

T responses
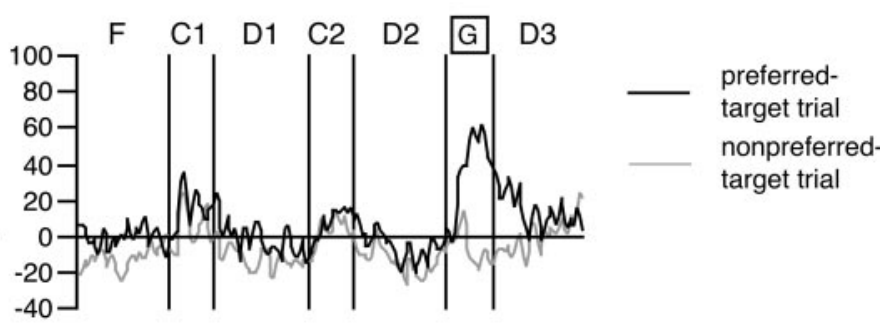

target trial

FIG. 21. A: example of response of neuron whose preferred object was the same during $\mathrm{C} 1, \mathrm{C} 2$, and color cue periods. $B$ : example of response of neuron whose preferred objects were different between $\mathrm{C} 1, \mathrm{C} 2$, and color cue period. Left: solid bars indicate response during C1 period, and hatched bars indicate response during C2 period. Right: solid bars indicate response when color cue was red, and hatched bars indicate response when color cue was green during color cue period. Error bars indicate SD. C: histograms of population activity of CT neurons whose preferred colors were red (left) and green (right). Black line indicates population activity during preferred-color preferred-target trials, and gray line indicates population activity during preferred-color nonpreferred-target trials. $D$ : histogram of population activity of $\mathrm{T}$ neurons when color cues were red (left) and green (right). Black line indicates population activity during preferred-target trials, and gray line indicates population activity during nonpreferred-target trials.

response, $n=4$ ) also showed the object-selective delay-period activity during the D1 and/or D2 period. Ten neurons showed the same object selectivity during the delay period and the color cue period (Table 2). As shown in Fig. 21C, the population activities of the neurons with the $\mathrm{CT}$ response during the D1 period were not different between the preferred-target (black line) and nonpreferred-target trials (gray line). However, near the end of the D2 period, the population activity in the preferred-target trials was higher than that in the nonpreferredtarget trials (Fig. 21C). Indeed, of six neurons with the CT response and C1-coding (D2) delay-period activity, three preferred red. Five neurons with the CT response also showed C2-coding delay-period activity, and all these five neurons preferred green. Population activities of the neurons with the $\mathrm{T}$ response did not show delay-period activity during the D1 and D2 periods (Fig. 21D).

\section{Target- and/or color-selective delay-period activity during D3 period}

During the D3 period, 260 neurons exhibited a significantly higher delay-period activity than the baseline activity during the fixation period. Similar to the response during the color cue period, we could detect CT, C, and T delay-period activities during the D3 period. Figure $22 \mathrm{~A}$ shows the histograms of the activities of a neuron that depended on both the color cue and the target object. The neuron was activated during the D3 period when the color cue was green and the target object was the double cone. However, when the target object was the cross or circle and the color cue was green, this neuron did not show a significant delay-period activity. When the color cue was red, this neuron did not show the activity during the D3 period. The response magnitude of this neuron was significantly different in terms of both the color factor $[F(1,144)=31.07, P<$ $0.0001]$ and the target factor $[F(2,144)=18.88, P<0.0001]$. Thus this activity during the D3 period depended on both the color cue and target object. This type of activity was classified as CT delay-period activity. One hundred two neurons were identified as having CT delay-period activity in this study.

Figure $22 B$ shows the histograms of activities of a neuron that depended on the color cue. The neuron exhibited delayperiod activity when the color cue was red regardless of the target object. The response magnitudes were significantly different in terms of the color factor $[F(1,150)=83.36, P<$ 
A

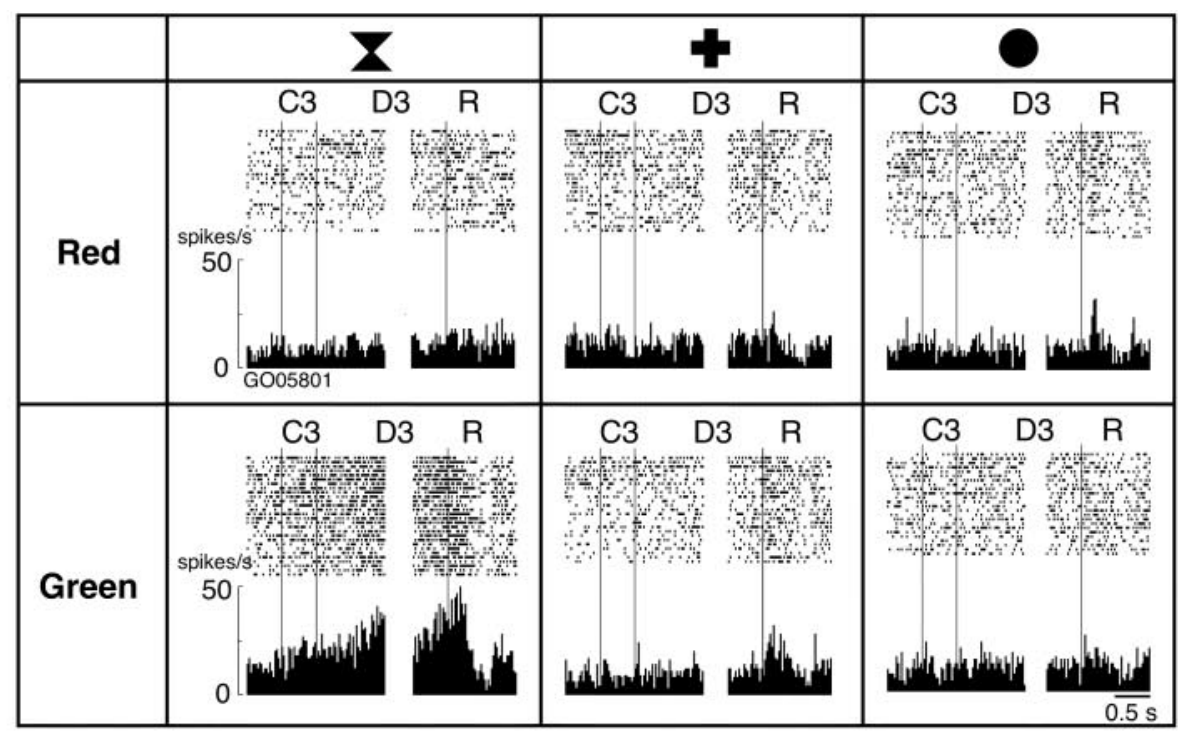

B

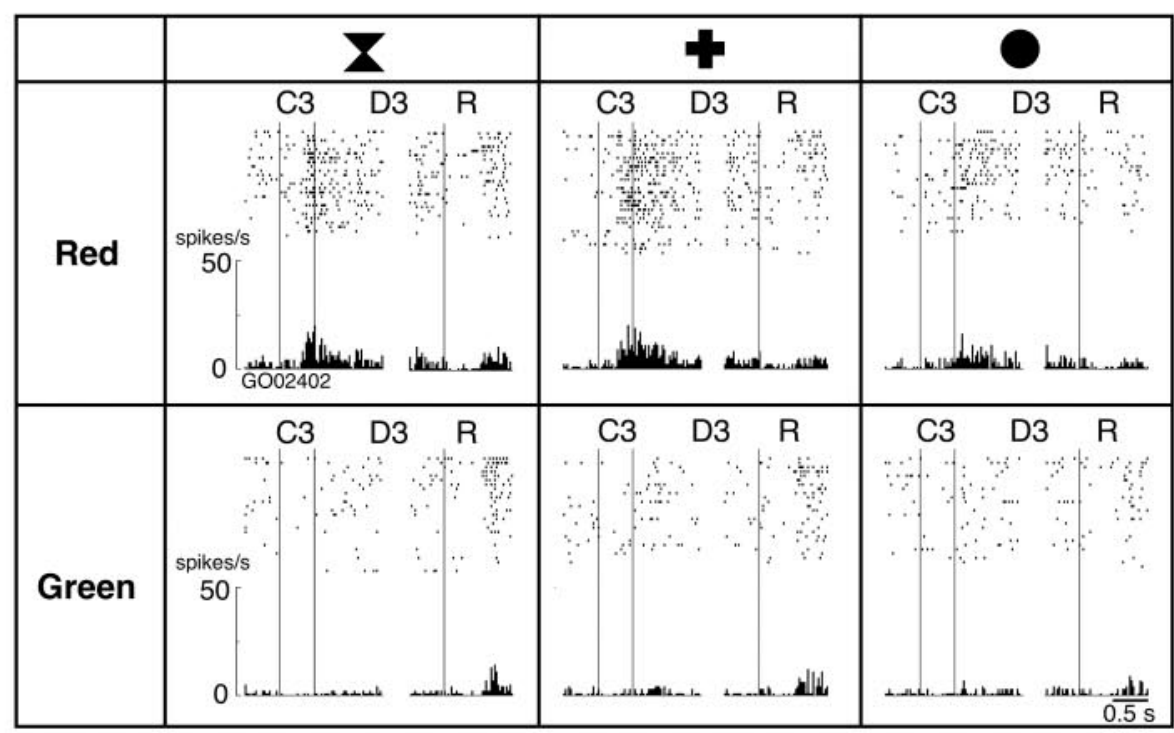

C

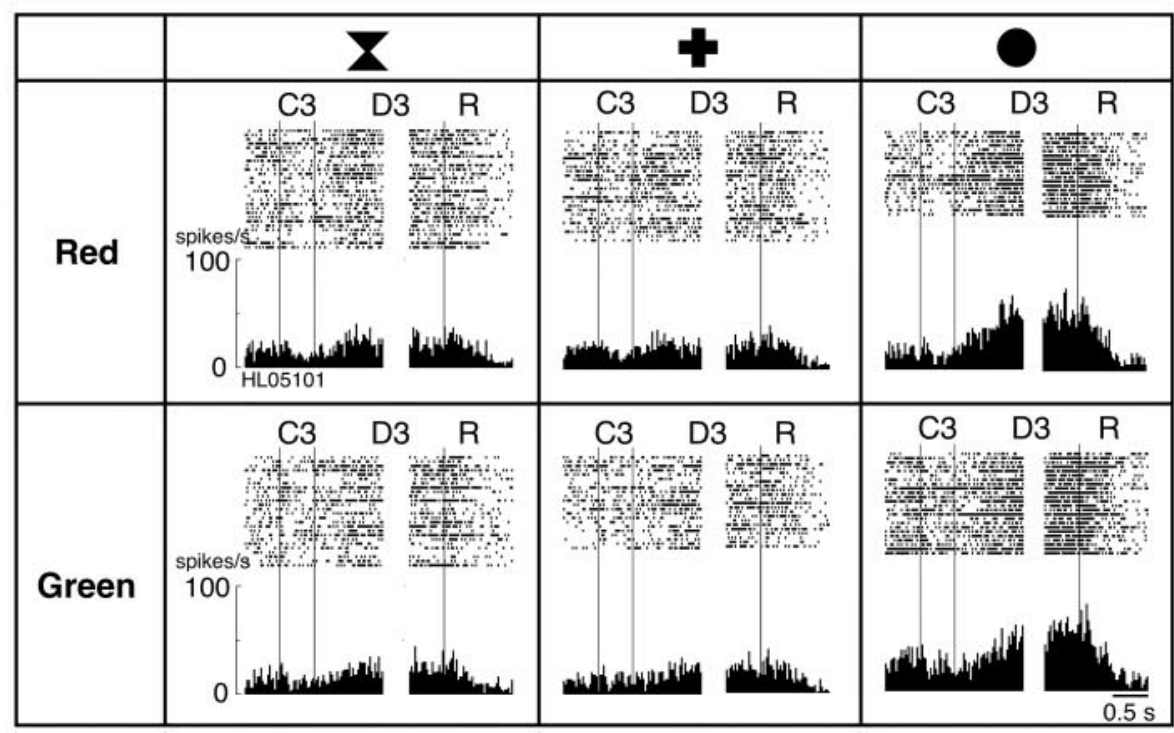

FIG. 22. A: histograms of CT delay-period activity of a neuron. Because duration of D3 period was randomly selected from 1 to $1.5 \mathrm{~s}$, histograms were aligned to onset of color cue presentation and onset of target stimulus presentation. Top and bottom histograms correspond to neuronal activities when color cues were red and green, respectively. Left, middle, and right histograms correspond to neuronal activities when the monkey had to perform a saccade to the double cone, cross, and circle, respectively. Three vertical lines in each histogram indicate onset and offset of color cue presentation and onset of target stimulus presentation. This neuron was activated when color cue was green and target object was the double cone. Bin width is $50 \mathrm{~ms}$. $B$ : histograms of $\mathrm{C}$ delay-period activity of a neuron. This neuron was activated when color cue was red. Activities did not depend on target object. $C$ : histograms of $\mathrm{T}$ delay-period activity of a neuron. This neuron was activated when target object was the circle. These activities did not depend on color. 
0.0001] but not significant in terms of the target factor $[F(2,150)=2.32, P>0.05]$. Thus this delay-period activity during the D3 period depended on the color cue. This type of activity was classified as $\mathrm{C}$ delay-period activity. Sixty-one neurons were identified as having $\mathrm{C}$ delay-period activity in this study.

Figure $22 C$ shows the histograms of activities of a neuron that depended on the target object. The neuron was activated when the target object was the circle and was not activated when the target object was the double cone or cross. These activities that depended on the color itself were not significantly different. The response magnitudes were significantly different in terms of the target factor $[F(2,139)=20.22, P<$ $0.0001]$ but not significant in terms of the color factor $[F(1,139)=2.43, P>0.05]$. Thus the delay-period activity of this neuron during the $\mathrm{D} 3$ period depended on the target object but not on the color. This type of delay-period activity was classified as $\mathrm{T}$ delay-period activity. Thirty-eight neurons were identified as having $\mathrm{T}$ delay-period activity in this study.

\section{Response during D3 period in error trials}

During the D3 period, the CT delay-period activities (Fig. $23 A$ ) during the error trials were significantly weaker than those during the correct preferred-color and preferred-target trials (Wilcoxon signed-rank test, $z=-4.07, P<0.0001$, mean $=25.30 \mathrm{spikes} / \mathrm{s}$ in correct trials, mean $=21.99 \mathrm{spikes} / \mathrm{s}$ in error trials). Similarly, the T delay-period activities (Fig. $23 B$ ) during the error trials were significantly weaker than those during the correct preferred-target trials $(z=-2.14, P<$ 0.05 , mean $=22.81$ spikes $/ \mathrm{s}$ in correct trials, mean $=20.14$ spikes/s in error trials). In contrast, neurons with $\mathrm{C}$ delayperiod activity (Fig. 23C) did not show a significantly different response magnitude between the correct and error preferredcolor trials $(z=-1.63, P>0.05$, mean $=19.61$ spikes $/ \mathrm{s}$ in correct trials, mean $=19.01 \mathrm{spikes} / \mathrm{s}$ in error trials).

\section{Relationship between neuronal activities during color cue period and D3 periods}

Of 139 neurons with response during the color cue period, 51 neurons (CT response, $n=36$; $\mathrm{C}$ response, $n=9$; $\mathrm{T}$ response, $n=6$ ) also showed delay-period activity during the D3 period. Of 36 neurons with the CT response during the color cue period, 23 neurons exhibited CT delay-period activity, 8 neurons exhibited $\mathrm{C}$ delay-period activity, and 5 neurons exhibited $\mathrm{T}$ delay-period activity during the $\mathrm{D} 3$ period. Of nine neurons with the $\mathrm{C}$ response during the color cue period, five neurons showed CT delay-period activity, four neurons showed $\mathrm{C}$ delay-period activity, and no neurons showed $\mathrm{T}$ delay-period activity during the $\mathrm{D} 3$ period. Of six neurons with the $\mathrm{T}$ response during the color cue period, two neurons showed CT delay-period activity, four neurons showed $\mathrm{T}$ delay-period activity, and no neurons showed $\mathrm{C}$ delay-period activity during the D3 period (Table 2).

\section{Recording sites}

All neurons with the object-selective response during the $\mathrm{C} 1$ and/or C2 period were recorded from the VLPFC (Fig. 24A; Table 3). We could not find a difference between the distributions of neurons with the order-nonselective response and those with the order-selective response (Fig. 24A). In the neurons with object-nonselective response during the $\mathrm{C} 1$ and/or $\mathrm{C} 2$ period, all neurons were recorded from the VLPFC, except for one neuron that was recorded from the DLPFC (Fig. 24B; Table 3). We could not find a difference in the distribution between neurons with the order-nonselective response and those with the order-selective response (Fig. 24B).

During the D1 and D2 periods, all neurons with objectselective delay-period activity were recorded from the VLPFC (Fig. 24C; Table 3). We could not find a difference in distribution between neurons with order-nonselective activity and those with order-selective delay-period activity (Fig. 24C). Object-nonselective delay-period activity during the D1 and D2 periods was recorded from both the DLPFC and VLPFC (Fig. 24D; Table 3). Of the neurons recorded from DLPFC, six neurons were activated during both the D1 and D2 periods.

The neurons with a response during the color cue period were recorded from both the DLPFC and the VLPFC (Fig. $25 A$; Table 3). Although the proportions of neurons with CT, $\mathrm{C}$, and $\mathrm{T}$ responses among neurons activated during the color cue period in the DLPFC were not different from those in the VLPFC, the proportion of neurons activated during the color cue period was much smaller in the DLPFC (10\%). Thus the neurons activated during the color cue period were mainly located in the VLPFC (90\%). In addition, the response latencies of all DLPFC neurons were $>200 \mathrm{~ms}$ (mean $=289 \mathrm{~ms}$ ). In contrast, the response latencies of most of the VLPFC neurons $(80 \%)$ were $<200 \mathrm{~ms}$ (mean $=163 \mathrm{~ms}$ ) as observed in Fig. 25B. This difference was statistically significant $(z=$ 4.62, $P<0.0001)$.

The neurons with delay-period activity during the $\mathrm{D} 3$ period were recorded from both the DLPFC and the VLPFC (Fig. $25 C$; Table 3). Similar to the response during the color cue

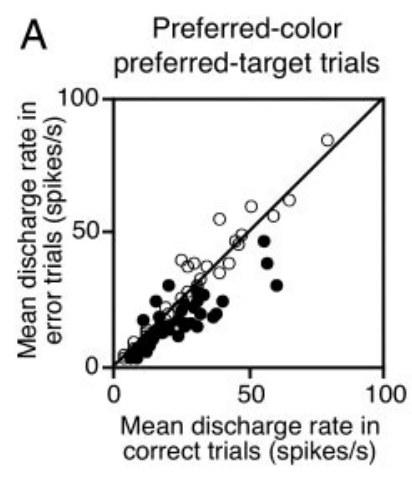

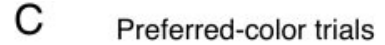



FIG. 23. A: comparison between CT delay-period activities during correct and error trials in preferred-color preferred-target trials. $B$ : comparison between $\mathrm{T}$ delay-period activities during correct and error trials in preferred-target trials. $C$ : comparison between $\mathrm{C}$ delay-period activities during correct and error trials in preferred-color trials. $\bigcirc$, discharge rate of neurons whose responses during correct and error trials were not significantly different (Mann-Whitney $U$ test, $P>0.05)$; $\bullet$, discharge rate of neurons whose responses during correct and error trials were significantly different (MannWhitney $U$ test, $P<0.05$ ). 


\section{A}

\section{Object-selective response Monkey G}

Left

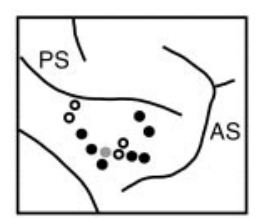

Monkey $\mathrm{H}$

Left
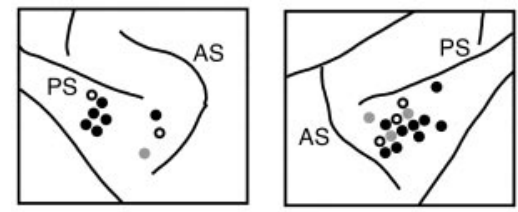

\section{Object-selective delay-period activity Monkey G}

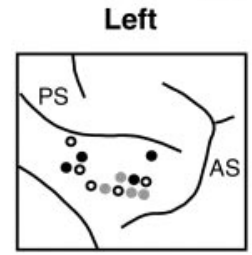
Right

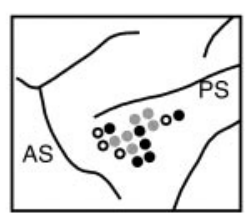

Monkey H
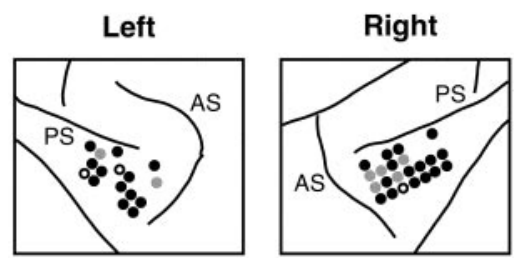

B

\section{Object-nonselective response Monkey G}

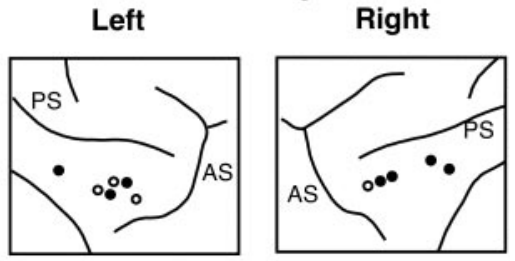

\section{Monkey H}

Left
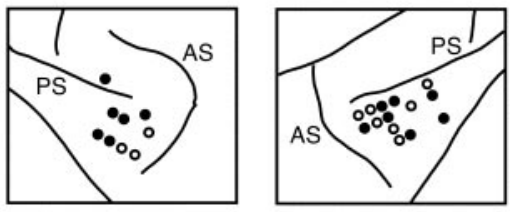

D Object-nonselective delay-period activity Monkey G

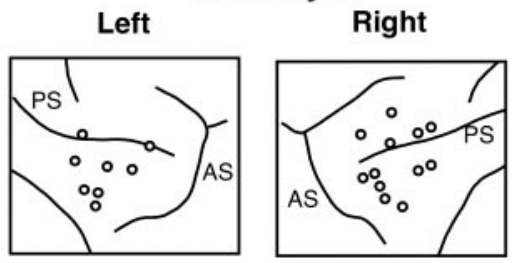

Monkey H
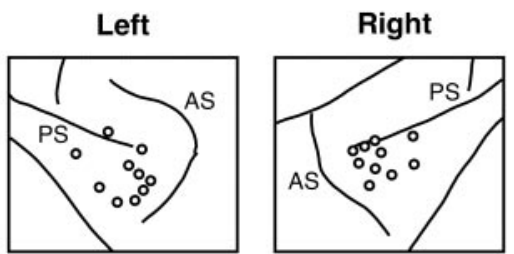

- Order-nonselective

- Order-selective

- Order-selective + Order-nonselective
FIG. 24. Surface location of neurons with object-selective response $(A)$ and object-nonselective response $(B)$ during $\mathrm{C} 1$ and/or $\mathrm{C} 2$ period. Recording area of neurons with objectselective delay-period activity $(C)$ and object-nonselective delay-period activity $(D)$ during the D1 and/or D2 period. $O$, surface locations where order-nonselective response was recorded; $\bullet$, surface locations where order-selective response was recorded. Gray circles indicate surface locations where both order-nonselective and order-selective responses were recorded. AS, aracuate sulcus; PS, principal sulcus. period, the neurons with delay-period activity during the D3 period were mainly located in the VLPFC.

\section{I S C US S I O N}

To study the neuronal mechanisms for the encoding, mnemonic, and retrieval processes of the working memory dealing with multiple objects and the order of object presentation, we recorded neuronal activity from the lateral prefrontal cortex of monkeys performing the SPR task. We found order-selective activities during the cue and/or the delay period. Because our task does not contain motor aspects before the color cue presentation, these order-selective activities must be a part of the sensory processes rather than the preparation of sequential action. In addition, neurons with order-selective delay-period activity did not exhibit object-selective delay-period activity during the DMS task. This means that there are different groups of neurons being responsible for the order of object information and its memory. During the color cue period, we recorded object-selective activities (CT and $\mathrm{T}$ responses), although the target object was not presented during this period.

\section{Coding object and temporal order of object presentation during cue period}

Seventy-three percent of neurons with the object-selective response and $55 \%$ of neurons with the object-nonselective response showed the order-selective response. In these neurons, although the visual stimulus was physically identical, response magnitudes during the $\mathrm{C} 1$ and $\mathrm{C} 2$ periods were significantly different. 
TABLE 3. Classification of responses in DLPFC and VLPFC

\begin{tabular}{|c|c|c|}
\hline Type & DLPFC & VLPFC \\
\hline \multicolumn{3}{|l|}{$\mathrm{C} 1 / \mathrm{C} 2$ periods } \\
\hline \multicolumn{3}{|l|}{ Object-selective } \\
\hline Order-nonselective & 0 & 22 \\
\hline C1-dominant & 0 & 33 \\
\hline C2-dominant & 0 & 26 \\
\hline \multicolumn{3}{|l|}{ Object-nonselective } \\
\hline Order-nonselective & 0 & 17 \\
\hline C1-dominant & 1 & 20 \\
\hline C2-dominant & 0 & 0 \\
\hline \multicolumn{3}{|l|}{ D1/D2 period } \\
\hline \multicolumn{3}{|l|}{ Object-selective } \\
\hline Order-nonselective & 0 & 40 \\
\hline C1-coding (D1) & 0 & 16 \\
\hline C1-coding (D2) & 0 & 34 \\
\hline C1-coding (D1 and D2) & 0 & 2 \\
\hline C2-coding & 0 & 30 \\
\hline Object-nonselective & 7 & 54 \\
\hline \multicolumn{3}{|l|}{ Color cue period } \\
\hline CT response & 9 & 61 \\
\hline $\mathrm{C}$ response & 3 & 33 \\
\hline $\mathrm{T}$ response & 2 & 13 \\
\hline Nonselective & 0 & 18 \\
\hline \multicolumn{3}{|l|}{ D3 period } \\
\hline CT activity & 6 & 96 \\
\hline $\mathrm{C}$ activity & 11 & 50 \\
\hline $\mathrm{T}$ activity & 5 & 33 \\
\hline Nonselective & 18 & 41 \\
\hline
\end{tabular}

DLPFC, dorsolateral prefrontal cortex; VLPFC, ventrolateral prefrontal cortex.

The modulation of the visual response of prefrontal neurons has been described in many previous reports (Asaad et al. 2000; Everling et al. 2002; Funahashi et al. 1990; Hasegawa et al. 2000; Iba and Sawaguchi 2002; Kobayashi et al. 2002; Mikami et al. 1982; Rainer et al. 1998b; Sakagami and Niki 1994a,b; Sakagami and Tsutsui 1999; Sakagami et al. 2001; Watanabe 1981, 1986, 1990, 1992). Previous results and these results confirmed that not only the physical property but also the behavioral significance of a sensory stimulus is a factor critical to the activation of prefrontal neurons.

How are the object- and order-selective responses elicited? One possible mechanism may be that neurons with the objectand order-selective visual responses receive the object information and the order information separately and integrates them. However, our data do not support this mechanism. Latencies were not different among these responses. In addition, in some neurons the $\mathrm{C} 2$-dominant response during the $\mathrm{C} 2$ period depended on the cue object presented during the $\mathrm{C} 1$ period. Furthermore, we could not find the object-nonselective C2-dominant response. These findings suggest that neurons with the object- and order-selective responses are not receiving object information and order information separately. That is, our monkeys may be processing order information individually for each object and in parallel with order-nonselective object information.

When response magnitudes during the $\mathrm{C} 1$ and $\mathrm{C} 2$ periods were significantly different, the response was regarded as order-selective. This difference could be caused by the enhancement or suppression of sensory responses during the $\mathrm{C} 1$ or $\mathrm{C} 2$ period. To test this hypothesis, we compared responses during the SPR task and the DMS task. In $75 \%$ of neurons with the $\mathrm{C} 1$-dominant response, the response magnitude during the
C1 period was similar to that during the cue period of the DMS task, and the response magnitude during the $\mathrm{C} 2$ period was significantly smaller than that during the cue period of the DMS task. This result suggests that the $\mathrm{C} 1$-dominant response must be elicited by the suppression of sensory responses during the $\mathrm{C} 2$ period. Thus the $\mathrm{C} 1$-dominant response was actually generated by the same sensory input as in the order-nonselective response, but suppressed during the $\mathrm{C} 2$ period. That is, the C1-dominant response may be considered as a C2-dominant suppression rather than a $\mathrm{C} 1$-dominant activation. On the other hand, in about two-thirds of neurons with the C2-dominant response, the response magnitude during the $\mathrm{C} 1$ period was similar to that during the cue period of the DMS task, and the response magnitude during the $\mathrm{C} 2$ period was significantly larger than that during the cue period of the DMS task. In one-third of neurons with the $\mathrm{C} 2$-dominant response, the response magnitude during the $\mathrm{C} 1$ period was significantly smaller than that during the cue period of the DMS task, and the response magnitude during the $\mathrm{C} 2$ period was similar to that during the cue period of the DMS task. Thus the C2dominant response was based on either C2-dominant enhancement or C1-dominant suppression.

To generate the object- and order-selective responses during the $\mathrm{C} 2$ period, object-selective delay-period activity during the D1 period could contribute by enhancing or suppressing the response during the $\mathrm{C} 2$ period. In fact, just before the $\mathrm{C} 2$ presentation during the last phase of the D1 period, population activity was slightly higher in the trials when the preferred object was presented during the $\mathrm{C} 2$ period than in the trials when the nonpreferred object was presented during the $\mathrm{C} 2$ period (Fig. $4 A$ ) or the preferred object was presented during the $\mathrm{C} 1$ period (Fig. 16F).

The object-selective and C2-dominant response magnitudes in the error trials were significantly smaller than those in the correct trials. This finding will support the behavioral significance of the C2-dominant response in the performance of the SPR task. The order-nonselective and C1-dominant response magnitudes during the $\mathrm{C} 1$ period were not significantly different in the error trials. One possible interpretation of these results may be that these neurons have no significant roles in the performance of the SPR task. However, because we defined error trials as those in which the monkeys made wrong choices at the end of trials, most of the errors of this complex task may be caused by activity during the later periods of the task rather than firing rate at the beginning of each trial.

Recently, Ninokura et al. (2004) have examined prefrontal neuronal activity while monkeys performed a task in which the monkey had to memorize three objects and their order of presentation. They found visual responses that depended on the object, order, or both object and order. Although this result is similar to our result, there are differences. One major difference is the distribution of neurons with object-nonselective and order-selective responses. We recorded almost all neurons with this type of response from the VLPFC, but Ninokura et al. recorded such neurons from the DLPFC and not from the VLPFC. Although both of these tasks look similar in terms of visual objects and their sequence, the nature of memory may be different. In Ninokura's task, monkeys were required to do the sequential action toward the stimuli in the same sequence presented during the cue periods. In contrast, our monkeys were required to select one object at the time of color stimulus 
A

Monkey G

Left
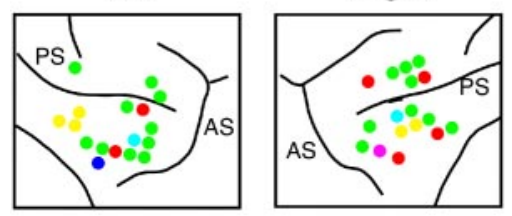

Monkey H

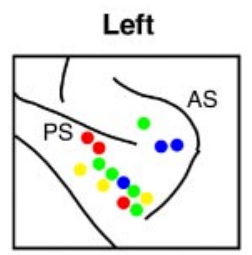

- CT response

- Tresponse

- C response

- CT response + T response

$\mathrm{CT}$ response $+\mathrm{C}$ response

- $\mathrm{CT}$ response $+\mathrm{T}$ response $+\mathrm{C}$ response
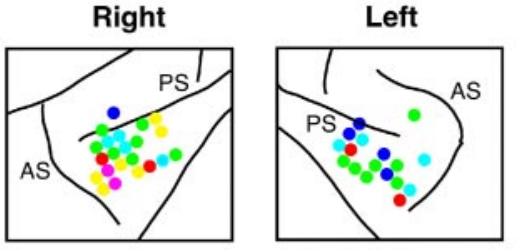

CT activity

- T activity

- C activity

- CT activity + T activity

CT activity $+\mathrm{C}$ activity

- $\mathrm{T}$ activity $+\mathrm{C}$ activity

- CT activity $+\mathrm{T}$ activity $+\mathrm{C}$ activity
FIG. 25. A: surface locations of neurons with response during color cue period. AS, aracuate sulcus; PS, principal sulcus. B: cumulative summation curve of response latencies of DLPFC neurons $(n=14)$ and VLPFC neurons $(n=125)$. $C$ : surface locations of neurons with delay-period activity during D3 period. AS, aracuate sulcus; PS, principal sulcus.

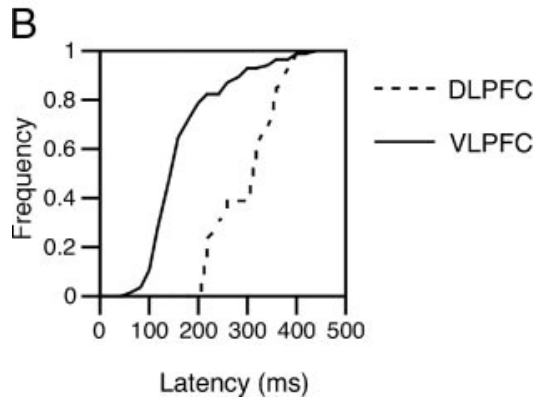

and that selected object became the target of action. Before this epoch our monkey did not know what the target of action would be. Thus in the task of Ninokura et al., memory of objects and their order contained motor aspect or preparation of action. In contrast, in our task, memory of objects and their order did not contain motor aspect before the presentation of color cue. This difference may explain why Ninokura et al. found object-nonselective and order-selective response in the DLPFC. Recently, Hasegawa et al. (2004) found neuronal activity that was modulated according to the step of a selfordered task from the DLPFC; this result indicates that the DLPFC could contribute to the processing of order information of action.

Ninokura et al. recorded object-nonselective and orderselective response to the first, second, and third cues. In contrast, we recorded object-nonselective and order-selective responses to the first cue, not to the second cue. These differences could be caused by the difference in the number of memorized objects. In our SPR task, monkeys had to memorize two objects and the order of its presentation. To recognize whether a cue is the first or second cue, monkeys could pay attention to the presence of the first cue. If not, the cue is the first one, and if yes, the cue is the second one. However, this simple strategy might not be sufficient for performing the task used by Ninokura et al., because there were three memorized objects. To recognize whether a cue is the first cue, second cue, or third cue, a more complex neuronal mechanism may be necessary.

\section{Order-selective delay-period activities}

In $67 \%$ of neurons with object-selective delay-period activity, delay-period activity depended on both the object and temporal order of its presentation (C1-coding and $\mathrm{C} 2$-coding delay-period activities). Most neurons (90\%) with order-selective delay-period activity did not exhibit object-selective delayperiod activity during the DMS task. In addition, neurons with order-selective delay-period activity showed decreased discharge rates during the delay period of the error trials. These results suggest that neurons with order-selective delay-period activity specialized to participate in the storing of information regarding both the object and the temporal order of its presentation during the SPR task.

Previous studies showed that some delay-period activities depended on both the cue and its order of presentation. Barone and Joseph (1989) recorded prefrontal neuronal activity while a monkey performed a delayed-response task in which the monkey was required to retain information regarding three target positions and the temporal order of presentation and to respond by performing sequential saccades and hand-reaching movements toward the targets in the same temporal order. They found that one class of neurons exhibited tonic activity 
with spatial and temporal selectivity, such that tonic activity was observed only when the first visual cue was presented at one particular position out of three. Funahashi et al. (1997) recorded prefrontal neuronal activity while a monkey performed a delayed sequential reaching task, in which the monkey is required to retain information on two of three target positions and the temporal order of presentation, and to respond by performing hand-reaching movements toward the targets in the same temporal order. They found positiondependent activity elicited when a cue was presented at a particular position in a particular temporal order. Ninokura et al. (2003) found that $43 \%$ of neurons with delay-period activity was selective for the sequence in which visual objects were presented during the cue period. Previous studies (Barone and Joseph 1989; Funahashi et al. 1997; Ninokura et al. 2003) showed the presence of delay-period activities coding both the item (spatial position or object) and the order of presentation. Our data are comparable to those of previous studies in a sense that we found object- and order-selective delay-period activities in the prefrontal cortex. The previous results suggest that the lateral prefrontal cortex contributes to the memorization of the temporal order, and our results suggest that the VLPFC participates in retaining not only object information but also temporal information.

However, our results are different from previous results in several points, and we believe that these differences provide us useful knowledge about the functions of the prefrontal cortex. In this study, we could not find delay-period activity that was elicited in only one of six sequences. In previous studies (Funahashi et al. 1997; Ninokura et al. 2003), some neurons were activated during the delay period in only one sequence. In these previous experiments, the monkeys memorized multiple spatial locations or objects and the order of their presentation, and during the response period, the monkeys had to respond sequentially for each spatial location or object in the same order of presentation. To execute a sequential response on the basis of the memorized items presented sequentially, the existence of delay-period activity specific for one sequence may have an advantage. In contrast, in our SPR task, the monkeys had to memorize the first and second cue objects and retrieved one object on the basis of the color cue. The monkeys selected one of three objects at the time of color cue appearance. They do not need to memorize each combination separately, because they were not required to repeat that sequence afterward. During the color cue period, the existence of delay-period activity that depended on the specific sequence of cue presentation has no advantage. This could be the reason why we did not detect delay-period activity that was elicited in only one of six sequences.

\section{Order-nonselective delay-period activity}

Thirty-three percent of neurons with object-selective delayperiod activity did not exhibit dependence on the temporal order of cue presentation (order-nonselective delay-period activity). In these neurons, delay-period activity followed the presentation of the preferred object and continued until the presentation of the next object cue or the color cue.

In these neurons, delay-period activity during the correct trials was not significantly different from that during the error trials in the SPR task. In most of the neurons (95\%) with the order-nonselective delay-period activity, object-selective delay-period activity was also found during the DMS task. In addition, during the DMS task, these delay-period activities significantly decreased during the error trials. Thus ordernonselective delay-period activity may participate in the mnemonic process in the DMS task.

Order-nonselective delay-period activity ended when an intervening stimulus was presented. This is inconsistent with previous results (di Pellegrino and Wise 1993; Miller et al. 1996), in which the delay-period activity of the prefrontal cortex was maintained throughout the trial even when other intervening stimuli were presented during the delay. These differences could be caused by the nature of the intervening stimulus. In previous studies (di Pellegrino and Wise 1993; Miller et al. 1996), the intervening stimuli were distractors, so the monkey neglected the intervening stimuli. On the other hand, in our study, the monkey had to recognize and memorize the visual stimulus during the $\mathrm{C} 2$ period. These differences could account for the difference in delay-period activity between our present and previous studies.

\section{Neuronal response related to retrieval of remembered object}

Two-thirds of the neurons with a response during the color cue period showed target object selectivity (CT and T responses), although the target object was not presented during this period. These $\mathrm{CT}$ and $\mathrm{T}$ responses could play a critical role in the retrieval of an item among items in the working memory.

The LPFC participates in selecting a relevant target among several distractors (Hasegawa et al. 2000; Iba and Sawaguchi 2002) and in selecting the forthcoming movement (Hasegawa et al. 1998; Hoshi and Tanji 2004; Hoshi et al. 2000; Kim and Shadlen 1999; Sakagami and Niki 1994a,b; Sakagami and Tsutsui 1999; Sakagami et al. 2001; Watanabe 1986). The results of these experiments confirmed the importance of the active maintenance of information for the subsequent use and response selection or decision-making. In these experiments, however, either a target was selected before it was memorized or a target was selected among the visible objects. Here in our task, when the monkey attempted to select a target during the color cue presentation, the objects were not visible and the monkey was required to retrieve memorized objects from the working memory. This is actually one of the typical processes of the working memory that we usually encounter in our daily life. In this study, the VLPFC neurons showed responses that depended on the target object retrieved from the working memory (CT and $\mathrm{T}$ responses). In addition, the neurons with $\mathrm{CT}$ and $\mathrm{T}$ responses showed lower activities during the error trials than those during the correct trials. These neurons can participate in the retrieval of a target object from two objects in the working memory. In contrast, the $\mathrm{C}$ response showed color selectivity but not target object selectivity. The neurons with the $\mathrm{C}$ response showed a similar activity during the correct and error trials. These results suggest that the $\mathrm{C}$ response is not affected by the retrieval of the target object.

In the DLPFC, we could detect the neurons with a response to the color cue. However, the number of neurons was small, and the response latencies of these neurons were $>200 \mathrm{~ms}$. These results suggest that the DLPFC could not contribute to the retrieval process. The proportions of neurons with the CT, $\mathrm{C}$, and $\mathrm{T}$ responses in the DLPFC were not significantly 
different from those in the VLPFC. The DLPFC receives input from the VLPFC (Barbas and Pandya 1989). These anatomical data suggest that neurons with the $\mathrm{CT}, \mathrm{C}$, and $\mathrm{T}$ responses in the DLPFC receive information from neurons with the CT, C, and $\mathrm{T}$ responses in the VLPFC.

\section{Neuronal response related to mnemonic process of retrieved object}

During the D3 period, we found the delay-period activities with $\mathrm{CT}, \mathrm{C}$, or $\mathrm{T}$ properties (CT, $\mathrm{C}$, and $\mathrm{T}$ delay-period activities). During this period, monkeys had to memorize the target object retrieved during the color cue period. Because CT and $\mathrm{T}$ delay-period activities depended on the target object retrieved during the color cue period, and the neurons with the $\mathrm{CT}$ and $\mathrm{T}$ delay-period activities showed lower activities during the error trials than those during the correct trials, these neurons may participate in the mnemonic processing of the target object retrieved during the color cue period.

Although, monkeys did not have to memorize the color in our task, some neurons showed $\mathrm{C}$ delay-period activity during the D3 period. This delay-period activity is not necessary for performing the SPR task, and the functional role of this $\mathrm{C}$ delay-period activity is unclear. Similar delay-period activities were recorded from the lateral prefrontal cortex in previous studies (Funahashi et al. 1993b; Takeda and Funahashi 2002). In these studies, monkeys had to perform a memory-guided saccade to the opposite direction of the visual cue (Funahashi et al. 1993b) or $90^{\circ}$ clockwise direction from the cue direction (Takeda and Funahashi 2002). Although monkeys had to memorized target direction but not had to memorize the cue location during the delay period, the directional delay-period activity of about two-thirds of neurons depended on the cue location.

\section{Contribution of the VLPFC in SPR tasks}

In this study, we found the object-selective response during the $\mathrm{C} 1$ and/or $\mathrm{C} 2$ period and delay-period activity during the D1 and/or D2 period in the VLPFC, not in the DLPFC. This suggests that the VLPFC contributes to the memorization of object information during the delay period. This is supported by previous anatomical, neuropsychological, and neurophysiological data. The DLPFC receives projections from the inferior parietal association cortex (Andersen et al. 1985; Barbas and Mesulam 1985; Cavada and Goldman-Rakic 1989; Petrides and Pandya 1984), which is involved in visuospatial processing (Barash et al. 1991a,b; Chafee and Goldman-Rakic 1998; Snyder et al. 1997). In contrast, the VLPFC receives dense projections from the inferotemporal association cortex (Barbas 1988; Seltzer and Pandya 1989; Ungerleider et al. 1989; Webster et al. 1994), which is involved in the representation of visual objects (Bruce et al. 1981; Desimone et al. 1984; Fuster 1990; Fuster and Jervey 1981; Miller et al. 1991, 1993; Perret et al. 1982). Lesions of the DLPFC, and more specifically those restricted to the principal sulcus or the middle third of its sulcus, produce a deficit in the performance of spatial delayed-response and spatial delayed-alternation tasks (Butters and Pandya 1969; Butters et al. 1971, 1972; Funahashi et al. 1993a; Mishkin 1957). Lesions of the VLPFC cause impairments in the performance of tasks based on the identity or features of object rather than spatial location. This impairment is observed in a delayed object alternation task (Mishkin and Manning 1978) and object/color delayed-matching or nonmatching-to-sample tasks (Iversen and Mishkin 1970; Kowalska et al. 1991; Mishkin and Manning 1978; Passingham 1975). In neurophysiological studies, it appears that neurons tuned specifically to the identity or features of an object are much fewer in the DLPFC than in the VLPFC (Fuster et al. 1982; O'Scalaidhe et al. 1997, 1999; Wallis and Miller 2003; Wilson et al. 1993). These previous results and our present results suggest that the VLPFC plays an important role in encoding and retaining information regarding the features of an object. In contrast, the contribution of the DLPFC to the encoding and retaining information regarding the feature of an object is small.

Neurons with the CT, C, and T response during the color cue period were recorded from both the DLPFC and VLPFC. However, larger population of these neurons was recorded from the VLPFC. In addition, the response latencies were shorter in the VLPFC. These results indicate that the neurons in the VLPFC were activated earlier than those in the DLPFC. A similar temporal difference in response between the DLPFC and VLPFC was found in human event-related functional MRI (fMRI) studies (Leung et al. 2000; Wagner et al. 2001) and a monkey neurophysiological study (Hoshi and Tanji 2004). These results suggest the greater contribution of the VLPFC in the retrieval of an object from multiple objects in the working memory. This is supported by human neuroimaging data. Human fMRI and PET studies showed that increases in activity are observed in the mid-VLPFC when human subjects retrieve one of the spatial and nonspatial aspects of an encoded stimulus on the basis of the color stimulus (Cadoret et al. 2001; Kostopoulos and Petrides 2003).

Neurons with delay-period activity during the D3 period were also recorded from both the DLPFC and VLPFC. However, large proportion of these neurons was recorded from the VLPFC. These results suggest the greater contribution of the VLPFC in the memorization of a target object. On the other hand, the fact that a small number of delay-period activities in the DLPFC was target object-selective and/or color-selective suggest some contribution of the DLPFC when the monkeys had to memorize what to respond.

Our results suggest the contribution of the VLPFC in performing this SPR task. However, some other cortical regions also could contribute to the performance of the SPR task. One possible cortical region is the inferotemporal cortex (IT). The IT is connected with the VLPFC (Barbas 1988; Seltzer and Pandya 1989; Ungerleider et al. 1989; Webster et al. 1994) and is involved in the representation of visual objects (Bruce et al. 1981; Desimone et al. 1984; Fuster 1990; Fuster and Jervey 1981; Miller et al. 1991, 1993; Perret et al. 1982). Many studies showed that IT neurons exhibited selective delay-period activity during the performance of a visual short-term memory task (Fuster 1990; Fuster and Jervey 1981, 1982; Mikami and Kubota 1980; Miller et al. 1993; Miyashita and Chang 1988). In addition, the contextual modulation of a visual response in the IT has been reported (Eskandar et al. 1992; Miller et al. 1993; Mikami and Kubota 1980). These results suggest that the IT could contribute to the encoding, mnemonic and retrieval processes of the SPR task. However, because the difference in 
the roles between the VLPFC and the IT is unclear, further experiments that compare neuronal activity in the IT with that in the VLPFC are necessary.

\section{Information flow in the SPR task}

Information flows proposed on the basis of our results are shown schematically in Fig. 26. We draw this schema based on the following hypotheses. At first, when a single neuron responds during the adjacent periods and maintains its response properties during these periods, the neuron carries the information from the first period to the second period; e.g., continuous activation from the cue period to the delay period. Second, when two neurons activated during adjacent periods share the same kind of response properties, and the timing of the activation-end of neuron 1 response and the timing of the activation-start of neuron 2 activation were synchronized, neuron 1 can send the information to neuron 2 .

During the $\mathrm{C} 1$ period, the VLPFC receives the object information from the visual association cortex, probably from the IT. This object information elicits the object-selective response in the order-nonselective and $\mathrm{C} 1$-dominant responses. It also elicits a small response in some of the neurons with the C2-dominant response.

Activity during the D1 period actually started during the $\mathrm{C} 1$ period. The object information travels from the neurons with the order-nonselective visual response to the neurons with either the order-nonselective delay-period activity or the C1- coding (D1) delay-period activity. This information flow was suggested by the following results. Among neurons with the order-nonselective object-selective response during the $\mathrm{C} 1$ period, 36\% (8/22) also exhibited the object-selective delayperiod activity. The delay-period activities of these neurons was either the order-nonselective or C1-coding (D1) activity (Table 1). At the population level, neurons with the ordernonselective visual response exhibited the object-selective delay-period activity (Fig. 16B).

Neurons with the $\mathrm{C} 1$-dominant response showed the objectselective response during the $\mathrm{C} 1$ period but they were not activated during the delay period (Fig. 16D). This result suggests that neurons with the $\mathrm{C} 1$-dominant response could not code visual information during the delay period. However, because the object-selective properties of the C1-dominant response are similar to those of the C1-coding (D1) delayperiod activity, and the end of the $\mathrm{C} 1$-dominant response synchronized with the start of the C1-coding (D1) delay-period activity, the C1-dominant response may contribute to generating the C1-coding (D1) delay-period activity. In addition, when the $\mathrm{C} 1$ object was presented, the difference between the preferred-object trials and nonpreferred-object trials was detected earlier for the order-nonselective delay-period activity than for C1-coding (D1) activity (Fig. 13E). This result suggests that the $\mathrm{C} 1$ object information encoded by the neurons with the order-nonselective delay-period activity is conveyed to the neurons with the C1-coding (D1) delay-period activity.

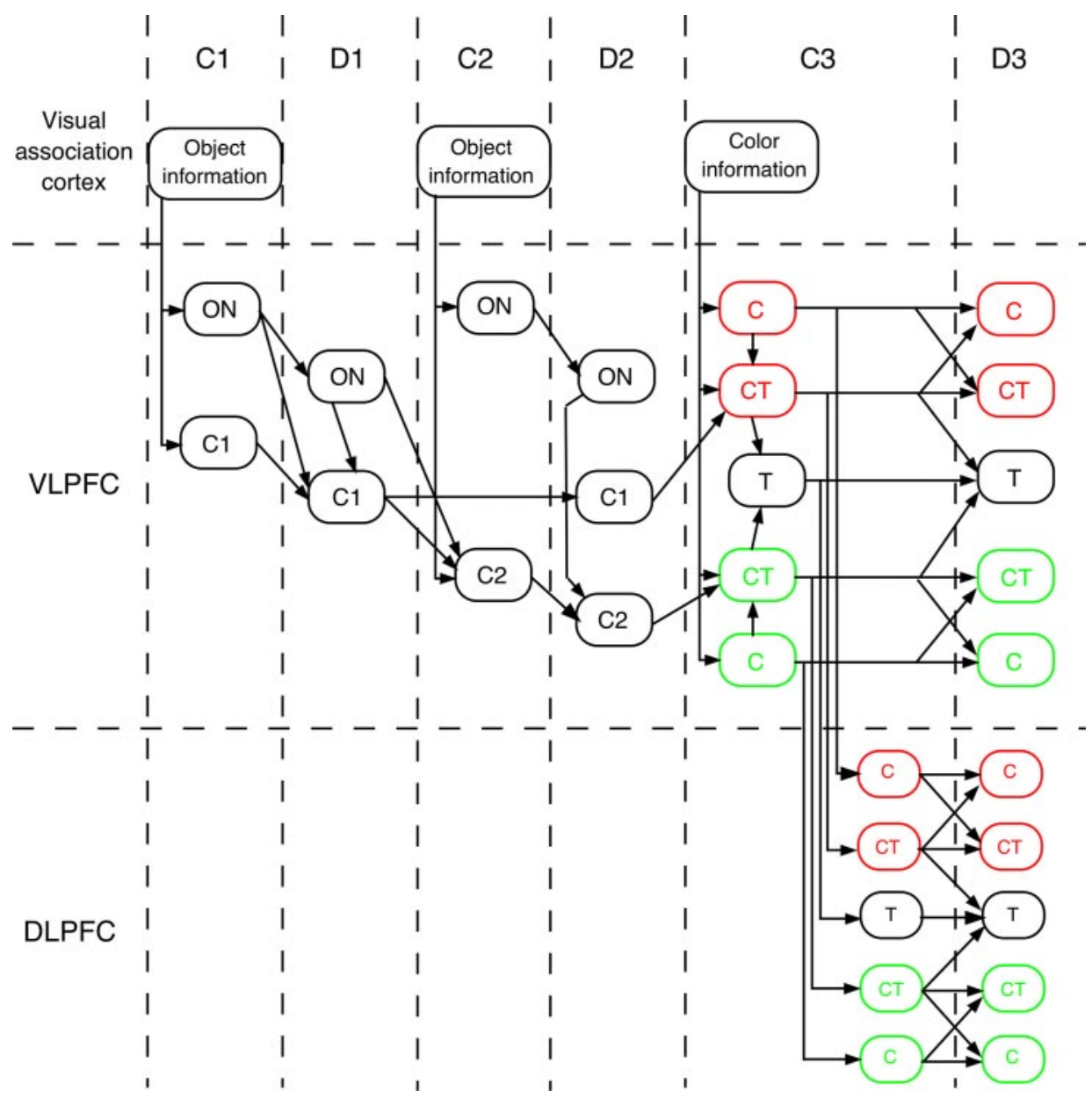

FIG. 26. Schema of information flow based on results of this experiment. 
During the C2 period, the VLPFC receives object information from the visual association cortex, probably from the IT. It also elicits the order-nonselective and the C2-dominant responses. As described already, to generate the $\mathrm{C} 2$-dominant responses during the $\mathrm{C} 2$ period, object-selective delay-period activity during the D1 period could contribute by enhancing the response during the $\mathrm{C} 2$ period.

Activity during the D2 period actually starts during the $\mathrm{C} 2$ period. The individual neurons with order-nonselective visual response do not share the same object preference during the D2 period at the population level as seen in Fig. 16B. At the same time, the individual neurons with order-nonselective delayperiod activity during the D2 period do not share the same object preference with the phasic component of activity during the $\mathrm{C} 2$ period at the population level as seen in Fig. 13A. These results suggest that individual neurons cannot participate in transmitting the $\mathrm{C} 2$ object information from the $\mathrm{C} 2$ period to the D2 period. However, different neurons can contribute to transmission of this information. Neurons with order-nonselective visual response can send $\mathrm{C} 2$ object information to neurons with the order-nonselective delay-period activity during the D2 period. This is because both neurons share the same properties.

Neurons with the C2-dominant response showed activity during the D2 period at the population level (Fig. 16F). However, the object preferences of these neurons were also different between the cue period and the delay period at the individual neuron level (Table 1) and at the population level (Figs. $16 F$ and 13D). Thus these neurons cannot transfer object-selective information by themselves from the cue period to the delay period. Instead, neurons with the C2-dominant response probably transfer object-selective information to neurons with the C2-coding delay-period activity, because both types of neurons shared the same type of selectivity and the activation-end and -start were synchronized.

Neurons with order-nonselective delay-period activity during the D2 period can also send information to neurons with C2-coding delay-period activity. This can be seen in the population activity related to $\mathrm{C} 2$-object information which starts earlier in order-nonselective neurons than in C2-coding neurons (Fig. 13E).

As seen in Fig. $13 E$, when the $\mathrm{C} 2$ object was presented, the C1-object-selective activity of order-nonselective neurons ended first, and the activity of C1-coding (D1) neurons ended. This was synchronized with the start of the activation in C1-coding (D2) neurons. These results suggest that the C1 object information is conveyed from the C1-coding (D1) neuron to the $\mathrm{C} 1$-coding (D2) neuron during the $\mathrm{C} 2$ period.

During the color cue period, the neurons with the CT response received color information because these neurons were activated by color stimuli during the fixation task. This result also suggests that the target selectivity of the CT response is achieved by suppressing the visual response to a color cue when the nonpreferred object was selected from the working memory. On the other hand, neurons with the $\mathrm{T}$ response did not respond to color stimuli during the fixation task. This result indicates that neurons with the $\mathrm{T}$ response do not receive color information. Although some of the neurons with $\mathrm{CT}$ and $\mathrm{T}$ responses showed the object-selective response during the $\mathrm{C} 1$ and/or $\mathrm{C} 2$ period, their object selectivity was often different from that during the color cue period. Thus the individual neuron may have multiple functions. For instance, it could code object A during the $\mathrm{C} 1$ and/or $\mathrm{C} 2$ period and code object B during the color cue period. Some neurons with the CT response were also activated during the delay period. Those delay-period activities also differed from the typical delayperiod activity. In these neurons, the delay-period activity was observed only near the end of D2 period. The neurons with the $\mathrm{T}$ response were not activated during the D1 and D2 periods. This observation suggests that the neurons with $\mathrm{T}$ response are a different class of neuron. At the end of the delay period, the neurons with the CT response whose preferred color was red exhibited C1-coding delay-period activity; the neurons with the CT response whose preferred color was green exhibited C2coding delay-period activity.

These results suggest that the neurons with the $\mathrm{C}$ response and $\mathrm{CT}$ response receive color information from the visual association cortex, probably from the IT. At the same time, neurons with the $\mathrm{CT}$ response receive object and temporal order information from neurons with delay-period activity, combined color, and object information. This combined information is then integrated into object information in neurons with the $\mathrm{T}$ responses to perform the future saccade.

During the color cue period, color information and retrieved target object information were conveyed from neurons with the visual response to those with the D3 delay-period activity. During the D3 period, most of neurons with the CT response also exhibited the delay-period activity with the CT property, and several neurons with the CT response exhibited the delayperiod activity with the $\mathrm{C}$ or $\mathrm{T}$ property. Neurons with the $\mathrm{T}$ response exhibited the delay-period activity with the CT or $\mathrm{T}$ property. Neurons with the $\mathrm{C}$ response exhibited the delayperiod activity with the $\mathrm{C}$ or CT property. These results suggest that both color information and target information are conveyed from neurons with the CT response during the color cue period to neurons with D3 delay-period activity carrying the CT property. Color information was conveyed from neurons with the CT or $\mathrm{C}$ response to neurons with the D3 delay-period activity carrying the $\mathrm{CT}$ or $\mathrm{C}$ property, and target information was conveyed from neurons with the $\mathrm{CT}$ or $\mathrm{T}$ response to neurons with the D3 delay-period activity carrying the CT or T property.

Most of the object-selective, order-selective, and colorselective neurons during the $\mathrm{C} 1, \mathrm{D} 1, \mathrm{C} 2, \mathrm{D} 2$, color cue, or D3 periods were mainly recorded from the VLPFC. Also, the latencies of the response of the VLPFC neurons were shorter than those of the DLPFC neurons. This suggests that the object and order information of our task are processed mainly in the VLPFC. During the color cue period, the retrieval process of an object is also processed mainly in the VLPFC. In the DLPFC, neurons with $\mathrm{CT}, \mathrm{C}$, or $\mathrm{T}$ responses receive information from neurons with the $\mathrm{CT}, \mathrm{C}$, or $\mathrm{T}$ responses in the VLPFC. The DLPFC uses this information for future execution of behaviors, such as saccade.

\section{Prefrontal cortex and working memory}

Neuronal activity during the delay period has been examined repeatedly while monkeys performed various types of working memory task (Chafee and Goldman-Rakic 1998; Constantinidis et al. 2001; di Pellegrino and Wise 1991, 1993; Funahashi et al. 1989, 1993b; Fuster 1973; Fuster et al. 1982; Kubota and Niki 1971; Kubota et al. 1974; Miller et al. 1996; Niki 1974; 
Niki and Watanabe 1976; Rainer et al. 1998a; Rao et al. 1997; Sawaguchi and Yamane 1999; Takeda and Funahashi 2002; Watanabe 1981; Wilson et al. 1993). The sustained delayperiod activity with directional preference or object preference has been considered to be a neuronal correlate of a mechanism that temporarily stores spatial or object information (Funahashi and Kubota 1994; Fuster 1997; Goldman-Rakic 1987).

Working memory involves both a short-term storage capacity for maintaining mental representation and a capacity for manipulating stored information (Baddeley 1986; Baddeley and Logie 1999). It has been suggested that the prefrontal cortex plays a critical role in working memory (Baddeley 1986; Funahashi and Kubota 1994; Fuster 1997; Goldman-Rakic 1987). This has been shown by both neurophysiological studies on monkey and neuroimaging studies on human. However, in most studies of monkeys, neuronal activities were examined during a delayed-response task or a delayed-matching-to-sample task, in which the monkey had to memorize single spatial or object information but did not have to manipulate stored information. In this study, monkeys had to memorize two objects and the order of their presentation and manipulate these pieces of information to select a target object. The orderselective delay-period activity found in this experiment was object- and order-selective as well as task period-specific. That is, most of the order-selective neurons were activated either during the D1 or D2 period but not both. These results suggest that prefrontal neurons operate in a way similar to the registers in the CPU of a microcomputer. Three major types of orderselective neurons [C1-coding (D1), C1-coding (D2), and C2coding] are registers that perform the SPR task, and temporally stored information must be manipulated during the color cue presentation to select the correct target. Thus our results indicate that the prefrontal cortex participates in the manipulation and integration of stored information and suggest that the prefrontal cortex plays a critical role in working memory.

Our SPR task contains several components of the working memory process; the encoding and maintenance processes of objects and temporal order and retrieval processes from the working memory. During the $\mathrm{C} 1$ and $\mathrm{C} 2$ periods, the object information and temporal order information must be encoded in the working memory. During these periods, different groups of neurons were found to encode the presentation of objects to those presented without order. This was in addition to the object-nonselective response neurons. During the D1 and D2 periods, the object information and temporal order information must be maintained in the working memory. During these periods, there were neurons that memorized the ordered presentation of objects in addition to the nonselective delay-period activity. Although there were some overlaps, neurons in each epoch were specialized. Logically it is possible the same neuron is responsible for coding $\mathrm{C} 1$ object and memorizing it during the D1 and D2 periods until the color cue period. However, neurons in the VLPFC of our monkeys did not work this way. Instead, $\mathrm{C} 1$ object information seemed to travel from the $\mathrm{C} 1$-coding (D1) delay-period activity to the C1-coding (D2) delay-period activity. In other words, functional units in the monkey VLPFC seem fragmented and specialized. In addition, there were neurons with order-nonselective or objectnonselective activities. These neurons may contribute to the SPR task by carrying object information.
During the color cue period, an object must be retrieved from two objects in the working memory. During this period, there were neurons encoding color and/or object retrieval. During the D3 period, retrieved object information must be maintained in the working memory. There were neurons related to these processes. In addition there were neurons carrying color information during the D3 period, although the color information is not necessary during this period. The VLPFC is participating to perform the SPR task using the various types of neurons described above. However, the VLPFC may also prepare for unexpected situations by keeping some information in reserve even if it is not directly related to performing the current task.

Thus there were neurons corresponding to each process of the SPR task. In other words, each process could be defined as a group of neurons that exhibits a particular function. These functions include encoding, maintenance and retrieval processes of the working memory, although there were some overlapping functions. These results suggest that the working memory is clearly fractionated into a number of different aspects.

\section{G R A N T S}

This study was supported by a Grant-in-Aid for Specially Promoted Research (10CE2005) and Research for the Future Program (96L00206).

\section{REFERENCES}

Andersen RA, Asanuma C, and Cowan WM. Callosal and prefrontal associational projecting cell populations in area 7A of the macaque monkey: a study using retrograde transported fluorescent dyes. J Comp Neurol 232: 443-455, 1985.

Asaad WF, Rainer G, and Miller EK. Task-specific neural activity in the primate prefrontal cortex. J Neurophysiol 84: 451-459, 2000.

Baddeley A. Working Memory. Oxford, UK: Oxford, 1986.

Baddeley A and Logie RH. Working memory: the multiple component model. In: Models of Working Memory: Mechanisms of Active Maintenance and Executive Control, edited by Miyake A and Shah P. New York: Cambridge University Press, 1999, p. 28-61.

Barash S, Bracewell RM, Fogassi L, Gnadt JW, and Andersen RA. Saccade-related activity in the lateral intraparietal area I. Temporal properties; comparison with area 7a. J Neurophysiol 66: 1095-1108, 1991a.

Barash S, Bracewell RM, Fogassi L, Gnadt JW, and Andersen RA. Saccade-related activity in the lateral intraparietal area II. Spatial properties. J Neurophysiol 66: 1109-1124, 1991 b.

Barbas H. Anatomic organization of basoventral and mediodorsal visual recipient prefrontal regions in the rhesus monkey. J Comp Neurol 276: 313-342, 1988.

Barbas H and Mesulam MM. Cortical afferent input to the principalis region of the rhesus monkey. Neuroscience 15: 619-637, 1985.

Barbas H and Pandya DN. Architecture and intrinsic connections of the prefrontal cortex in the rhesus monkey. J Comp Neurol 286: 353-375, 1989.

Barone $\mathbf{P}$ and Joseph JP. Prefrontal cortex and spatial sequencing in macaque monkey. Exp Brain Res 78: 447-464, 1989.

Bruce CJ, Desimone R, and Gross CG. Visual properties of neurons in a polysensory area in the superior temporal sulcus of the macaque. J Neurophysiol 46: 369-384, 1981.

Butters N and Pandya D. Retention of delayed-alternation: effect of selective lesions of sulcus principalis. Science 165: 1271-1273, 1969.

Butters N, Pandya D, Sanders K, and Dye P. Behavioral deficits in monkeys after selective lesions within the middle third of sulcus principalis. J Comp Physiol Psychol 76: 8-14, 1971.

Butters N, Pandya D, Stein D, and Rosen J. A search for the spatial engram within the frontal lobes of monkeys. Acta Neurobiol Exp 32: 305-329, 1972.

Cadoret G, Pike GB, and Petrides M. Selective activation of the ventrolateral prefrontal cortex in the human brain during active retrieval processing. Eur J Neurosci 14: 1164-1170, 2001.

Cavada C and Goldman-Rakic PS. Posterior parietal cortex in rhesus monkey. II. Evidence for segregated corticocortical networks linking sen- 
sory and limbic areas with the frontal lobe. J Comp Neurol 287: 422-445, 1989.

Chafee MV and Goldman-Rakic PS. Matching patterns of activity in primate prefrontal area $8 \mathrm{a}$ and parietal area 7ip neurons during a spatial working memory task. J Neurophysiol 79: 2919-2940, 1998.

Chiba AA, Kesner RP, and Reynolds AM. Memory for spatial location as a function of temporal lag in rat: role of hippocampus and medial prefrontal cortex. Behav Neural Biol 61: 123-131, 1994.

Constantinidis C, Franowicz MN, and Goldman-Rakic PS. The sensory nature of mnemonic representation in the primate prefrontal cortex. Nature Neurosci 4: 311-316, 2001.

Desimone R, Albright TD, Gross CG, and Bruce C. Stimulus selective properties of inferior temporal area TEO in macaque monkeys. J Neurosci 4: 2051-2062, 1984.

di Pellegrino G and Wise SP. A neurophysiological comparison of three distinct regions of the primate frontal lobe. Brain 114: 951-978, 1991.

di Pellegrino G and Wise SP. Visuospatial versus visuomotor activity in the premotor and prefrontal cortex of a primate. J Neurosci 13: 1227-1243, 1993.

Eskandar EN, Richmond BJ, and Optican LM. Role of inferior temporal neurons in visual memory I. Temporal encoding of information about visual images, recalled images, and behavioral context. J Neurophysiol 68: 12771295, 1992.

Everling S, Tinsley CJ, Gaffan D, and Duncan J. Filtering of neural signals by focused attention in the monkey prefrontal cortex. Nat Neurosci 5: 671-676, 2002

Funahashi S, Bruce CJ, and Goldman-Rakic PS. Mnemonic coding of visual space in the monkey's dorsolateral prefrontal cortex. J Neurophysiol 61: 331-349, 1989.

Funahashi S, Bruce CJ, and Goldman-Rakic PS. Visuospatial coding in primate prefrontal neurons revealed by oculomotor paradigms. J Neurophysiol 63: 814-831, 1990.

Funahashi S, Bruce CJ, and Goldman-Rakic PS. Dorsolateral prefrontal lesions and oculomotor delayed-response performance: evidence for mnemonic "scotomas". J Neurosci 13: 1479-1497, 1993a.

Funahashi S, Chafee MV, and Goldman-Rakic PS. Prefrontal neuronal activity in rhesus monkeys performing a delayed anti-saccade task. Nature 365: 753-756, 1993b.

Funahashi S, Inoue M, and Kubota K. Delay-period activity in the primate prefrontal cortex encoding multiple spatial positions and their order of presentation. Behav Brain Res 84: 203-223, 1997.

Funahashi S and Inoue M. Neuronal interactions related to working memory processes in the primate prefrontal cortex revealed by cross-correlation analysis. Cereb Cortex 10: 535-551, 2000.

Funahashi $\mathbf{S}$ and Kubota K. Working memory and prefrontal cortex. $\mathrm{Neu}$ rosci Res 21: 1-11, 1994.

Fuster JM. Unit activity in prefrontal cortex during delayed-response performance: neuronal correlates of transient memory. J Neurophysiol 36: 61-78, 1973.

Fuster JM. Inferotemporal units in selective visual attention and short-term memory. J Neurophysiol 64: 681-697, 1990.

Fuster JM. The Prefrontal Cortex. Philadelphia, PA: Lippincott-Raven, 1997.

Fuster JM, Bauer RH, and Jervey JP. Cellular discharge in the dorsolateral prefrontal cortex of the monkey in cognitive tasks. Exp Neurol 77: 679-694, 1982.

Fuster JM and Jervey JP. Inferotemporal neurons distinguish and retain behaviorally relevant features of visual stimuli. Science 212: 952-955, 1981.

Fuster JM and Jervey JP. Neuronal firing in the inferotemporal cortex of the monkey in a visual memory task. J Neurosci 2: 361-371, 1982.

Goldman-Rakic PS. Circuitry of primate prefrontal cortex and regulation of behavior by representational memory. In: Handbook of Physiology. The Nervous System. Higher Functions of the Brain. Bethesda, MD: American Physiological Society, 1987, sect. 1, vol. 5, part 1, p. 374-417.

Hasegawa R, Sawaguchi T, and Kubota K. Monkey prefrontal neuronal activity coding the forthcoming saccade in an oculomotor delayed matching-to sample task. J Neurophysiol 79: 322-333, 1998.

Hasegawa RP, Blitz AM, and Goldberg ME. Neurons in monkey prefrontal cortex whose activity tracks the progress of a three-step self-ordered task. J Neurophysiol 92: 1524-1535, 2004.

Hasegawa RP, Matsumoto M, and Mikami A. Search target selection in monkey prefrontal cortex. J Neurophysiol 84: 1692-1696, 2000.

Hoshi E, Shima K, and Tanji J. Neuronal activity in the primate prefrontal cortex in the process of motor selection based on two behavioral rules. J Neurophysiol 83: 2355-2373, 2000.
Hoshi E and Tanji J. Area-selective neuronal activity in the dorsolateral prefrontal cortex for information retrieval and action planning. J Neurophysiol 91: 2707-2722, 2004.

Iba M and Sawaguchi T. Neuronal activity representing visuospatial mnemonic processes associated with target selection in the monkey dorsolateral prefrontal cortex. Neurosci Res 43: 9-22, 2002.

Inoue $\mathbf{M}$ and Mikami A. Ventrolateral prefrontal neuronal activity related to hold the information of object to respond. Neurosci Res 26: 201, 2001.

Inoue $\mathbf{M}$ and Mikami A. Prefrontal neuronal activity related to both color and the selected object. Jpn J Physiol 52: 165, 2002a.

Inoue $\mathbf{M}$ and Mikami A. Delay period activity of the primate prefrontal cortex during the serial probe reproduction task. Soc Neurosci Abstr 28: 676.13, 2002b.

Inoue $M$ and Mikami A. Prefrontal cortex contributes selection of an object from memorized objects. Neurosci Res 46: 18, 2003.

Iversen SD and Mishkin M. Preservation interference in monkeys following selective lesions of the inferior prefrontal convexity. Exp Brain Res 11: 376-386, 1970 .

Kesner RP and Holdbrook T. Dissociation of item and order spatial memory in rats following medial prefrontal cortex lesions. Neuropsychologia 25: 653-664, 1987

Kesner RP, Hopkins RO, and Fineman B. Item and order dissociation in humans with prefrontal cortex damage. Neuropsychologia 32: 881-891, 1994.

Kim JM and Shadlen MN. Neural correlates of a decision in the dorsolateral prefrontal cortex of the macaque. Nat Neurosci 2: 176-185, 1999.

Kobayashi S, Lauwereyns J, Koizumi M, Sakagami M, and Hikosaka O. Influence of reward expectation on visuospatial processing in macaque lateral prefrontal cortex. J Neurophysiol 87: 1488-1498, 2002.

Kostopoulos $\mathbf{P}$ and Petrides $\mathbf{M}$. The mid-ventrolateral prefrontal cortex: insight into its role in memory retrieval. Eur J Neurosci 17: 1489-1497, 2003.

Kowalska DM, Bachevalier J, and Mishkin M. The role of the inferior prefrontal convexity in performance of delayed non-matching-to-sample. Neuropsychologia 29: 583-600, 1991

Kubota K, Iwamoto T, and Suzuki H. Visuokinetic activities of primate prefrontal neurons during delayed-response performance. J Neurophysiol 37: 1197-1212, 1974.

Kubota $\mathbf{K}$ and Niki H. Prefrontal cortical activity and delayed alternation performance in monkeys. J Neurophysiol 34: 337-347, 1971.

Leung HC, Skudlarski P, Gatenby JC, Peterson BS, and Gore JC. An event-related functional MRI study of the Stroop color word interference task. Cereb Cortex 10: 552-560, 2000.

McAndrew MP and Milner B. The frontal cortex and memory for temporal order. Neuropsychologia 29: 849-859, 1991.

Mikami A, Ito S, and Kubota K. Modifications of neuron activities of the dorsolateral prefrontal cortex during extrafoveal attention. Behav Brain Res 5: 219-233, 1982 .

Mikami A and Kubota K. Inferotemporal neuron activity and color discrimination with delay. Brain Res 182: 65-78, 1980.

Miller EK, Erickson CA, and Desimone R. Neural mechanisms of visual working memory in prefrontal cortex of the macaque. J Neurosci 16: 5154-5167, 1996.

Miller EK, Li L, and Desimone R. A neural mechanism for working and recognition memory. Science 254: 1377-1379, 1991.

Miller EK, Li L, and Desimone R. Activity of neurons in anterior inferior temporal cortex during a short-term memory task. J Neurosci 13: 1460 1478, 1993.

Milner B. Interhemispheric differences in the localization of psychological processes in man. Br Med Bull 27: 272-277, 1971.

Milner B, Corsi P, and Leonard G. Frontal-lobe contribution to recency judgments. Neuropsychologia 29: 601-618, 1991.

Mishkin M. Effect of small frontal lesions on delayed alternation in monkeys. J Neurophysiol 20: 615-622, 1957.

Mishkin M and Manning FJ. Non-spatial memory after selective prefrontal lesions in monkeys. Brain Res 143: 313-323, 1978.

Miyashita Y and Chang HS. Neuronal correlate of pictorial short-term memory in the primate temporal cortex. Nature 331: 68-70, 1988.

Niki H. Differential activity of prefrontal units during right and left delayed response trials. Brain Res 70: 346-349, 1974.

Niki H and Watanabe M. Prefrontal unit activity and delayed response: relation to cue location versus direction of response. Brain Res 105: 79-88, 1976. 
Ninokura Y, Mushiake H, and Tanji J. Representation of the temporal order of visual objects in the primate lateral prefrontal cortex. J Neurophysiol 89: 2868-2873, 2003.

Ninokura Y, Mushiake H, and Tanji J. Integration of temporal order and object information in the monkey lateral prefrontal cortex. $J$ Neurophysiol 91: 555-560, 2004.

O'Scalaidhe SP, Wilson FAW, and Goldman-Rakic PS. Areal segregation of face-processing neurons in prefrontal cortex. Science 278: 1135-1138, 1997.

O'Scalaidhe SP, Wilson FAW, and Goldman-Rakic PS. Face-selective neurons during passive viewing and working memory performance of rhesus monkeys: evidence for intrinsic specialization of neuronal coding. Cereb Cortex 9: 459-475, 1999.

Passingham RE. Delayed matching after selective prefrontal cortex lesions in monkeys (Macaca mulatta). Brain Res 92: 89-102, 1975.

Perret DI, Rolls ET, and Caan W. Visual neurons responsive to faces in the monkey temporal cortex. Exp Brain Res 47: 329-342, 1982.

Petrides M. Functional specialization within the dorsolateral frontal cortex for serial order memory. Proc R Soc Lond B Biol Sci 246: 299-306, 1991.

Petrides $M$ and Pandya DN. Projection to the frontal cortex from the posterior parietal region in the rhesus monkey. J Comp Neurol 228: 105-116, 1984.

Rainer G, Asaad WF, and Miller EK. Memory fields of neurons in the primate prefrontal cortex. Proc Natl Acad Sci USA 95: 15008-15013, 1998a.

Rainer G, Asaad WF, and Miller EK. Selective representation of relevant information by neurons in the primate prefrontal cortex. Nature 393: 577-579, 1998b.

Rao SC, Rainer G, and Miller EK. Integration of what and where in the primate prefrontal cortex. Science 276: 821-824, 1997.

Rowe JB and Passingham RE. Working memory for location and time: activity in prefrontal area 46 relates to selection rather than maintenance in memory. Neuroimage 14: 77-86, 2001.

Rowe JB, Toni I, Josephs O, Frackowiak RSJ, and Passingham RE. The prefrontal cortex: response selection or maintenance within working memory? Science 288: 1656-1660, 2000.

Sakagami M and Niki H. Encoding of behavioral significance of visual stimuli by primate prefrontal neurons: relation to relevant task conditions. Exp Brain Res 97: 423-436, 1994a.

Sakagami M and Niki H. Spatial selectivity of go/no-go neurons in monkey prefrontal cortex. Exp Brain Res 100: 165-169, 1994b

Sakagami $\mathbf{M}$ and Tsutsui K. The hierarchical organization of decision making in the primate prefrontal cortex. Neurosci Res 34: 79-89, 1999.
Sakagami M, Tsutsui K, Lauwereyns J, Koizumi M, Kobayashi S, and Hikosaka O. A code for behavioral inhibition on the basis of color, but not motion, in ventrolateral prefrontal cortex of macaque monkey. J Neurosci 21: 4801-4808, 2001.

Sawaguchi T and Yamane I. Properties of delay-period neuronal activity in the monkey dorsolateral prefrontal cortex during a spatial delayed matchingto-sample task. $J$ Neurophysiol 82: 2070-2080, 1999.

Seltzer B and Pandya DN. Frontal lobe connections of the superior temporal sulcus in the rhesus monkey. J Comp Neurol 281: 97-113, 1989.

Shimamura AP, Janowsky JS, and Squire LR. Memory for the temporal order of events in patients with frontal lobe lesions and amnesic patients. Neuropsychologia 28: 803-824, 1990.

Snyder LH, Batista AP, and Andersen RA. Coding of intention in the posterior parietal cortex. Nature 386: 167-170, 1997.

Takeda K and Funahashi S. Prefrontal task-related activity representing visual cue location or saccade direction in spatial working memory task. J Neurophysiol 87: 567-588, 2002.

Ungerleider LG, Gaffan D, and Pelak VS. Projections from inferior temporal cortex to prefrontal cortex via the uncinate fascicle in rhesus monkey. Exp Brain Res 76: 473-484, 1989.

Wagner AD, Maril A, Bjork RA, and Schacter DL. Prefrontal contribution to executive control: fMRI evidence for functional distinctions within lateral prefrontal cortex. Neuroimage 14: 1337-1347, 2001.

Wallis JD, Anderson KC, and Miller EK. Single neurons in prefrontal cortex encode abstract rules. Nature 411: 953-956, 2001

Wallis JD and Miller EK. From rule to response: neuronal processes in the premotor and prefrontal cortex. J Neurophysiol 90: 1790-1806, 2003.

Watanabe M. Prefrontal unit activity during delayed conditional discriminations in the monkey. Brain Res 225: 51-65, 1981.

Watanabe M. Prefrontal unit activity during delayed conditional go/no-go discrimination in the monkey. I. Relation to the stimulus. Brain Res 382: $1-14,1986$.

Watanabe M. Prefrontal unit activity during associative learning in the monkey. Exp Brain Res 80: 296-309, 1990.

Watanabe M. Frontal units of the monkey coding the associative significance of visual and auditory stimuli. Exp Brain Res 89: 233-247, 1992.

Webster MJ, Bachevalier J, and Ungerleider LG. Connections of inferior temporal TEO and TE with parietal and frontal cortex in macaque monkeys. Cereb Cortex 5: 470-483, 1994.

Wilson FAW, O'Scalaidhe SP, and Goldman-Rakic PS. Dissociation of object and spatial processing in primate prefrontal cortex. Science 260: 1955-1958, 1993. 